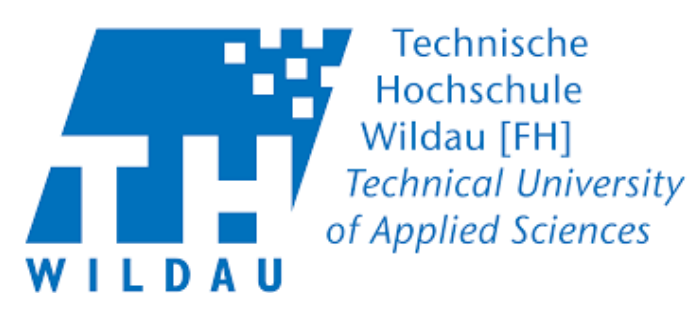

\title{
The Common Agricultural Policy of the European Union and its possible future effects on the reduction of greenhouse gases of the agricultural industry
}

\author{
by \\ Paul Philip Kowas \\ A thesis submitted in partial fulfillment of the requirements \\ for the degree of \\ Master of Arts-European Management \\ Faculty Business, Computing and Law \\ University of Applied Science Wildau \\ 2020 \\ Common Agricultural Policy to achieve the 2030 greenhouse gas reduction \\ targets and what tradeoffs would need to be overcome to reach these targets?
}

Research question: What are the policy measures and the main budgetary options of the EU

Supervisor: $\quad$ Prof. Dr. Christian Hederer

Examiner: $\quad$ Prof. Dr. rer. pol. habil. Iciar Dominguez Lacasa

Student Number: $\quad 50072097$

Seminar group: $\quad$ EMM/18

Date: $\quad$ September $23^{\text {th }}, 2020$ 


\section{Abstract}

The aim of this thesis is to inform the reader about the climate mitigation potential in the European agricultural policy. Political stakeholder from different spectrums agree that climate change is one of the pressing topics of our societies in the $21^{\text {st }}$ century and that future policies should reflect this. Therefore, the thesis chiefly analyzes the current Common Agricultural Policy (CAP) of the European Union in order to identify advantageous and disadvantageous schemes and measures regarding this issue. Furthermore, it accesses whether it is possible to precisely measure the greenhouse gas reduction potential for each of these instruments. This is done to predict whether the industry, with the help of the CAP incentives, can fulfil the 2030 reduction targets set out in the European Green New Deal. Since climate change is a crosscutting issue, relevant external developments such as the Farm-to-Fork Strategy will be consulted to provide a full picture of the climate regulations and initiatives concerning the agricultural industry.

Based on literature research, an expert interview as well as a budgetary analysis of the CAP, a detailed analysis of all the relevant policy instruments, schemes and subsidies forms the basis of the recommendations for the future CAP post-2020. In these recommendations, it is e.g. suggested to integrate key CAP Pillar II measures in a long-term intervention logic that facilitates the change to and the maintenance of beneficial practices at farm level. Another key finding concerns the Pillar I Voluntary Coupled Support which can be granted to highly polluting sectors such as the meat and dairy sector. For this scheme, it is advised to strengthen the obligations regarding, for instance, fodder sources or manure management that holdings have to fulfill. This is paired with attractive Pillar II measures to finance the conversion to beneficial practices. Perhaps most importantly, a concrete budget proposal is elaborated, bolstering the qualitative recommendations mentioned. Additionally, the reader gains insight into the trade-offs between ecological and economic factors as well as the administrative burden expected when implementing the recommendations. 


\section{Table of Contents}

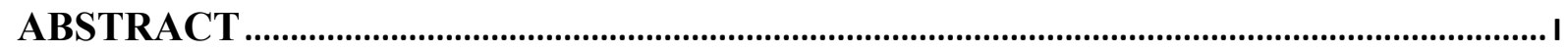

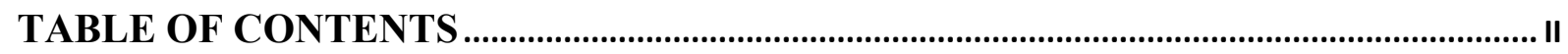

LIST OF ABBREVIATIONS ............................................................................................

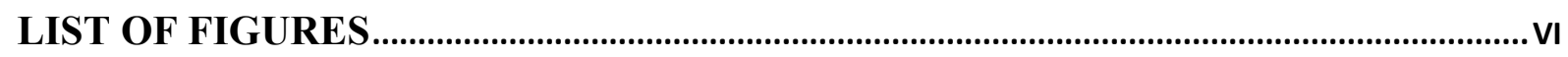

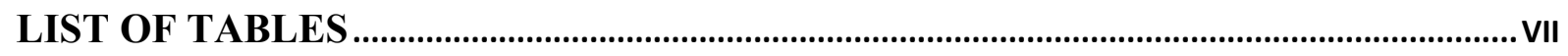

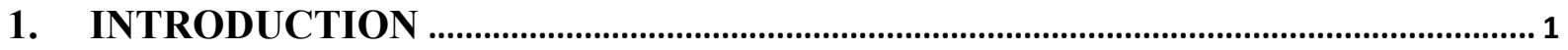

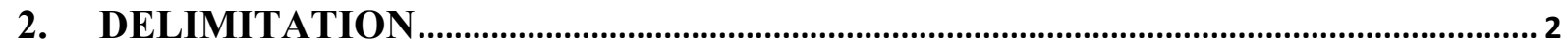

3. THE AGRICULTURAL INDUSTRY IN THE EUROPEAN UNION AND ITS

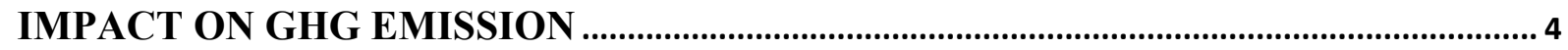

4. CURRENT COMMON AGRICULTURE POLICY FRAMEWORK 2014-2020 ...... 7

4.1 Pillar I MARKet MEASURES \& INCOME SUPPORT ................................................... 11

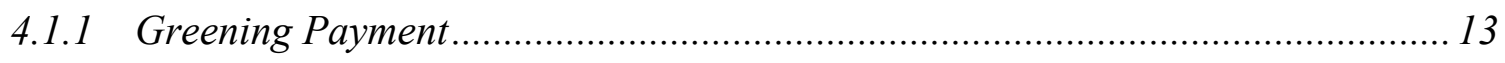

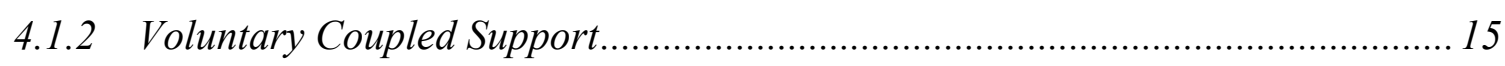

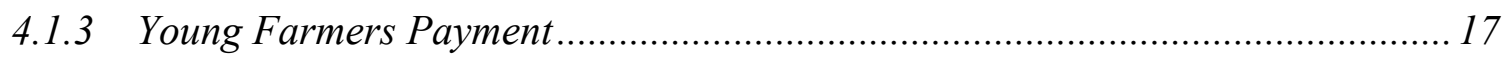

4.1.4 Payment for Areas with Natural Constraints ...................................................... 18

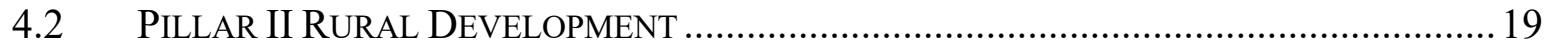

4.2.1 Knowledge Transfer and Innovation in Agriculture, Forestry and Rural Areas . 20

4.2.2 Restoring, Preserving and Enhancing Ecosystems ....................................... 21

4.2.3 Resource-Efficient, Climate Resilient Economy ............................................. 21

4.3 Key Pillar II MeAsures Beneficial to GHG ReduCtion.................................... 22

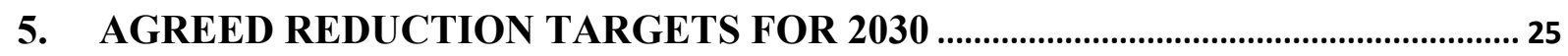

6. POLICY PROPOSALS WITHIN THE CURRENT CAP FRAMEWORK ............. 28

6.1 Analysis of Budget Reallocation Between the Pillars .............................. 29

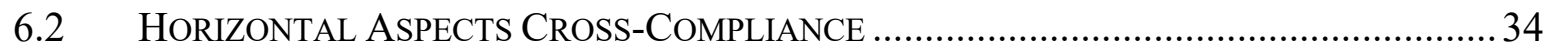

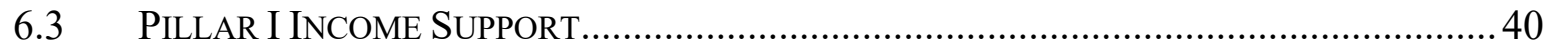

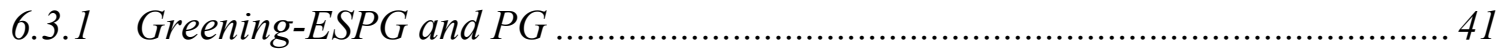

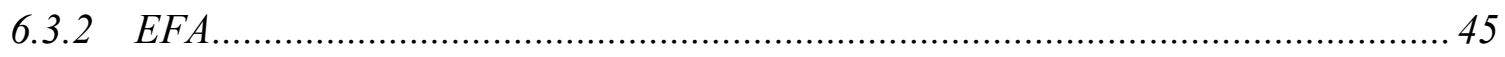

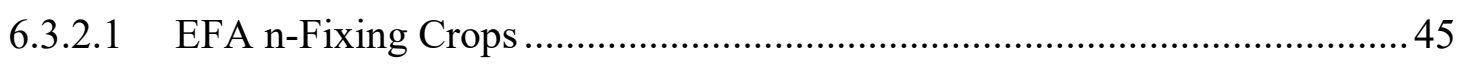

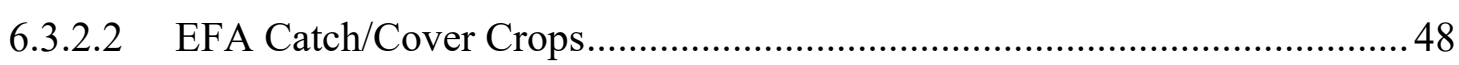




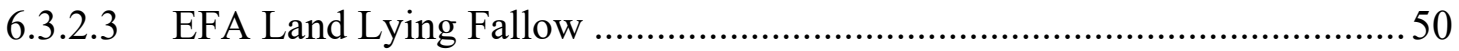

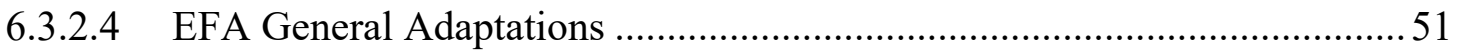

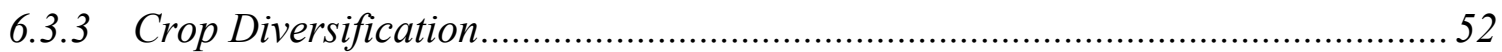

6.3.4 General Adaptations to the Greening Measures and the Greening Framework. 54

6.3.4.1 The Eco Schemes and the Greening Framework ...................................... 54

6.3.4.2 Areal Thresholds and Budgetary Implications of the Greening Architecture 59

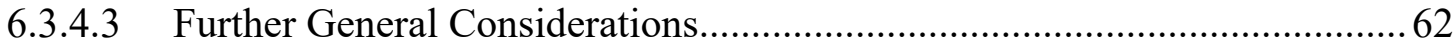

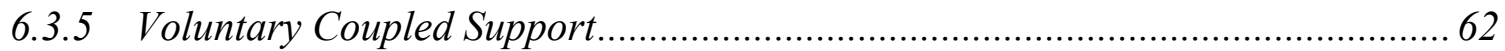

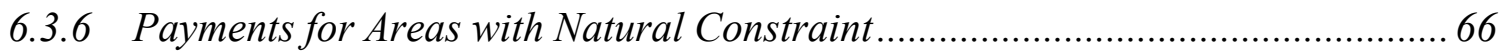

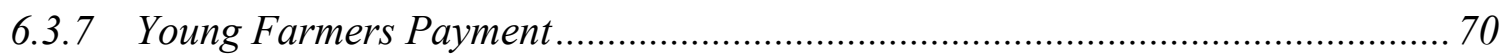

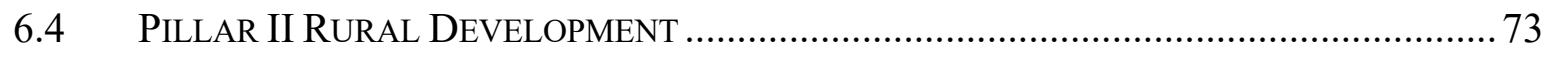

6.4.1 Limitations and Considerations for the Analysis of the Pillar II Measures and

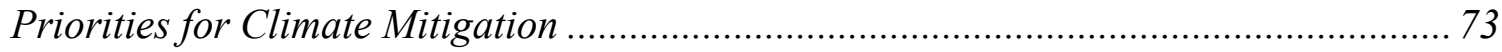

6.4.2 Targeting the Relevant Measures Towards Climate Mitigation ......................... 75

6.4.3 Targeting of Priorities 4 and 5 Towards Climate Mitigation ............................. 77

6.4.4 Qualitive Recommendations for Pillar II ........................................................... 78

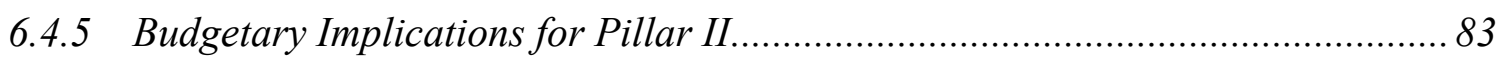

7. POLICY PROPOSALS OUTSIDE OF THE CURRENT CAP FRAMEWORK..... 87

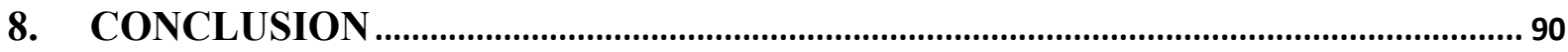

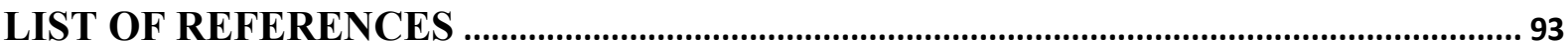

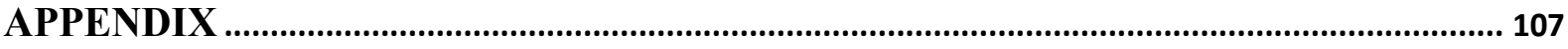

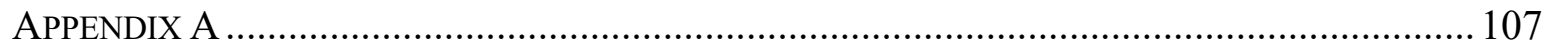

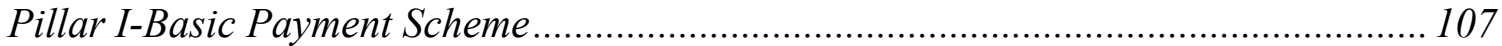

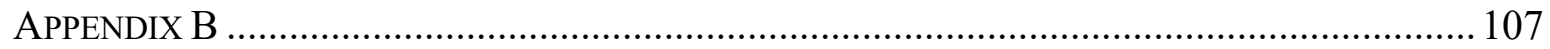

Pillar I-Small Farmers Scheme ............................................................................... 107

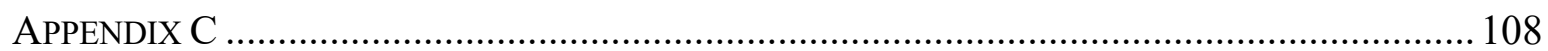

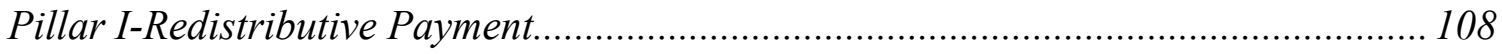

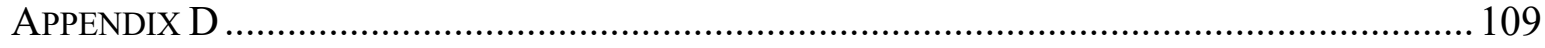

List of equivalent practices referred to in Article 43(3)............................................... 109

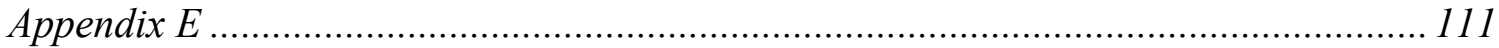

Pillar II-Food Chain Organization and Risk Management .......................................... 111

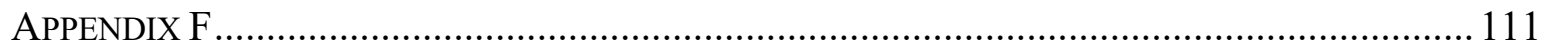


Pillar II-Social Inclusion and Economic Development.............................................. 111

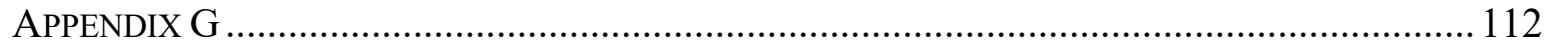

Pillar II-Farm Viability and Competitiveness...................................................... 112

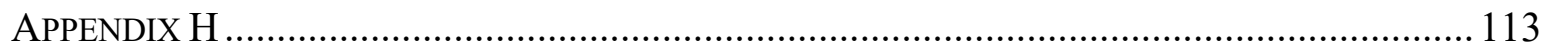

Pillar II- European Menu of Measures ................................................................... 113

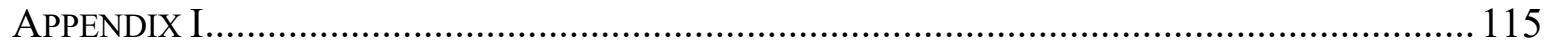

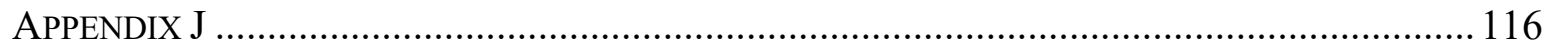

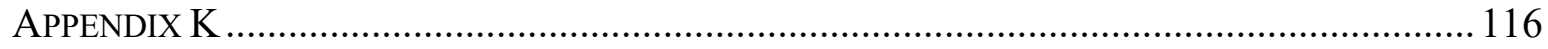

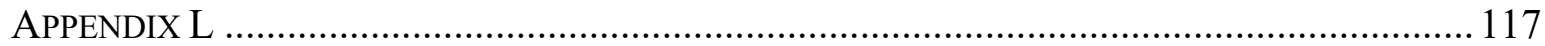

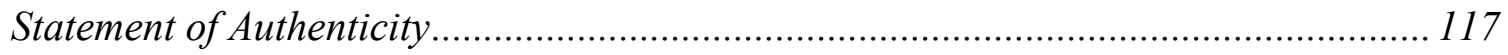




\section{List of Abbreviations}

\section{Abbreviation}

\begin{tabular}{|c|c|}
\hline AECM & Agri-environment-climate measure \\
\hline $\mathrm{ANC}$ & Area of natural constraint(s) \\
\hline BPS & Basic payment scheme \\
\hline CAP & Common Agricultural Policy \\
\hline $\mathrm{CH} 4$ & methane \\
\hline $\mathrm{CO} 2$ & carbon dioxide \\
\hline EAFRD & European Agricultural Guarantee Fund \\
\hline EAGF & $\begin{array}{l}\text { European Agricultural Fund for Rural } \\
\text { Development }\end{array}$ \\
\hline $\mathrm{EC}$ & European Commission \\
\hline EFA & Ecologic focus area \\
\hline EU & European Union \\
\hline EU ETS & European Union Emissions Trading System \\
\hline ESPG & ecologically sensitive permanent grassland \\
\hline FA & focus area(s) \\
\hline $\mathrm{F} 2 \mathrm{~F}$ & farm to fork strategy \\
\hline GAEC & $\begin{array}{l}\text { Good Agricultural Environmental } \\
\text { Conditions }\end{array}$ \\
\hline GDP & gross domestic product \\
\hline GHG & greenhouse gases \\
\hline ha & hectare \\
\hline $\mathrm{Kg}$ & kilogram \\
\hline $\mathrm{Kt}$ & kilo tonnes \\
\hline $\mathrm{M}$ & measure \\
\hline MFF & multi annual financial framework \\
\hline MS & member state(s) \\
\hline Mt & mega tonnes \\
\hline n-fertilizer & nitrogen fertilizer \\
\hline n-fixing & nitrogen fixing \\
\hline $\mathrm{N} / \mathrm{ha}$ & nitrogen per hectare \\
\hline $\mathrm{N} 2 \mathrm{O}$ & nitrous oxide \\
\hline PG & permanent grassland \\
\hline SAPS & single area payment scheme \\
\hline SFS & small farmers scheme \\
\hline SMR & Statutory Management Requirements \\
\hline SWOT & $\begin{array}{l}\text { strength weaknesses opportunities threats } \\
\text { analysis }\end{array}$ \\
\hline UAA & utilized agricultural areas \\
\hline VAT & value added tax \\
\hline VCS & voluntary coupled support \\
\hline WTO & World Trade Organization \\
\hline YFP & Young farmers payment \\
\hline
\end{tabular}




\section{List of Figures}

FIGURE 1: FARMS AND FARM LAND BY SIZE IN \% OF TOTAL UAA IN THE EU- 27; SOURCE:

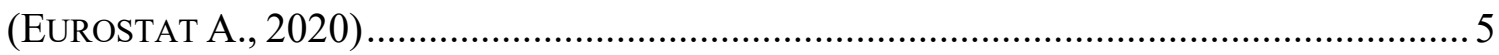

Figure 2: OUtPUT OF AGRICULTURAL INDUSTRY EU-28; SOURCE: (EUROSTAT C., 2020) .......... 6

FiguRE 3: INTERVENTION LOGIC HORIZONTAL MEASURES; SOURCE: (DIRECTORATE-GENERAL

for Agriculture and Rural Development (European Commission) A., 2017) ....... 8

FiguRE 4: INTERVENTION LOGIC PILlAR I SOURCE: (DIRECTORATE-GENERAL FOR

Agriculture and Rural Development (European Commission) A., 2017) ............ 12

FIGURE 5: SUBSIDY SCHEMES UNDER PILLAR I INCOME SUPPORT ........................................... 12

FiguRE 6: BREAKDOWN OF DECLARED EFA AREAS BY MAIN EFA TYPE, AT EU LEVEL, BEFORE AND AFTER APPLYING WEIGHTING FACTORS; SOURCE: (EUROPEAN COMMISSION A., 2017)

Figure 7: Beneficiaries of The Voluntary COUPLED SuPPORT; SOURCE: (DireCTORATEGenERAl For Agriculture AND RuRAl DEVElopMENT (EUROPEAN COMMisSion) A., 2019)

Figure 8: InTERVENTION LOGIC PiLlar II SOURCE: (DiReCTORATE-GENERAL FOR

Agriculture AND RuRAL DeVElopment (EuROPEAn COMMISSION) A., 2017)

FiguRE 9: SimUlated EMISSION IMPACT BY MEASURES PILlAR I AND II; SOURCE:

(MOTTERSHEAD A., ET AL., 2019).

FIGURE 10: ON-FARM NITROGEN CYCLE, SHOWING THE EFFECT OF LEGUME PRE-CROPS; SOURCE

(BUES, ET AL., 2013) 46

FIGURE 11:COMPARISON OF THE CAP'S CURRENT AND PROPOSED NEW GREEN ARCHITECTURE;

SOURCE: (MEREDITH \& HART, 2019). 55

Figure 12: Proposed PiLlar I ARCHITECTURE; SOURCE: OWN COMPILATION 56

FigURE 13: RELEVANCE OF CAP INSTRUMENTS AND MEASURES TO EU CLIMATE NEEDS;

SOURCE: (MOTTERSHEAD A., ET AL., 2019).... 115

FiguRE 14: EFFECT OF MANAGEMENT PRACTICES ON THE GHG REDUCTION POTENTIAL OF PERMANENT GRASSLAND; SOURCE: (HART, ET AL., 2017)

Figure 15: CONNECTION OF PILlAR II MEASURES WITH SELECTED PILlar I SCHEMES; SOURCE:

OWN COMPILATION 116

FIGURE 16: SUMMARY OF PROPOSED PILLAR I AND II ARCHITECTURE AND BUDGETARY IMPLICATIONS; SOURCE: OWN COMPILATION . 


\section{List of Tables}

TABLE 1: GAEC REQUIREMENTS WITH DIRECT EFFECT ON GHG EMISSIONS; SOURCE:

(EUROPEAN PARLIAMENT; COUNCIL OF THE EUROPEAN UNION AA., 2013).

TABle 2: EFFECTS OF SHIFTING FUNDS FROM PILlar I tO PILlAR II, SOURCE: OWN COMPILATION BASED ON FINDING OF THE PREVIOUS CHAPTERS

TABle 3: EfFects of SHIFTING FUndS FROM Pillar II to Pillar I, SOURCE: OWN COMPILATION BASED ON FINDING OF THE PREVIOUS CHAPTERS.

TABLE 4: SUMMARIZED PROPOSED CHANGES TO THE GAEC BASED ON CLASSIFICATION IN REGULATION (EU) 1306/2013; SOURCE: OWN COMPILATION

TABLE 5: SOIL CARBON LOSS ASSOCIATED WITH A 1\% CHANGE IN THE AREA OF PERMANENT GRASSLAND CONVERTED OR PLOUGHED, PLOUGHED AND RESEEDED OR MAINTAINED WITHOUT PLOUGHING; SOURCE: (MOTTERSHEAD A., ET AL., 2019) 41

TABLE 6: DifFERENCES BETWEEN ESPG AND PG (HART, ET AL., 2017). 43

TABLE 7: SUMMARY OF PILlAR I SCHEME ADAPTATIONS; SOURCE: OWN COMPILATION..... 73

TABLE 8: RESUltS OF THE TARGETING OF THE INDIVIDUAL PILLAR II MEASURES TOWARDS CLIMATE MitiGATION; SOURCE: (OWN CALCULATIONS BASED ON EAFRD DATA, 2020).. 75

TABLE 9: RESUltS OF THE TARGETING OF PRIORITY 4 AND 5 TOWARDS CLIMATE MITIGATION;

SOURCE: (OWN CALCULATIONS BASED ON EAFRD DATA, 2020) 77

TABLE 10: EAFRD BUDGET SCENARIOS FOR 2021-2027; SOURCE: (OWN CALCULATIONS BASED

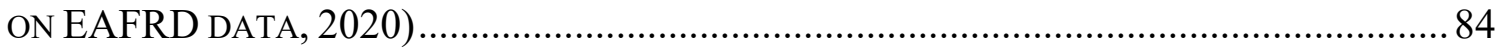

TABLE 11: SUMMARY OF PILlAR II MEASURE ADAPTATIONS; SOURCE: OWN COMPILATION..... 87 


\section{Introduction}

The global challenge of human-caused climate change and its dramatic effects have been widely recognized among world leaders and are playing an increasingly important role in the decision making of national and international institutions. The European Union, guided by the European Commission (EC), has frequently laid out ambitious reduction targets to become a net carbonfree society, leading the efforts to maintain the global increase of medium temperatures at no more than two degrees Celsius.

Those efforts in a variety of areas concerned and their interconnections have been addressed in the European Green New Deal strategy which aims to conduct and finance relevant activities in an inclusive manner. (European Commission B., 2019). The strategy has a broad focus and aims to rethink "policies for clean energy supply across the economy, industry, production and consumption, large-scale infrastructure, transport, food and agriculture, construction, taxation and social benefits." (European Commission B., 2019)

While the eight overreaching goals are aimed at all these industries, both in the public and private sector, three of which namely a zero pollution ambition for a toxic-free environment, preserving and enhancing ecosystems and biodiversity, and, especially, 'from farm to fork': a fair, healthy and environmentally friendly food system possess implications for the agricultural industry. (European Commission B., 2019)

So as to achieve these goals in this industry and to become a net carbon-free society by 2050 , the European Common Agricultural Policy (CAP) is seen as a main facilitator to realize these ambitions. Historically, since the Treaty of Rome signed in 1957, the constantly growing and changing European institutions have regarded this sector as a pivotal stepping stone for further integration and, most importantly, ever since the end of WWII, for the industries' responsibility to feed the population. Consequently, throughout the decades a large part of its budget has been allocated to stimulate growth and enhance productivity.

In recent years though, the agricultural industry, and with it the EU subsidies and measures of the CAP, have faced criticism for being unaware of the industry's climate impact and incapable of incentivizing farmers to adapt to a more environmentally friendly production. However, the ongoing negotiations for the Multiannual Financial Framework 2021-2027 (MFF) paired with the lasting pressure of the civil society and the introduction of the European Climate Law by the new Commission, promise great possibility and momentum for a positive change.

Given the urgency of the matter and the current developments, this thesis aims to provide recommendations on possible adaptations of schemes and measures as well as, if quantifiable, 
budget allocations in order to achieve the first 2030 Green New Deal reduction hurdle for the agricultural industry.

To fulfill this task and answer the outlined research question, the thesis will be structured first, to provide the reader with the frame of analysis followed by an introduction to the agricultural industry and its impacts on EU GHG emissions. Paired with the presentation of the current CAP Pillars, schemes and intervention logics these chapters will form the theoretical basis of this thesis. To classify the CAP schemes and measures with direct or indirect effects on GHG pollution, the CAP intervention logic and scientific research will be consulted.

Connecting the theoretical part with the successive analysis, Chapter 5 will introduce the reduction targets based on the Paris Agreement on Climate Change. Moreover, additional relevant strategies affecting the GHG emissions of the agricultural industry, such as the Farm to Fork Strategy (F2F), will provide the reader with the needed goal-setting for the given 2030 timeframe.

The core of Chapter 6 will split the analysis along the introduced CAP pillars and analyze each relevant scheme and measure. For Pillar I, this will be chiefly conducted in a qualitative manner based on scientific research and political decisions upon which the proposals for change will be formulated. Regarding Pillar II, analyzed from Chapter 6.4 onward, the publicly available spending data of the fund will allow for quantitative analysis of the budget spending and targeting of the monetary resources with GHG reduction efforts. These considerations will form the basis for the Pillar II adaptation proposals. Bearing in mind that the pillars are inherently connected, meaningful connections will be pointed out to provide a long-term, sustainable intervention logic that adequately considers the divers ecological and economic realities of farm holdings.

Given that the reduction of GHG is a cross-cutting matter, the CAP policy cannot address all issues in a coherent matter. This is why Chapter 7 will mention meaningful adaptations in other policy and trade-related areas affecting the agricultural industry.

With this analysis at hand, Chapter 8 will conclude the thesis and sum up the policy recommendations while also considering the areas in which there is need for additional research.

\section{Delimitation}

Despite the broad scope of the research question and the methods employed to answer it, some aspects need to be discarded in order to provide the reader with a cohered result while following 
the general university guidelines for master thesis'. Therefore, this chapter will briefly elaborate on these limitations.

First and foremost, the thesis will disregard the Pillar I Market measures which aim to stabilize the agricultural markets and protect producers from unsustainable crisis. These measures can be generally provided in four forms depending on the severity and kind of crisis. As such, the EC can intervene as part of a public intervention i.e. setting a price floor for a given product, aid private companies with storage costs, apply exceptional measures such as restrictions on intra-union trade in the case of, for example, a disease, and, lastly, support specific sectors deemed especially vulnerable to market imbalances. The sectors covered range, depending on the intervention, from olive oil, hops to butter, wheat, pig meat, and beef, to name but a few. (Directorate-General for Communication (European Commission) A., 2020). From the budgetary perspective, this excludes $€ 17.4$ billion or $4.3 \%$ of the CAP budget for 2014-2020. (Massot, 2020) As to why this considerable amount will not be analyzed, the general argument that can be made is that they are solely employed in times of market crisis and therefore do not provide conclusive data for an environmental analysis. Furthermore, none of them are specifically targeted on GHG reductions or climate adaptations. Although the support of certain markets may have indirect effects on the production and hence the resulting pollution, these are not recorded by the authorities.

The second limitation one has to bear in mind, is that the analysis will only focus on the GHG emissions resulting directly out of the agricultural production on land. This excludes pollution from i.e. fertilizer production, fishery, the food processing industry or logistics. A lifecycle analysis of the entire industry and its pollution would have resulted in a much more profound analysis which is not achievable given the scope of this thesis. Additionally, the CAP policies do not consider these aspects as well, which is why changes to it would likely only have resulted into minor adaptations for theses upstream and downstream industries. Furthermore, it is important to note that due to this limitation some Pillar II measures (M) such as Village renewal are disregarded despite having possible reduction potential when being applied to energysaving renovations of public buildings, to name one example.

As to the analysis of Pillar I and II, which will be further explained in Chapter 4, some aspects of the presented intervention logics were discarded as well. This applies to the indicators that have been selected to quantify the effects of the measures and schemes out of different perspectives. Despite the fact that the responsible authority provides public access to these figures, discussing the accountability framework factoring in, amongst others, type of indicator, its plausibility or administrative burden, is out of scope for this thesis. However, it would be of 
interest to develop a framework based on the recommendation given in this text in future research papers.

Deriving from the exclusion of the indicator framework, the penalty system was also ignored in the research. Although some general recommendations regarding this aspect will be suggested, the merits upon which to impose these or the national and supranational process to penalize infringements are not subject of the proposed adaptations.

Lastly, some Pillar II measures have been further structured into sub-measures as can be seen in the case of M16 Cooperation and M10 Agri-environment-climate. Taking the former as an example, the sub measures are tenfold ranging from diversification and social farming to pilot projects or environment and climate change. (European Network for Rural Development A., 2017). The distinction seems to have been made to conduct a quantitative analysis of the variety of projects supported and to showcase the combination of measures applied to certain projects. Although the analysis is certainly helpful to estimate, for instance, the climate impact of specific projects, these documents do not reveal conclusions as to the effect across the entirety of the supported projects. Furthermore, the Pillar II budget, which will be the core subject of the analysis in Chapter 6.4 does not define the expenses according to the sub-measure classification. Hence, this thesis disregards these submeasures and will base the analysis on the broader classifications. With these limitations in mind, the following chapter will introduce the EU agricultural industry.

\section{The Agricultural Industry in the European Union and its Impact on GHG Emission}

The modern agricultural industry of Europe is a highly productive and diverse part of the economy employing roughly 9.7 million people full or part-time which makes it the largest employer in the EU. The share of the total employment varies greatly within the MS with Romania taking the lead with 23\% followed by Bulgaria with $17.5 \%$ and Greece with $10.7 \%$. The overwhelming majority of $95 \%$ of farms are family farms which is to say that these holdings depend on no or only a marginal external workforce. (Eurostat A., 2016) (Eurostat B., 2016)

In 2016, 10.3 million agricultural holdings farmed 156.7 million ha of land of which 108 million ha are managed by families. The disparity between the ha cultivated and the percentage of family farms indicates that these holdings while large in number make use of relatively small patches of land. A closer look at the statistics of this matter in Figure 1, will prove this fact. It 
compares the percentage of farms in the respective size category in ha with the percentage of land being cultivated by the given farms.

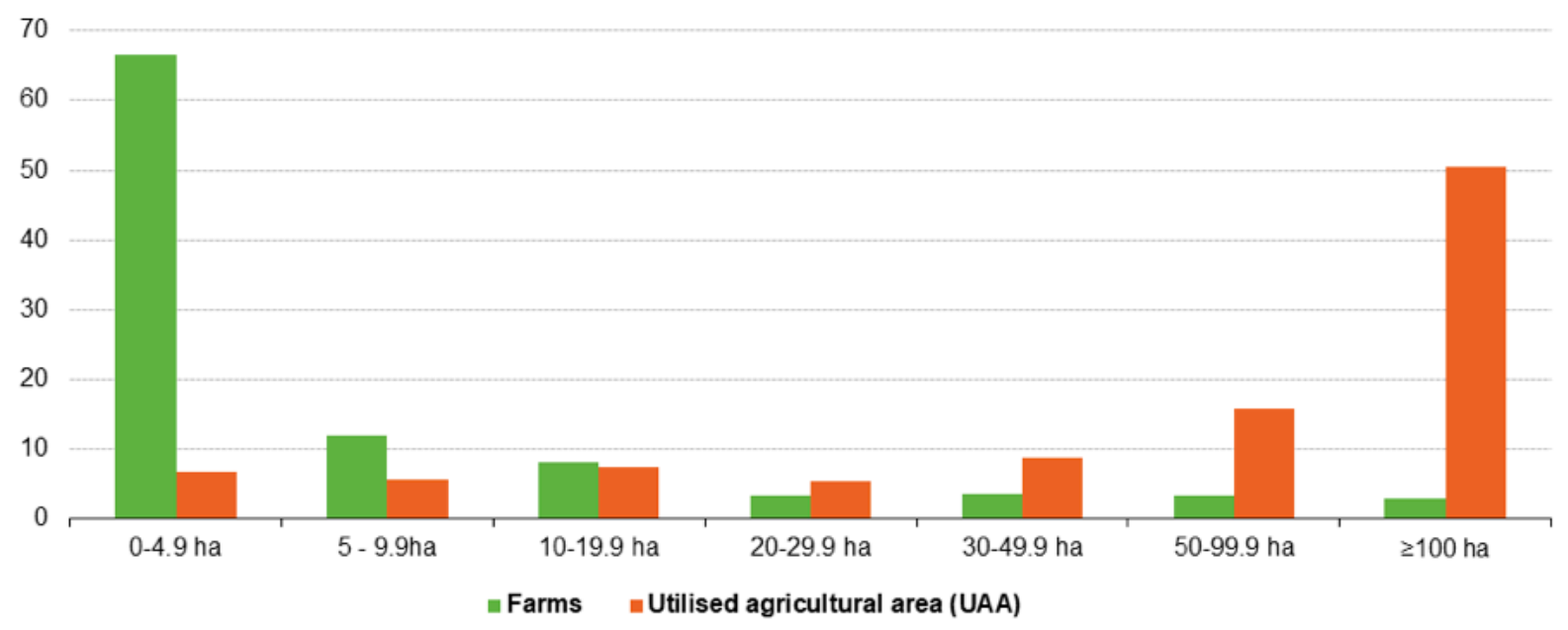

Figure 1: Farms and farm land by size in \% of total UAA in the EU- 27; Source: (Eurostat A., 2020)

While about $50 \%$ of the Utilized Agricultural Areas (UAA) is made up of large scale, $>100$ ha farm holdings managed by less than $4 \%$ of the farms, roughly $68.3 \%$ of the farms cultivate rather small areas between 0.4 and 0.9 ha. In terms of overall production, the disparity continues with the smallest holdings contributing $5 \%$ to the overall annual output while the largest farms contribute 54.4\%. (Eurostat A., 2020) (Eurostat B., 2020)

Another decisive factor of the industry is the overall decrease of farm holdings that goes along with an increasing specialization of the remaining ones. Between 2005 and 2016 roughly 4 million out of the 10.5 million farm holdings ceased to exist with the most notable decrease of $50 \%$ in Bulgaria and Slovakia. In the meantime, the share of crop specialists' holdings increased by $10 \%$ and mixed farming decreased by $8 \%$. (Eurostat A., 2019)

In further extension of the agricultural production, the industry supplies a great variety of commodities for the domestic and foreign markets. As Figure 2 demonstrates, the estimated value of the production lies at $€ 434.3$ billion out of which $51.8 \%$ are attributed to crop cultivation, followed by animal-based production accounting for $39.6 \%$ 


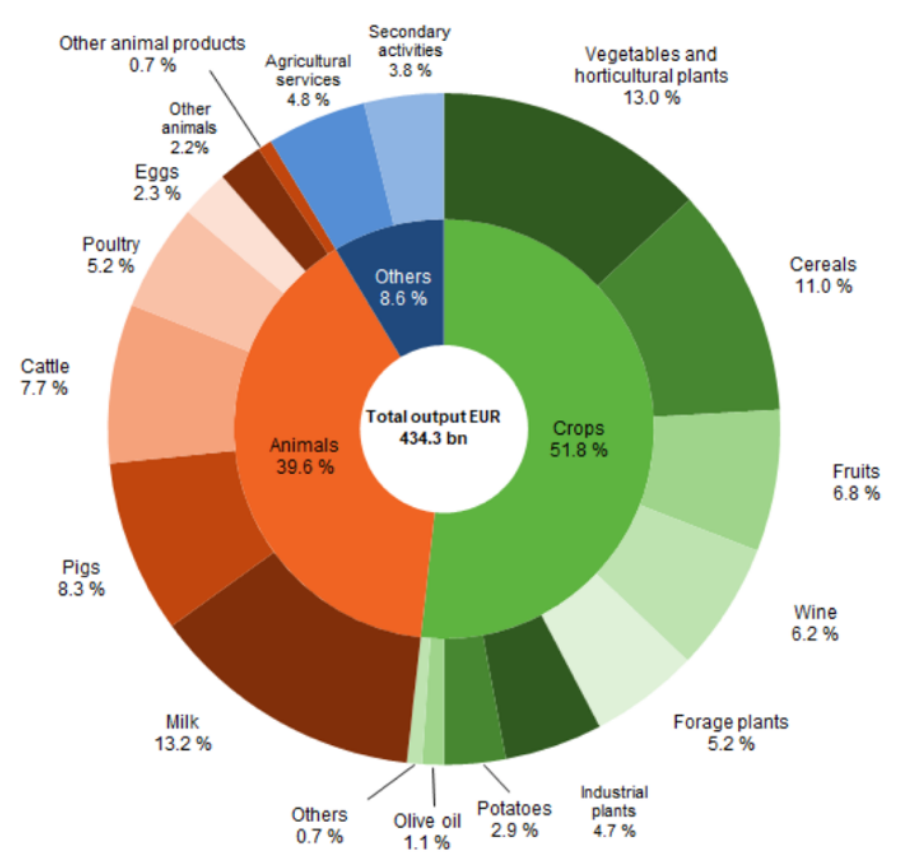

Figure 2: Output of agricultural industry EU-28; Source: (Eurostat C., 2020)

Across the farm types, the most significant shares of output are contributed by the milk and dairy industry with $13.2 \%$, followed by vegetables and horticultural plants making up $13 \%$ and cereals accounting for $11 \%$. These shares of the overall output, apart from measuring the production of goods, are of utmost importance for understanding the overall GHG emission of the industry.

To contextualize the inherent correlation between the output of a certain product and its GHG emissions, the emission intensity of two products, namely cow milk and cereals, will serve as examples. For the former product, the entire 2017 output in Europe caused an estimated 121.89 $\mathrm{Mt}$ of $\mathrm{CO} 2$ equivalent, whereas the cereal production (excluding rice) contributed an estimated 54.93 $\mathrm{Mt}$ of $\mathrm{CO} 2$ equivalent in the same timeframe. (Food and Agriculture Organization of the United Nations, 2019) Even when factoring in the 2.1\% lower participation of the latter product in the overall output, it becomes apparent that certain agricultural products (especially animalbased products) contribute disproportionally to the emittance of GHG.

In the context of Europe's entire annual emissions, the agricultural industry has emitted $436 \mathrm{Mt}$ of $\mathrm{CO} 2$ equivalent or $9.22 \%$ of all aggregated emissions in 2018 while only contributing $1.1 \%$ of the European Gross domestic product (GDP) in the same year. (European Envionmental Agency, 2020) (Eurostat B., 2019)

When taking a closer look at the relevant emission types in the industry, the emission intensity of the livestock sector becomes even more prevalent. Out of the given percentage of aggregated emissions for the industry, $55 \%$ is methane (CH4) while nitrous oxide (N2O) makes up 42,6\% and the remainder of $12.4 \%$ is $\mathrm{CO} 2$. The main source of $\mathrm{CH} 4$ is the enteric fermentation which 
commonly occurs during the digestion process of livestock, especially cattle. Another significant emitter is the manure management of the animal's residues. These sources make the agricultural industry the largest single source of $\mathrm{CH} 4$ in the European Union. (European Envionmental Agency, 2020) As for the N2O pollution, the main sources are direct emissions from managed agricultural soils followed by indirect emissions from managed agricultural soils. (European Envionmental Agency, 2020)

However significant, these emissions have seen a long-term downwards trend with overall emissions decreasing by $20.5 \%$ between 1990 and 2018. As for $\mathrm{CH} 4$, the emissions saw a $21.7 \%$ decrease, and for $\mathrm{N} 2 \mathrm{O}$ one of $17.7 \%$. Meanwhile the $\mathrm{CO} 2$ emissions have dropped by $28.3 \%$. This can be largely attributed to the reduction in herd size across the EU. (European Envionmental Agency, 2020)

In spite of the positive long-term trend, the emissions have been largely stagnant from 2005 onwards and even increased from 2017 to 2018, which may imply the industry has difficulties in complying with the 2030 reduction targets. What the exact reduction targets mean for the industry will be outlined in Chapter 5 following the introduction of the CAP framework in the succeeding chapter.

\section{Current Common Agriculture Policy Framework 2014-2020}

The currently enacted CAP consists of two main pillars; namely Pillar I Market Measures \& Income Support and Pillar II Rural Development. (Directorate-General for Communication (European Commission) B., 2020) Jointly, the pillars work towards the achievement of three CAP general objectives in line with the Europe 2020 Strategy which are later broken down into more targeted sections. Those objectives are as follows:

With these goals in mind the CAP has defined three relevant intervention logics of which two are specific to the pillars and one is for the objective-setting of the horizontal instrument. First, the horizontal instrument will be explained as they apply together to many measures of the two pillars. Combined, they all work to create coherence between the Pillar I and Pillar II schemes/measures and are thus connected to the pillar-specific priorities and the general objectives previously outlined. (Ranner \& di Virgilio, 2020)

The horizontal specific objectives as depicted in Figure 3 are categorized into six fields and in turn correspond to one of the three overall CAP general objectives. These specific objectives are: 
- Enhance farm income

- Improve agricultural competitiveness

- Maintain market stability

- Meet consumer expectations

- Provide environmental public goods and climate action

- Foster Innovation

- Maintain agricultural diversity (Directorate-General for Agriculture and Rural Development (European Commission) A., 2017)

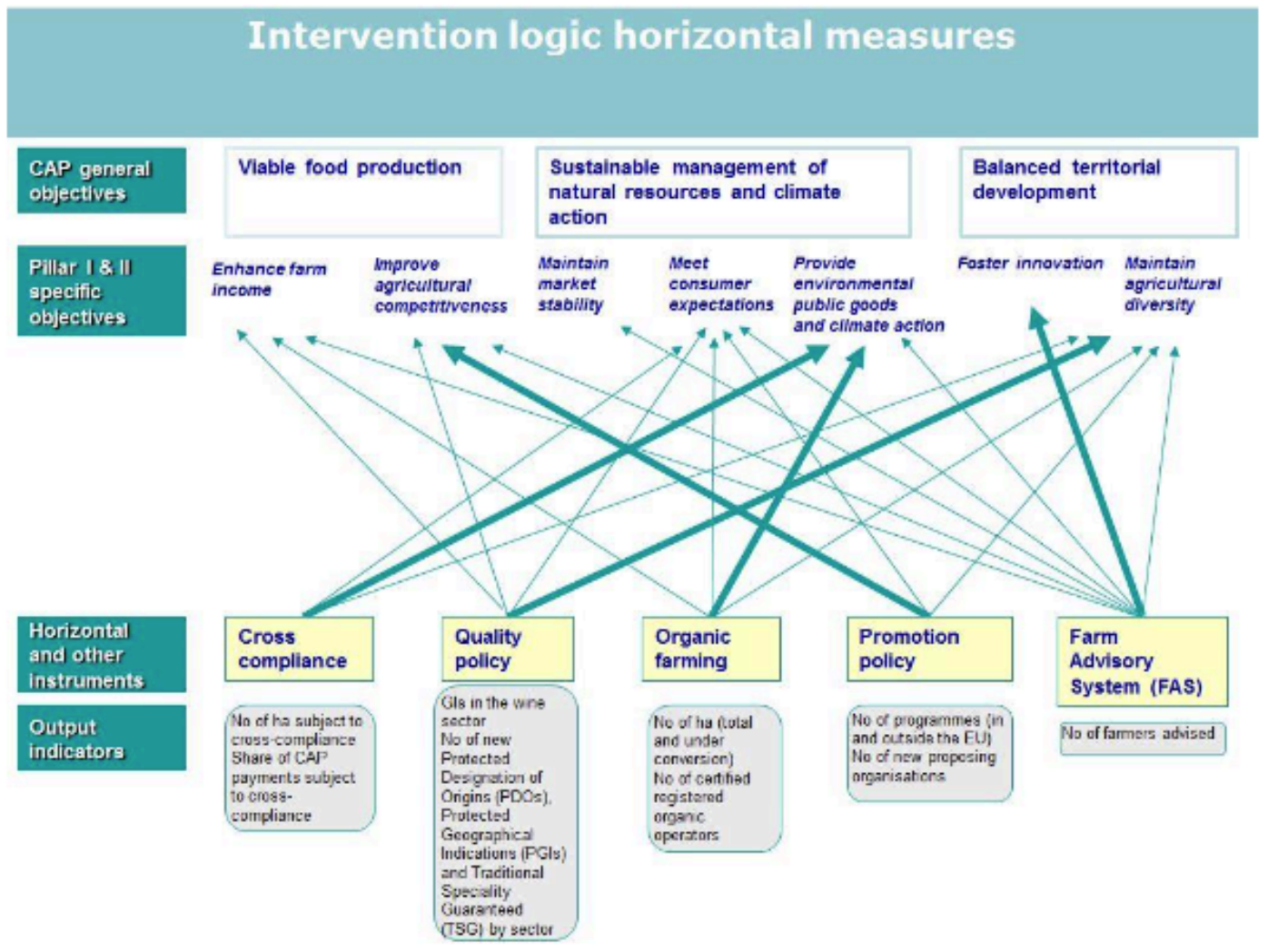

Figure 3: Intervention logic horizontal measures; Source: (Directorate-General for Agriculture and Rural Development (European Commission) A., 2017)

The first horizontal instrument, Cross-compliance will be explained further below. It serves towards the achievement of the objectives Environmental public goods and climate action, Consumer expectations, and Maintaining agricultural diversity. The CAP general objective with the strongest link with this instrument is Objective 2 while also loosely contributing to Objective 3. (Directorate-General for Agriculture and Rural Development (European Commission) A., 2017)

Secondly, the Quality policy aims to achieve three horizontal specific objectives; their strongest correlation is with the objective Maintaining agricultural diversity followed evenly by a modest 
correlation with the Enhance farm income and Improve agricultural competitiveness. Thus, the instrument contributes strongly to the achievement of CAP general objective 3 and modestly to 1. (Directorate-General for Agriculture and Rural Development (European Commission) A., 2017)

The proceeding instrument, Organic farming, chiefly affects the objective Environmental public goods and climate action and, on a lesser scale, Meet consumer expectations and Enhance farm income. As a result, the intervention logic assigns this instrument an impact on all of the CAP general objectives with a more profound effect on Objective 2. (DirectorateGeneral for Agriculture and Rural Development (European Commission) A., 2017)

Following this, the fifth instrument called Promotion policy is to have a strong effect on the horizontal goal Enhance farm income while also having a modest impact on the goals Meet consumer expectation and Maintain agricultural diversity. As the former instrument, promotion policy affects all of the CAP general objectives yet has the closest alignment with Objective 1 . (Directorate-General for Agriculture and Rural Development (European Commission) A., 2017)

Lastly, the Farm advisory system (FAS) targets all horizontal objectives and thus contributes broadly to all CAP general objectives. The strongest correlation is towards Objective 3 and the foster innovation goal. (Directorate-General for Agriculture and Rural Development (European Commission) A., 2017)

To be eligible for the payments of the two pillars, two horizontal regulations, the Statutory Management Requirements (SMR) and the Good Agricultural Environmental Conditions (GAEC), have been put in place creating the baseline requirement in a system called Crosscompliance. The SMR stem from a variety of directives and regulations, ranging from the proper registration of animals and the use of plant protection products to the environmental issues of water pollution or the conservation of wild birds. The seven GAEC, however, solely focus on environmental issues regarding climate change, soil carbon content, biodiversity etc. (European Parliament; Council of the European Union B., 2013) As such, they are paramount for the GHG reduction potential of the policy.

In the currently enacted framework the Cross-compliance requirements are applied to all payments of Pillar I except the Small Farmers Scheme (SFS), and Pillar II payments to beneficiaries of the "annual premia for afforestation and creation of woodland, establishment of agroforestry systems, agri-environment-climate measures (AECM), organic farming, Natura 2000 and Water Framework Directive payments, payments to areas facing natural or other specific constraints, animal welfare payments and Forest-environmental and climate services 
and forest conservation." Furthermore, the framework applies to "Green harvesting" and "Restructuring and conversion of vineyards" within the wine sector (European Parliament; Council of the European Union B., 2013)

As this thesis focuses on the GHG emissions by the agricultural industry, the following table provides an overview of the relevant GAEC requirements that are linked to climate mitigation. GEACs focusing mainly on the efficient use and appropriate discharge of water will be disregarded since they do not have a direct association to the GHG emissions.

\begin{tabular}{|c|c|c|}
\hline Area & Main issue & Requirement and standards \\
\hline \multirow{5}{*}{$\begin{array}{l}\text { Environment, climate } \\
\text { change, good agricultural } \\
\text { condition of land }\end{array}$} & Water & $\begin{array}{l}\text { GAEC 1: Establishment of buffer strips along } \\
\text { water courses }\end{array}$ \\
\hline & $\begin{array}{l}\text { Soil and } \\
\text { carbon stock }\end{array}$ & GAEC 4: Minimum soil cover \\
\hline & & $\begin{array}{l}\text { GAEC 5: Minimum land management } \\
\text { reflecting the specific conditions to limit soil } \\
\text { erosion }\end{array}$ \\
\hline & & $\begin{array}{l}\text { GEAC 6: Maintenance of soil organic matter } \\
\text { level through appropriate practices including } \\
\text { ban on burning arable stubble, except for plant } \\
\text { health reasons }\end{array}$ \\
\hline & $\begin{array}{l}\text { Landscape, } \\
\text { minimum } \\
\text { level of } \\
\text { maintenance }\end{array}$ & $\begin{array}{l}\text { GAEC 7: Retention of landscape features, } \\
\text { including where appropriate, hedges, ponds, } \\
\text { ditches, trees in line, in group or isolated, field } \\
\text { margins and terraces, and including a ban on } \\
\text { cutting hedges and trees during the bird } \\
\text { breeding and rearing season and, as an option, } \\
\text { measures for avoiding invasive plant species }\end{array}$ \\
\hline
\end{tabular}

Due to the nature of a directive which the SMR and GAEC are derived from and the Obligations of Member States relating to good agricultural and environmental condition laid out in Regulation (EU) No 1306/2013, Article 94, MS have been given the right to define the details of their Cross-compliance framework on a national or regional basis in a consistent way. In this 
process MS factor in the specific characteristics such as geography, soil types or climate in the region.

Despite commonly applied horizontal measures and objectives the pillars have distinct funding methods and intervention logics, which is why Subchapters 4.1 and 4.2 will provide all specific information regarding each pillar, payment scheme and measure.

\subsection{Pillar I Market Measures \& Income Support}

The Market Measure \& Income Support Pillar is the biggest aggregation of policy measures in the EU budget judging by the $27 \%$ of the overall budget being spent on direct payments belonging to this pillar. These direct payment schemes are entirely funded by the MFF through the European Agricultural guarantee fund (EAGF) and are aimed at genuine farmers (Directorate-General for Agriculture and Rural Development (European Commission) A., 2018). The EC does not, however, directly provide funds to farmers, but reimburses national paying agencies monthly for their expenditure in the selected schemes. Furthermore, the farmers receive all Pillar I payments on an annual basis upon activating their claims at a national or regional management authority. (European Parliament; Council of the European Union C., 2013) These payments are monitored by the EC based on various data sources and subject to a multi-annual evaluation plan. (European Parliament; Council of the European Union D., 2013) The planned budget expenditure is $€ 291.273$ billion for 2014-2020 (excluding the Market measures) making up $71.3 \%$ of the current CAP budget. (Massot, 2020) As the name suggests, this pillar aims to support the overall income of farmers. Without any subsidies the market prices would only yield $40.6 \%$ of the income compared to the average income in the wider EU economy. Additionally, it is recognized that the industry requires a high capital investment at farm level while directly depending on the often-changing conditions of the global commodity market. (Directorate-General for Communication (European Commission) A., 2016) The specific objectives outlined in the previous chapter (except Foster innovation), along with the main output indicators assigned to each direct payment instrument, provide the intervention logic for direct payments as depicted in Figure 4. 
requirements and the other details of importance, will be outlined in the following subchapters. To maintain the focus on the subsidies relevant for the GHG emissions, schemes that do not affect this metric, be it positive or negative as well as direct or indirect, will be enclosed in Appendix A-C. The selection of those is based on the intervention logic outlined in the relevant regulation and in scientific studies.

\subsubsection{Greening Payment}

The second most significant subsidy in Pillar I is called Greening payment; it has a set allocation of $30 \%$ of the pillar's payments. (European Parliament; Council of the European Union E., 2013) This payment, however, requires the farmer to comply with stricter environmental provisions or implement measures yielding an equivalent benefit to the ecosystem and being voluntary at farm level. For the sake of simplicity, only the three core environmental provisions will be the main subject of discussion, and the accepted equivalent measures of each are annexed in Appendix D. Despite being made available, these measures make up only a small proportion of the overall Greening practices in place and are thus of lower importance. An example of this is shown in Figure 6, for the types of Ecological Focus Areas.

The Greening payment aims to achieve the Pillar I goal Provide public environmental goods and climate action and the CAP general objective of Sustainable management of natural resources and climate action. (Directorate-General for Agriculture and Rural Development (European Commission) A., 2017)

As a result, the Regulation (EU) 1307/2013 defines three characteristics regarding land use and soil. Because organic farming is considered to be environmentally friendly by definition, these holdings are granted the greening payment without having to comply with the greening framework. (European Court of Auditors, 2017)

- Crop diversification- Holdings above 10 ha and 30 ha are obliged to grow two and three different crops respectively. Furthermore, the main crop may not cover more than $75 \%$ of the arable land, though some exemptions exist regarding farms with a large coverage of permanent grassland, herbaceous crops or land lying fallow. The former exceptions are specifically targeted at livestock farms to encourage the production of fodder on their holdings. (European Parliament; Council of the European Union F., 2013)

- Permanent grassland (PG)- MS are obliged to maintain a defined ratio of grassland, restricting ploughing or other harmful adaptations. The formula for all MS takes into account organic farms, declared areas of grassland, total agricultural areas etc. Based on this formula a ratio of PG to total agricultural area is established, and all MS are 
obliged to maintain 95\% of their permanent grassland compared to their 2012 or 2013 (Croatia) figures to comply with the legislation. (Directorate-General for Agriculture and Rural Development (European Commission) A., 2015)

The total PG area to be maintained includes another classification of grassland, the ecological sensitive permanent grassland (ESPG). Although mainly applied to areas of great importance to birds and insects (Natura 2000), and not specifically listed in the CAP related regulation but rather based on the directive 2009/147/EC, ESPG has in practical terms an effect on the subsidies of agricultural holdings in these areas. As the name suggests, ESPG limits even more the management practices in order to preserve these habitats. Further details on these differences will be outlined in Chapter 6.3.1.

- Ecological Focus Area (EFA) Farmers with more than 15 ha must protect $5 \%$ of the area in order to ensure biodiversity and carbon sequestration. Notable exceptions are, for example, farms with more than $75 \%$ of the land lying fallow or being covered by herbaceous crops or leguminous crops while the remaining land does not exceed 30 ha or holdings with more than 50\% forest cover. (Loudjani , Angileri, \& Milenov, 2015) EFA types include landscape features, afforested areas, terraces as well as nitrogenfixing (n-fixing) crops and catch crops, to name but a few. (European Parliament; Council of the European Union F., 2013). For all productive EFA types such as n-fixing crops a ban on the use of pesticides has been agreed upon from 2018 onward. (Mottershead A., et al., 2019) Within these options, MS have the right to make available to farmers EFA they consider to be suitable under local conditions. This has resulted in some MS offering a wide variety of applications while others only define a moderate or low amount as eligible. (European Commission A., 2017). As a consequence, the EFA types and their positive impact on limiting inputs and soil erosion as well as higher resilience to droughts etc. vary depending on the type and the local conditions. Across the EU on average $14 \%$ of the arable land has been declared as EFA thus overfulfilling the $5 \%$ threshold. (Mottershead A., et al., 2019) Despite the great variety offered in the regulation, three EFA types make up more than $95 \%$ of the declared area in 2015 . While the n-fixing crops are declared to grow on $37.45 \%$ of EFA, catch crops and fallow land make up $33.24 \%$ and $25.94 \%$ respectively. (European Commission A., 2017). This is graphically depicted in Figure 6 along with the potential environmental effects. 
Before weighting factors

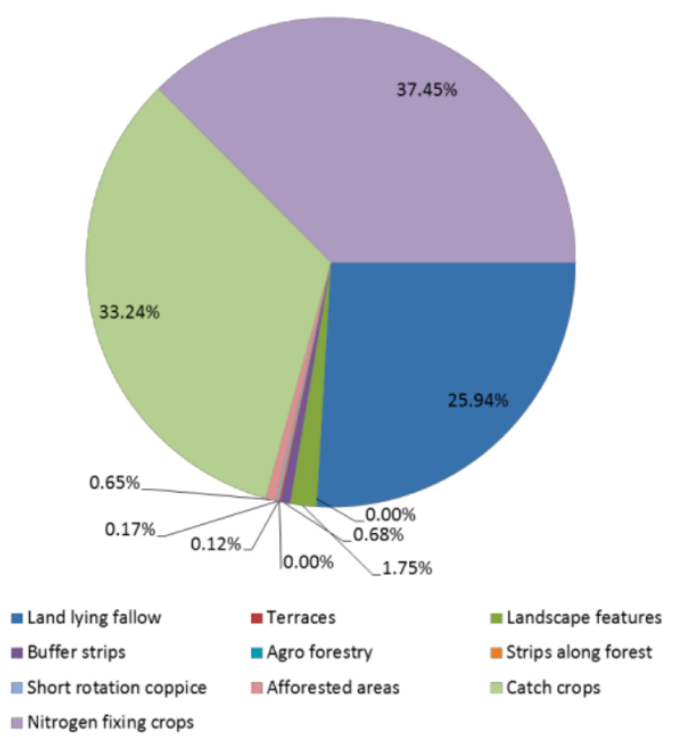

After weighting factors

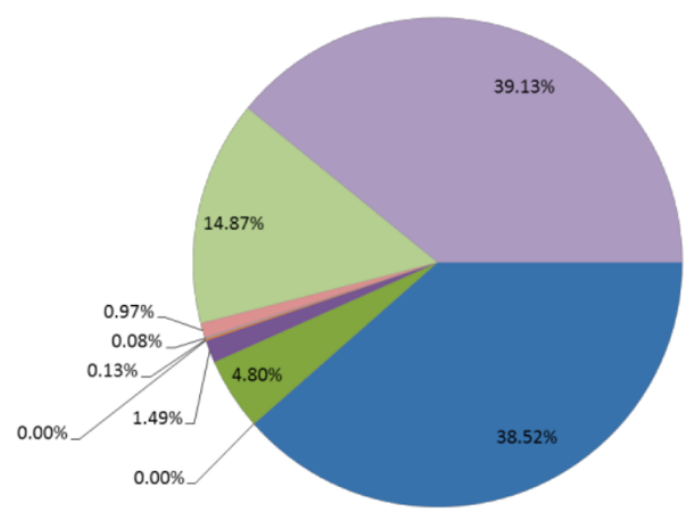

- Land lying fallow nuffer strips

Short rotation coppice Nitrogen fixing crops
- Terraces

- Agro forestry

= Afforested areas
= Landscape features

U Strips along forest = Catch crops

Figure 6: Breakdown of declared EFA areas by main EFA type, at EU level, before and after applying weighting factors; Source: (European Commission A., 2017)

As to the effects of the sum of all EFAs declared in the EU, the three aforementioned types prove to have the greatest positive impact on the environment although the effect of catch crops is shrinking while that of the other two is increasing. (Angileri, et al., 2017) Nonetheless, these figures need to be analyzed with caution as the evaluation of the weighting factors on the right pie chart was based on the eco-system services such as nitrogen runoff or pest control, and biodiversity services such as a variety of birds, bees and fungi etc. Hence, they are only partially valid to analyze the effectiveness of GHG reduction because they also consider ecosystem services related to climate adaptation and biodiversity.

Due to its clear indication of farm size thresholds and, more importantly, its concrete environmental provisions to follow, the greening payment can be classified as an income support top-off, linking as it does beneficial practices with an annual financial incentive per ha.

\subsubsection{Voluntary Coupled Support}

The Voluntary Coupled Support (VCS) scheme is in place to support "sectors or regions, where specific types of farming or specific agricultural sectors particularly important for economic, social or environmental reasons undergo certain difficulties." (European Parliament; Council of the European Union G., 2013) MS can voluntarily make this scheme available to specific sectors and regions complying with the legal definition mentioned. Furthermore, VCS is a production-limiting and therefore coupled scheme based on a fixed area and yields or on a fixed number of animals, which differentiates it from the Basic Payment Scheme (BPS) presented in 
Appendix A. The aforementioned fixed values are to ensure a coupled production at a level similar to that of the historic production of 2014 and thereby protect the sector's and region's production as well as prevent over-production of certain agricultural goods. (European Parliament; Council of the European Union A., 2017) Based on this broad targeting, VCS supports the achievements of three Pillar I goals, namely, Provide environmental public goods and climate action, Maintain agricultural diversity and Enhance farm income with a strong correlation to the latter objective. For the CAP general objectives, the most significant contribution of this scheme is towards the goal Viable food production with looser links to the other objectives. (Directorate-General for Agriculture and Rural Development (European Commission) A., 2017)

Another difference of VCS in comparison to BPS (explained in Appendix A) is the semi-fixed budgetary limit set at $8+2 \%$ or $13+2 \%$ of the national Pillar I budget under certain conditions. By the term certain conditions, the regulation refers to a possible increase of payments to incentive the maintenance of the historic production, whereas the $+2 \%$ is reserved to incentive the production of protein crops. Additional flexibility is given to MS in the process of designing the scheme. As such it is possible to link the support to environmental or contractual obligations. (European Parliament; Council of the European Union H., 2013)

Although VCS can be applied voluntarily, 27 MS (all except Germany) have decided to opt for this scheme which results in $€ 4.2$ billion of subsidies from the year 2015 onwards or an average of $10 \%$ of the Pillar I being spent using the VCS scheme. (Directorate-General for Agriculture and Rural Development (European Commission) A., 2019)

As depicted in the following figure, the main beneficiaries of this scheme are the three animalbased sectors beef and veal, milk and milk products, and sheep and goat. Together they account for almost $75 \%$ of the expenditure while protein crop subsidies make up another $11.2 \%$. (Directorate-General for Agriculture and Rural Development (European Commission) C., 2019) 


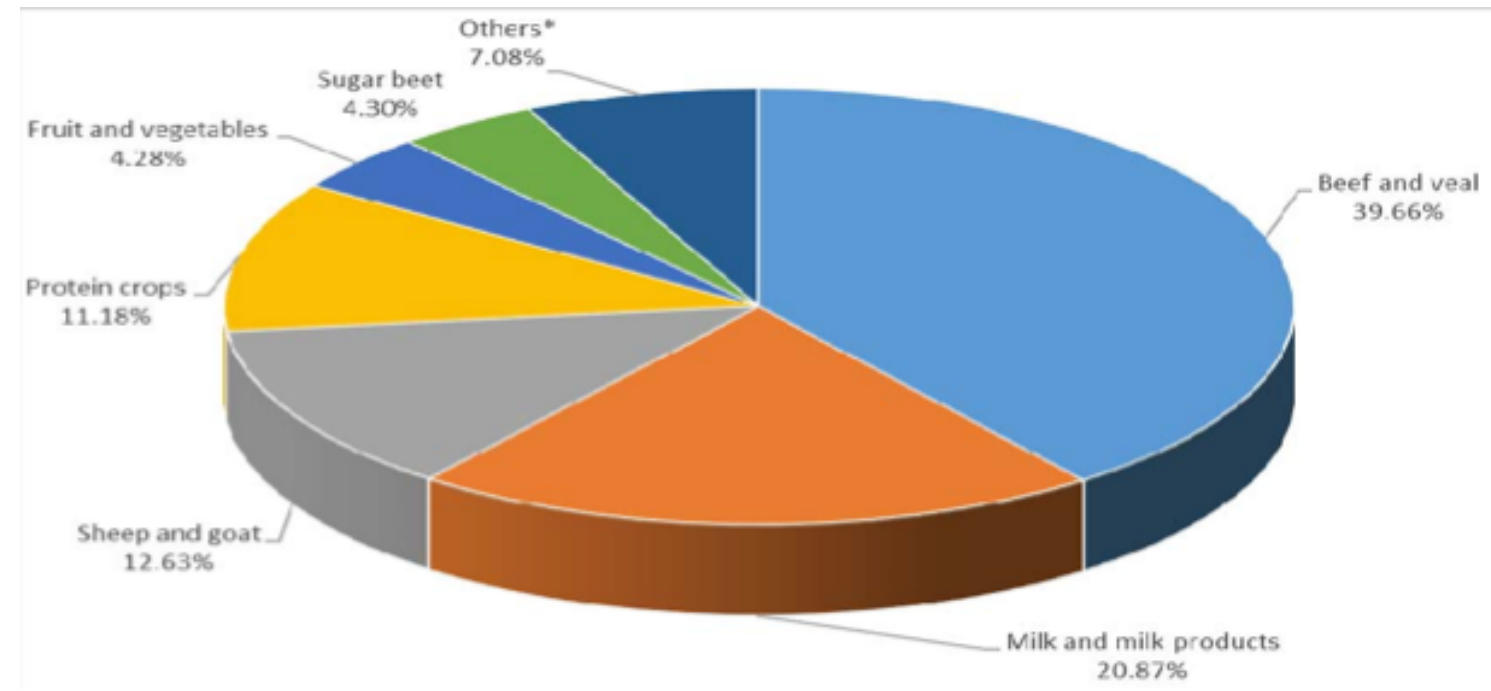

Figure 7: Beneficiaries of the Voluntary Coupled Support; Source: (Directorate-General for Agriculture and Rural Development (European Commission) A., 2019)

When examining the motivations of the MS applying VCS, several factors mentioned in the legal definition are cited. Taking the example of the beef and veal sector, much of the support is paid on economic and social grounds to keep production alive in economically depressed, rural areas (e.g. Finland, Bulgaria, Greece). In some instances, it was used to support the export capabilities of the sector (Spain) while others grant it on the basis of biodiversity and landscape maintenance (France, Austria). (Directorate-General for Agriculture and Rural Development (European Commission) A., 2019)

The fact that VCS overwhelmingly supports and incentivizes the animal-based sector, makes it particularly relevant for a possible reductions of greenhouse gases, given that a significant amount of the industry's pollution is linked to these sectors.

\subsubsection{Young Farmers Payment}

The mandatory Young Farmers Payment (YFP) was added to the CAP subsidy portfolio for only $11 \%$ of EU farms are managed by farmers younger than 40 years of age. This scheme encourages generation renewal within the industry and aims to secure food production in the long term. (Directorate-General for Communication (European Commission) A., 2019) Consequently, the subsidy is targeted to farmers below the age of 40 that are setting up or taking over an agricultural holding for the first time. The scheme is limited to a maximum of five years per farmer and may not make up more than $2 \%$ of the national envelope of Pillar I. Throughout the programming period, of the YFP, it is estimated that $€ 2.6$ billion will be spent which accounts for $1.23 \%$ of the Pillar I expenditure. (Directorate-General for Communication (European Commission) B., 2016) Concerning the calculation of individual payments and the 
maximum size of the eligible holding, the MS have the flexibility to adapt the scheme to their local conditions. (European Parliament; Council of the European Union I., 2013)

Given the scope of the YFP, it is classified to contribute to the Pillar I goals Improve agricultural competitiveness to a high extent, and Enhance farm income to a lower extent. Therefore, the scheme is aimed to accomplish the CAP general objective Viable food production. (Directorate-General for Agriculture and Rural Development (European Commission) B., 2017)

\subsubsection{Payment for Areas with Natural Constraints}

Throughout the EU a variety of areas can be defined as Areas with Natural Constraints (ANC) which limits their agricultural productivity. They qualify for this voluntary scheme fulfilling several criteria. Despite being listed as a voluntary Pillar I payment scheme, it is also a measure in Pillar II under the name M13 Areas with natural and other specific constraints.

Firstly, ANC can be declared by MS in the case of terrains such as mountains with steep slopes, or agricultural land situated above the 62nd parallel which implies shorter growing periods. (European Parliament; Council of the European Union J., 2013)

Secondly, ANC can feature climate and natural constraints such as low temperature, dryness, unfavourable texture, stoniness and four additional criteria. The specific holding has to fulfil at least one of the constraints laid out in Annex III of the Regulation (EU) No 1305/2013. This category is additionally subject to a process called fine-tuning in which the MS institution revises the status of the natural constraint and in the case of improvements via investment or economic activity, declassifies the area from the list of ANC. Other than mountain areas, this category of land is therefore grouped as areas facing significant natural constraints. (European Parliament; Council of the European Union J., 2013)

Thirdly, an ANC can be an area where it is important to keep up agricultural activity, for instance, to maintain the coastline, preserve the touristic potential or improve the ecosystem. As this definition is quite broad, ANC of this type cannot be more than $10 \%$ of the country's total area. These areas are considered as other areas affected by specific constraints. (European Parliament; Council of the European Union J., 2013)

The targeting of the ANC scheme closely correlates it to the Pillar I goal Maintain agricultural diversity and loosely aligns it to the goal Provide environmental public goods and climate action and Enhance farm income. As a result of this allocation, the scheme aims to fulfil all CAP general objectives with a strong correlation to the balanced territorial development. 
(Directorate-General for Agriculture and Rural Development (European Commission) B., 2017)

The funding for the Pillar I ANC is capped at 5\% of the annual national allocations of Pillar I and had to be declared by MS before August 1 ${ }^{\text {st }}, 2014$. (European Parliament; Council of the European Union K., 2013) Currently, only two countries (Denmark and Slovakia) make ANC payments under a Pillar I, scheme while all other MS have integrated the annual payment per ha based on income forgone and additional cost in their rural development programme under Pillar II. (European Commission B., 2017) (European Commission; Council of the European Union, 2013) This Pillar II integration may be advantageous for many MS, as mountainous countries like Austria may spend more than the allowed 5\% threshold, which is not prohibited under Pillar II funding. In the current programming period, Pillar II M13 payments for the entire EU amount to almost $€ 25$ billion, constituting $16.61 \%$ of all Pillar II spending. (Own calculations based on EAFRD data, 2020)

\subsection{Pillar II Rural Development}

The second pillar of the CAP framework was introduced in 2013 in order to enable rural areas to develop and adapt to the ever-changing conditions of the $21^{\text {st }}$ century. As such, the pillar addressed a wide range of socioeconomic, environmental and societal challenges for these regions; it is not solely open for genuine farmers but also for the rural communities as a whole. (Ranner \& di Virgilio, 2020) Pillar II rural development has a planned public budget of $€ 99.587$ billion which is an overall share of $24.4 \%$ of the CAP budget for the years 2014-2020 and is co-financed by MS and the EC via the European Agricultural Fund for Rural Development Fund (EAFRD). (Massot, 2020)

Regulation 1305/2013 as well as Omnibus Regulation 2017/2329, establish significant flexibilities for MS to address current problems at their local core. Based on a seven-year rural development plan, this is done by national or local authorities utilizing the European Menu of Measures. As environmental and climate change-related issues have been identified as EUwide problems, $30 \%$ of the EAFRD funding must address these priorities. (Nègre A., 2020). Key measures utilized for this purpose will be further explained in Chapter 4.3 and the complete European Menu of Measures can be found in Appendix H.

As for Pillar I, the three CAP general objectives outlined in Chapter 3 form the basis for the pillar's priorities. Regulation 1305/2013 establishes six clearly defined priorities and 18 aligned focus areas (FA) creating the intervention logic for Pillar II supports. An overview of them and their targeting towards the CAP general objectives is demonstrated in Figure 8. 


\section{Intervention logic for Pillar II}

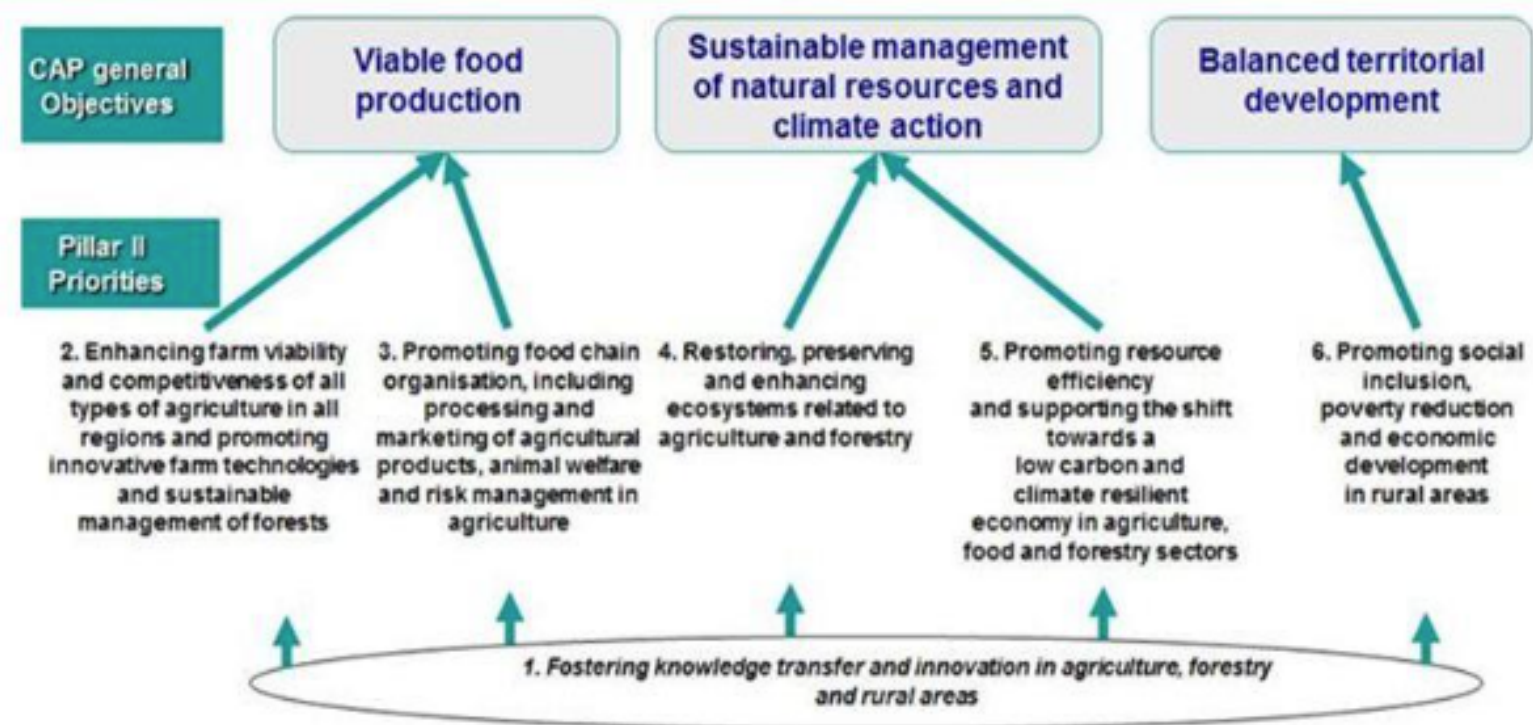

Figure 8: Intervention Logic Pillar II Source: (Directorate-General for Agriculture and Rural Development (European Commission) A., 2017)

MS are obliged to programme at least four of the six priorities either on a local or a national level. Within the selected priorities, the MS can furthermore apply FA according to the local farming conditions and the industry at hand. This adds to the local approach and thus enhances the flexibility for MS to set their own targets and choose aligned performance indicators. (Directorate-General for Communication (European Commission) C., 2020)

The climate-relevant priorities will be briefly introduced in the following Subchapters 4.2.14.2.3 along with key data regarding the funding allocation. The selection of the priorities is, again, based on the intervention logic outlined and scientific studies. As for the subsidy schemes of Pillar I, the priorities that do not affect GHG emissions in any way will be enclosed in Appendix E-G to maintain the focus on the issue at hand.

\subsubsection{Knowledge Transfer and Innovation in Agriculture, Forestry and Rural Areas}

As depicted in Figure 8, this measure has a cross aim by supporting, and the other priorities and FA by providing, the necessary education, cooperation etc. to implement the priorities. The priority disposes of three FA outlined in the following:

a. fostering innovation, cooperation, and the development of the knowledge base in rural areas (Focus Area 1A);

b. strengthening the links between agriculture, food production and forestry and research and innovation, also for the purpose of improved environmental management and performance (Focus Area 1B); 
c. fostering lifelong learning and vocational training in the agricultural and forestry sectors (Focus Area 1C). (European Network for Rural Development B., 2017)

Its current budget spending lies at $2.83 \%$ of Pillar II spending, falling short of the common target indicator set at $3.9 \%$ of the planned public expenditure. (Own calculations based on EAFRD data, 2020) (European Network for Rural Development B., 2017)

\subsubsection{Restoring, Preserving and Enhancing Ecosystems}

This priority is connected to the CAP general objective of Sustainable management of natural resources and climate action. This is to be achieved by the definition of three FA, which are:

a. Restoring, preserving and enhancing biodiversity, including in Natura 2000 areas, and in areas facing natural or other specific constraints, and high nature value farming, as well as the state of European landscapes (Focus Area 4A)

b. improving water management, including fertilizer and pesticide management (Focus Area 4B)

c. preventing soil erosion and improving soil management (Focus Area 4C). (European Network for Rural Development B., 2017)

This priority and its target indicators pursue the objective of GHG reduction and have great potential for future reductions, as all FA are of importance to this matter. Out of the total EAFRD budget an astonishing $45.48 \%$ of the funding or $€ 68.4$ billion is targeted to this priority, surpassing the $30 \%$ green-related investment threshold. The most prevalent measures utilized are M12 Natura 2000 and water framework directive payments, M10 Agri-environment-climate measures and M11 Organic farming. (Own calculations based on EAFRD data, 2020) (European Network for Rural Development B., 2017)

\subsubsection{Resource-Efficient, Climate Resilient Economy}

Just as the previous priority Resource-Efficient, Climate Resilient Economy is targeted on the improvement at GHG emissions and additionally aims to achieve of the CAP general objective Sustainable management of natural resources and climate action. The priority is structured around five FA:

a. increasing efficiency in water use by agriculture (Focus Area 5A);

b. increasing efficiency in energy use in agriculture and food processing (Focus Area 5B); 
c. facilitating the supply and use of renewable sources of energy, of by-products, wastes and residues and of other non-food raw material, for the purposes of the bio-economy (Focus Area 5C);

d. reducing greenhouse gas and ammonia emissions from agriculture (Focus Area 5D);

e. fostering carbon conservation and sequestration in agriculture and forestry (Focus Area 5E). (European Network for Rural Development B., 2017)

For this priority, $€ 9.9$ billion or $6.6 \%$ of the total EARDF budget is planned to be spent, adding to the more substantial amount of the previous priority. The main measures utilized were M04 Physical investment, M08 Investment in forest areas and M10 Agri-environment-climate measures. (Own calculations based on EAFRD data, 2020) (European Network for Rural Development B., 2017) Hence, this priority and all its FA have great potential for the realization of GHG reduction today and in the future.

\subsection{Key Pillar II Measures Beneficial to GHG Reduction}

Based on the analysis of (Mottershead A., et al., 2019), seven Pillar II measures have been recognized as relevant for emission reduction and/or increase removals. ${ }^{1}$ Additionally, measures which are only partially relevant yet quantifiable in terms of GHG emission reduction when compared to a no-CAP baseline, are added. These measures will be explained in more detail, because the analysis conducted in Chapter 6.4 focuses on both the measures' and the priorities' climate-mitigation targeting. Therefore, it is important to provide a more in-depth introduction of each relevant measure to make it comparable to the relevant priorities introduced in the previous chapter. The list below contains these measures:

- M02: Advisory services

- M04: Physical investments

- M08: Forest investments

- M10: Agri-environmental-climate measures (AECM)

- M11: Organic farming

- M12: Natura 2000 and water framework directive payments

- M15: Forest-environment-climate measures

The first measure, M02 Advisory Services, covers advice on topics ranging from the set-up of young farmers, the various legal requirements such as the SMR or the GAEC, to the economic

\footnotetext{
${ }^{1}$ Further information in Appendix I
} 
and ecological performance of holdings etc. Beneficiaries of M02 can be genuine farmers as well as forest holders. (European Parliament; Council of the European Union L., 2013) It can thus be seen as a general facilitator for the implementation of the CAP policies and their aligned provisions.

The second relevant measure, M04 Physical investment, comprises both tangible and intangible investments addressing the improvement of the performance or sustainability of holdings, the processing and marketing of agricultural products, the infrastructure cost for the modernization, development and adaptations of holdings and, lastly, the non-productive investments related to M10 AECM as well as high nature value farming systems. (European Parliament; Council of the European Union M., 2013) Under M04, non-productive investments can be granted e.g. in the form of purchasing necessary equipment and seeds to establish and maintain non-productive M10 areas. These investments take a key role in reducing GHG emissions and can be financed up to $100 \%$, while support rates for other types of investment range from $40 \%$ to $75 \%$. (European Parliament; Council of the European Union N., 2013) Based on this broad scope, the measure has great potential to address, among other goals, climate mitigation.

For the third measure, M08 Forest investments, Regulation (EU) 1305/2013, Article 21 defines the following aims: a) afforestation and creation of woodland b) establishment of agroforestry systems c) prevention and restoration of damage to forests from forest fires, natural disasters and catastrophic events, including pest and disease outbreaks, and climate-related threats (d) investments improving the resilience and environmental value as well as the mitigation potential of forest ecosystems; e) investments in forestry technologies and in the processing, mobilizing and marketing of forest products. (European Parliament; Council of the European Union V., 2013) For the increase of GHG intake forests play a vital role, and aims a), b) and d) address this issue directly. While c) contributes to the issue, too, its support is limited as its focus lies on reactions to disasters, which excludes it from contributing to an increased GHG reduction potential.

The fourth measure, M10 AECM, provides financial support to farmers or groups of farmers that voluntarily commit to practices going beyond the SMR, GAEC, the Greening framework and all national environmental provision. It is tied to the achievement of specific goals measured by appropriate indicators and can address commitments regarding the soil, biodiversity, climate mitigation etc. (European Parliament; Council of the European Union W., 2013) M10 has great potential to contribute to the reduction of GHG; it also motivates farmers to reach desirable targets providing solid and measurable outcomes. 
The fifth relevant measure, M11 Organic farming, grants a per ha payment to beneficiaries converting to or maintaining organic farming practices. (European Parliament; Council of the European Union X., 2013) The measure is considered to increase the GHG reduction potential of the CAP, as organic farming practices, for instance, do not allow farmers to use $\mathrm{N} 2 \mathrm{O}$ fertilizer.

In the climate mitigation measures M10 AECM, and M11 Organic farming, payment should cover "all or part of the additional costs and income foregone resulting from the commitments made. Where necessary they may also cover transaction costs to a value of up to $20 \%$ of the premium paid for the commitments. Where commitments are undertaken by groups of farmers, the maximum level shall be $30 \%$." Nonetheless, the maximum amount of payments is fixed at $€ 200-900$ (AECM) and €450-900 (organic farming) annually per ha. Within these ranges, the crop type and the growing season (annual/multi-annual) determine the payment. (European Parliament; Council of the European Union N., 2013)

Additionally, the funding for M10 and M11 under Pillar II can be provided for up to five years or even beyond under certain conditions based on the project's duration, thus creating a reliable income flow for beneficiaries wanting to convert to environmentally friendly practices. (European Parliament; Council of the European Union Q., 2013)

The sixth measure, M12 Natura 2000 and water framework directive payments, based on Regulation (EU) 1305/2013, Article 30, compensates farmers and forest holders for additional costs and income foregone resulting from the Water Directive and the Habitats Directive. It takes the form of an annual ha-based payment (European Parliament; Council of the European Union Y., 2013) The payments are capped at $€ 500$ in the first five years and can range from $€ 50-200$ in the following years. (European Parliament; Council of the European Union N., 2013) This compensation payment is crucial to protect the permanent grassland and forest in the areas concerned (called Natura 2000 areas) and thus contributes towards the sequestration of GHG in the soils.

The last measure, M15 Forest environment climate measures, compensates forest holders for additional costs and income foregone resulting from voluntary environmental commitments that go beyond the nationally defined management standards. (European Parliament; Council of the European Union O., 2013) M15 is bound to a maximum support rate of $€ 200$ per ha per year. (European Parliament; Council of the European Union N., 2013) Again, this compensation payment is seen to be essential to motivate forest holders to undertake environmental action with possible positive effects on the GHG intake. 


\section{Agreed Reduction Targets for 2030}

To combat global climate change and the resulting risks for humanity, the international community has accepted the Paris Agreement on Climate Change which came into effect on November 4, 2016. In the legal framework it aims to limit the average increase of temperature since the Industrial Revolution at two degrees. (United Nations C.; 2016) As of today, 187 countries (including the EU nations) responsible for $96.91 \%$ of the global GHG emissions have ratified the treaty. However, one should consider that a major emitter, the United States of America, is in the process of withdrawing from the agreement. Since this country is responsible for $17.89 \%$ of global GHG emissions today, this would lower the coverage to $79.02 \%$. (World Resources Institute, 2016) Nonetheless, the Paris Agreement on Climate Change has provoked the deployment or adaptation of key EU policy regarding agriculture and carbon trade.

In general, it regulates the supranational approach to the GHG reductions while delegating the ultimate say over concrete emission levels and targeting to national authorities. The setting of the emission reduction targets is to reflect the development and economic well-being of a nation, which is to say that developed countries with high GDP per capita have to fulfil the specifications more stringently. (United Nations B., 2016)

Following these rules, the EU has defined the Effort Sharing Principle and the EU Emissions Trading System (EU ETS). The former assigns lower GHG reduction targets to poorer MS resulting in reduction goals between $0 \%$ and 40\%. (European Parliament; Council of the European Union A., 2018) As for the concept of the latter, the Paris Agreement specifically outlines a cap and trade system for pollution allowances as a voluntary measure to achieve emission reduction in the most economical way. (United Nations A., 2016). It shall ensure a market-driven approach to the reduction effort in which the most cost-effective possibility is implemented. In the subsequently created carbon emission allowance market, stakeholders may purchase or sell emission allowances factoring in carbon removals according to their current pollution. Over the years, this system has been further extended in its coverage by including several high pollution sectors such as aviation or the energy industry. (Directorate-General for Climate Action (European Commission), 2015). Despite not being a sector covered by the EU ETS directly, the regulation has several major ramifications for the agricultural industry. The first is the $30 \%$ reduction target set for the non-ETS sectors, i.e. the agricultural industry compared to the GHG emissions of 2005. (European Commission A., 2020) More precisely, the agricultural industry is obliged to reduce its greenhouse gas equivalency pollution to $308,441.084$ thousand tonnes by 2030 compared to the 2005 emissions of $440,630.12$ 
thousand tonnes. (Own calculations based on (European Environmental Agency; Eurostat A., 2020))

This reduction can be achieved by tackling the pollution of all relevant agricultural practices as all relevant greenhouse gases are covered. Additionally, it has been recognized that the industry is in a special position regarding the fight against climate change. On the one hand, it has the potential to store and sequestrate GHG through afforestation, the creation of grasslands and wetlands, or other interventions. On the other hand, the industry faces a more limited mitigation potential than other parts of the economy due to unavoidable GHG resulting, for instance, from the production of meat. (European Parliament; Council of the European Union B., 2018) (European Parliament; Council of the European Union C.;, 2018)

The relevant legislation therefore allows MS to compensate pollution above the allocated allowances by applying the outlined beneficial land management practices. Across the EU a maximum of 280 million tonnes of $\mathrm{CO} 2$ equivalent can be compensated in this way. Beside the motivation stemming from the compensation of emissions, the MS and industries also have an economic interest since net removals can be sold as ETS allowances to other parties, thus generating income. (European Parliament; Council of the European Union C.; 2018) It should be pointed out that the ETS regulation also grants other flexibilities such as the one-off flexibility to certain MS, yet as they do not have a direct link with the agricultural industry they can be disregarded for the purpose of this thesis.

The Paris Agreement moreover encourages result-based intervention schemes rewarding beneficiaries for clear and measurable results over a set timeframe. (United Nations D., 2016). This has probably motivated European stakeholders to offer, or continue the two previously outlined Pillar II result-based measures M10 and M15 as well as the Eco schemes in the new proposal. $^{2}$

The last agricultural policy area touched by the Agreement is the encouragement of non-market approaches to enable climate mitigation potential and increase the participation of public and private parties. (United Nations A., 2016). Concerning the currently enacted CAP, the areas set aside as part of the Greening framework fit this description since they do not possess any direct economic value for the farmers.

Apart from these legally binding agreements and regulations, the EC has put forward the F2F strategy as a cornerstone of the European green new deal. It focuses on the sustainable

\footnotetext{
${ }^{2}$ Further explanation of the Eco schemes will be provided in Chapter 6.3.4.1.
} 
conversion of the entire food production value chain and is thus of significance to the agricultural policy and industry. (European Commission B., 2020)

Key F2F aspects are directly related to GHG compensation efforts referred to in the ETS regulation. On the one hand, the EC will propose a certification scheme for carbon removals for two reasons. The first is to authenticate and quantify carbon removal. The second aims to induce higher participation and thus the creation of a diversified carbon removal market by streamlining the certification of such actions. (European Commission G., 2020) (European Commission B., 2020)

On the other hand, the EC emphasizes the importance and untapped potential of biogas production from various kinds of waste products. Consequently, it will critically review the MS' CAP strategic plans concerning investment in biogas-refineries or other environmental investments such as solar panels. Beneficiaries shall either be compensated by the CAP or the carbon market (European Commission B., 2020) If successful, these initiatives can crucially decrease the agricultural emissions-especially in the highly polluting livestock sector.

Recognizing the significant impact of that sector, the EC furthermore plans to develop the going-to-market strategy of sustainable and innovative feed additives and thus decrease the dependency on imported fodder (especially soya). Apart from tackling the direct GHG emissions from livestock, it aims to lessen the destruction of natural habitats where livestock fodder is cultivated. (European Commission B., 2020)

As regards the pollution arising from agricultural soils and management practices, the F2F strategy sets ambitious targets for several mitigation actions. Firstly, the integrated pest management will encourage the use of alternative pest control techniques such as mechanical wedding or crop rotation instead of chemical pesticides aiming to halve the use of hazardous pesticides by 2030. (European Commission B., 2020)

Secondly, the EC plans to develop an integrated nutrient action plan focused on the nitrogen and phosphorous contents in the soil. Given that not all nutrients are absorbed by plants, the residues may endanger the immediate surrounding and the climate by leaching into the air, soil and water. By the year 2030, the initiative wants to decrease nutrient leaching by $50 \%$ and the use of fertilizer by $20 \%$ without compromising soil fertility. (European Commission B., 2020) In the current CAP proposal, the EC has envisioned a Farm Sustainability Tool addressing this issue. (European Commission B., 2020)

Thirdly, the F2F declares organic farming practices to be beneficial to the environment in general, which is why the EC wants $25 \%$ of the EU agricultural land to be managed accordingly by 2030. (European Commission B., 2020) The ambition to increase this figure can be seen in 
the Pillar II measure M11 of the current CAP framework. However, it remains to be seen if the current subsidies, along with the rising consumer demand, are sufficient to increase the share from $7.5 \%$ in 2018 to the set target. (Eurostat B., 2018)

The fourth relevant initiative in the F2F is the proposed use of the value added tax (VAT) as a means to incentivize healthy diets by lowering VAT rates i.e. for organic products or vegetables while possibly increasing the tax for other products based on externalities such as GHG emissions. Whether this approach to the VAT will materialize largely depends on the MS because they retain the power over taxation matters. (European Commission B., 2020) As for imported food, the EC plans to strengthen its import controls and propose stricter dissuasive measures for producers to avoid fraud in the internal and external supply chains. (European Commission B., 2020) Why this is and why in general increasing environmental provisions from the EU are of key importance for the global food market can be explained by the Brussels Effect. Whenever the EU regulates a market most stringently, multinational companies concerned, in this case, food exporters in third countries, are forced to comply with the EU regulations to be granted access to the single market. In the case of food exporters, the products are furthermore non-divisible, which is to say that complying with two standards and cultivating the product according to different standards would not be economically achievable. Although a local government may impose laxer rules regarding climate mitigation in the agricultural industry, all exporters decide to comply with the stricter rules to be able to sell their products in the entire world as the most stringent regulation prevails in all jurisdictions. Sometimes this is even followed by the de jure Brussels Effect in which these exporters lobby the national governments to emulate the EU regulation because they are disadvantaged compared to national competitors. (Bradford A. A., 2020) In the light of the proposed changes to the livestock sector and the general management practices, this may lead to increased climate adaptation/mitigation measures being undertaken worldwide with the aim to maintain access to the single market and comply with its rules.

Based on this theoretical background, the following chapter will give a detailed view of the policy proposals within the CAP framework which would allow the industry to target the 2030 benchmark of 308,441.084 thousand tonnes of GHG.

\section{Policy Proposals within the Current CAP Framework}

Based on the introduction of the CAP framework in Chapter 4 and the reduction targets in Chapter 5, this chapter will provide the reader with the context of the environmental performance of the policy and the effects to be expected when adapting it. So that this may be 
done adequately, the first part of the chapter will outline a scenario in which the funding is shifted between the pillars without adjusting the percentage of the funding in the pillars' schemes and measures. This aims to provide a wider perspective on the possible consequences for the GHG reduction potential and on administrative aspects without specific adaptations to the measures and schemes themselves.

The concrete reasoning for the presumed effects of the aforementioned approach will be analyzed along with the specific adaptations in Subchapters 6.2, 6.3 and 6.4 for the horizontal aspects, Pillar I and Pillar II respectively. For this thesis, a meaningful limitation has to be made for this second part, were only schemes and measures with a direct or indirect effect on the GHG emissions will be analyzed. The Pillar I schemes with a direct impact are selected based on the intervention logics previously outlined, while selection of indirect schemes is based on scientific studies.

For Pillar II, the analysis focuses more on quantitative factors because there are publicly available data upon which the relevant spending for climate mitigation per measure and priority was calculated. The measures and priorities analyzed are based on the intervention logic and the findings of Chapter 4.2. Along with the proposed adaptations found in the relevant literature, the calculations form the basis of the quantitative and qualitative adjustments proposed.

\subsection{Analysis of Budget Reallocation between the Pillars}

Beginning with the possible effects likely to occur when shifting monetary resources from Pillar I to Pillar II, the following table, along with the comments, provide positive and negative effects for the CAP GHG reduction potential and the execution of the policy across the EU. These will be further elaborated in the following paragraphs.

\begin{tabular}{|l|l|l|l|}
\hline $\begin{array}{l}\text { Pro } \\
\text { possible less funding of }\end{array}$ & VCS & $\begin{array}{l}\text { Contra } \\
\text { Deviation of policy due } \\
\text { to high subsidiarity }\end{array}$ & $\begin{array}{l}\text { Comment } \\
\text { concentrate } \\
\text { funds on } \\
\text { irrelevant } \\
\text { measures and } \\
\text { defund relevant } \\
\text { ones }\end{array}$ \\
\hline Co-financed & $\begin{array}{l}\text { MS have } \\
\text { interest in } \\
\text { success of } \\
\text { projects } \\
\text { Co-financing } \\
\text { with MS }\end{array}$ & $\begin{array}{l}\text { SWOT-Analysis is } \\
\text { main compliance tool } \\
\rightarrow \text { less oversight }\end{array}$ & $\begin{array}{l}\text { No ex-post } \\
\text { thorough } \\
\text { revision process }\end{array}$ \\
\hline $\begin{array}{l}\text { Less direct EU MFF } \\
\text { budget }\end{array}$ & monitoring & $\begin{array}{l}\text { Result non- } \\
\text { transferable to } \\
\text { other regions }\end{array}$ \\
\hline
\end{tabular}




\begin{tabular}{|c|c|c|c|}
\hline Long-term projects & $\begin{array}{l}\text { Financial } \\
\text { security for } \\
\text { farmers }\end{array}$ & $\begin{array}{l}\text { Less farming-related } \\
\text { expenditure }\end{array}$ & $\begin{array}{l}\text { Pillar II has a } \\
\text { wider } \\
\text { beneficiary } \\
\text { range }\end{array}$ \\
\hline $\begin{array}{l}\text { Project-based } \\
\text { monitoring }\end{array}$ & $\begin{array}{l}\text { Concrete } \\
\text { results }\end{array}$ & $\begin{array}{l}\text { Decrease funding of } \\
\text { Young farmers } \\
\text { payment }\end{array}$ & $\begin{array}{l}\text { Fewer pro- } \\
\text { environmental } \\
\text { farmers }\end{array}$ \\
\hline $\begin{array}{l}\text { More subsidiarity and } \\
\text { MS flexibility }\end{array}$ & $\begin{array}{l}\text { Higher MS } \\
\text { support }\end{array}$ & $\begin{array}{l}\text { Decreased funding of } \\
\text { Greening measures }\end{array}$ & $\begin{array}{l}\text { Lower incentive } \\
\text { for } \\
\text { environmentally- } \\
\text { beneficial } \\
\text { practices }\end{array}$ \\
\hline Cooperative approach & $\begin{array}{l}\text { Through rural } \\
\text { producer } \\
\text { communities } \\
\text { covering more } \\
\text { ha }\end{array}$ & Co-financed & $\begin{array}{l}\text { Less financial } \\
\text { power of EC } \\
\text { over MS }\end{array}$ \\
\hline Investment financing & $\begin{array}{l}\text { Could be done } \\
\text { with GHG } \\
\text { reduction in } \\
\text { mind }\end{array}$ & $\begin{array}{l}\text { No incentive paying in } \\
\text { Pillar II }\end{array}$ & $\begin{array}{l}\text { Only cost } \\
\text { incurred and } \\
\text { income forgone }\end{array}$ \\
\hline More local approach & $\begin{array}{l}\text { MS authorities } \\
\text { select projects } \\
\text { based on local } \\
\text { needs }\end{array}$ & Long-term projects & $\begin{array}{l}\text { Possibly lower } \\
\text { willingness to } \\
\text { commit to } \\
\text { adaptations, no } \\
\text { trial period }\end{array}$ \\
\hline Overall decrease in BPS & $\begin{array}{l}\text { BPS has no } \\
\text { environmental } \\
\text { effect }\end{array}$ & & \\
\hline $\begin{array}{l}\text { Less deviation based on } \\
\text { GAEC definitions }\end{array}$ & $\begin{array}{l}\text { MS can adapt } \\
\text { GAEC } \\
\text { baseline } \\
\text { nationally }\end{array}$ & & \\
\hline
\end{tabular}

Firstly, and most important for the GHG reduction would be a decrease in the funding of VCS to the meat and dairy industry responsible for a large part of the $\mathrm{N} 20$ and $\mathrm{CH} 4$ emissions. However, this is debatable and will be further discussed in Chapter 6.3.5. Another scheme without a direct impact on GHG reduction is BPS. Similarly to VCS, a decrease in Pillar I funding would lower the total subsidy payments of this scheme and possibly allocate the financial resources to more beneficial measures or schemes.

Secondly, increased funding of the long-term projects and the possibility of environmentallyfriendly investments under Pillar II, along with the increased positive effects when applying a cooperative, multi-stakeholder approach, provides farmers with a reliable compensation for environmental actions. Pillar II investments could facilitate the change to beneficial practices by lowering or removing the costs associated with them. A meaningful combination of Pillar II 
measures may thus be ideal for the necessary conversion of land into more sustainable and thus GHG-reducing land by providing the necessary investments and securities to farmers and collectives. Especially, the targeting of farmers' collectives has the potential to convert more ha compared to the individual funding approach of Pillar I. However, another factor which might increase the willingness to use land more sustainably is the subsidy payment form of annual payments per ha in Pillar I. Compared to, for instance, a multi-year AECM project covered under Pillar II, farmers may opt to declare such areas as EFA or ESPG/PG (Greening payment) on an annual basis. This gives them the possibility of a trial period under the current regulation to analyze the benefits and disadvantages for their farm, which would not be possible when committing to a long-term contract. This approach and its combination with other measures is currently discussed among the political stakeholders for the new CAP post-2020. (Lampkin, et al., 2020)

The flexible annual Greening payment mentioned above can also be interpreted as a disadvantage since farmers cannot rely on a long-term financial contribution to finance climate adaptation and mitigation actions. Moreover, the annual approach always includes the risk that areas set aside for carbon sequestration can be eradicated quickly. This threat may materialize when the global commodity prices, which are frequently subject to high volatility, experience a sudden spike. In this scenario, the compensation paid would not cover the income forgone and the cost of maintenance, hence motivating farmers to maximize their profits by cultivating more crops.

Another possible effect undermining the reduction of GHG emissions in the agricultural industry would be overall lower funding to individual genuine farmers. This can be explained by the wider beneficiary range of Pillar II. Unlike Pillar I funds, Pillar II funds can be used to support, among others, rural communities or scientific projects and could therefore deviate funds to support GHG reductions outside the agricultural industry.

Another disadvantage of a decrease in overall Pillar I funds would lower the total ring-fenced payments of holdings under the Greening obligations. For instance, $30 \%$ of $€ 100$ million would result in a lower total subsidy amount than $30 \%$ of $€ 120$ million. Hence, the Greening payment, based on clear provisions to incentivize beneficial practices, would be weakened. This is exacerbated by the fact that Pillar II financing is offered on the basis of cost incurred and income foregone, which is to say that farmers cannot receive incentive payments to maintain beneficial practices once in place. Moreover, the clear Greening provisions minimize the room for deviations because national authorities do not have the same flexibility as in Pillar II when dedicating their funds. Due to these factors, farmers would have less economic incentive to 
maintain (non-productive) habitats that foster carbon sequestration. From an economic point of view, it would act against the aim to permanently include the externalities (in this case the natural habitats) in the agricultural market by decreasing their price. This could possibly trigger a process in which the opportunity costs arising from the non-cultivation of an area in a conventional way, along with the added income would outweigh the economic and ecologic benefits associated with the maintenance of the habitat.

Yet another important setback would be the reduced overall amount provided under the YFP scheme possibly leading to a slowdown of the generation renewal which in turn bolsters the entry of young, environmentally sensitive, farmers into the market.

In terms of the EU-wide effective execution of the policy the most important positive aspect is that Pillar II closely integrates national agencies; these usually are more aware of the local conditions and hence can tackle the problems of GHG reduction considering the areas at hand. If conducted properly by these authorities, this may maximize the GHG reduction compared to an EU-wide approach lacking the local knowledge. An additional point reinforcing the former would be that since Pillar II is co-financed, MS can be expected to have an increased interest in the exact monitoring and success of the climate actions as they utilize their own national budgets. Yet, co-financing and its monitoring approach have downsides to consider. From the EU budget perspective, co-financing would earmark fewer financial resources from the MFF budget which could be used to finance other policies. This is, however, accompanied by a decrease in financial leverage of the institutions over MS, since they would finance a lower percentage of the CAP. From the monitoring perspective, it is likely to obtain more precise monitoring results. But these cannot be generalized as the Pillar II project-based monitoring approach yields figures that are highly depended on the local conditions (climate, soil etc.).

In the current CAP post-2020 negotiations, the co-financing approach seems to be favoured by MS and is thus likely to be supported in the ongoing legislative process. (Ranner \& di Virgilio, 2020) It can be further explained by the development of a strong anti-EU sentiment in MS (i.e. Brexit) and the rising number of anti-EU parties (i.e. AFD, VOX etc.) in the European Parliament. All this has had profound effects on the policymaking, shifting its aim towards more subsidiarity and away from union-wide frameworks. (Ranner \& di Virgilio, 2020)

On the other hand, the significant subsidiarity granted in Pillar II may backfire, as the MS may use the obtained flexibility to turn their priorities away from GHG reduction and fund intensified cultivation or other practices harmful to the climate instead. In this case, the EC 
would have little control and correction power as the ex-ante SWOT Analysis of the agricultural situation of each MS would be the only compliance tool.

Another point to be considered is the fact that the GAEC baseline requirements for almost all Pillar I schemes outlined in Chapter 4 have been found to hold possibilities of deviations. This is because MS may define these criteria on a national or local basis leaving them open for an application of their own merits. In some cases, it has been found that this definition was made not on the basis of sound environmental practices but rather in favour of a minimal disruption for existing farms and national authorities. As such, it could be beneficial to direct more funds to Pillar II as the GEAC baseline is only partially used here. (Mottershead A., et al., 2019)

Conversely, the shift of funds from Pillar II to Pillar I also has benefits and disadvantages. The arguments presented stand in contrast to the arguments made in the first model, which is to say that positive aspects in the former model may be negative in the latter model. Therefore, they will not be elaborated in detail again but are listed in the following table for the sake of understandability and coherence.

\begin{tabular}{|c|c|c|c|}
\hline Pro & Comment & Contra & Comment \\
\hline $\begin{array}{l}\text { Financed by EU MFF } \\
\text { Budget }\end{array}$ & Financial power & $\begin{array}{l}\text { Possible lack of } \\
\text { considerations of local } \\
\text { conditions }\end{array}$ & $\begin{array}{l}\text { Climate, Soil, } \\
\text { crop patterns } \\
\text { etc. }\end{array}$ \\
\hline $\begin{array}{l}\text { Flexible annual } \\
\text { payments }\end{array}$ & $\begin{array}{l}\text { Possible trial- } \\
\text { period for } \\
\text { farmers }\end{array}$ & Resistance from MS & $\begin{array}{l}\text { No political } \\
\text { willingness }\end{array}$ \\
\hline $\begin{array}{l}\text { Increase of Greening } \\
\text { payments }\end{array}$ & $\begin{array}{l}\text { Lower risk of } \\
\text { Pillar II } \\
\text { deviations, } \\
\text { concrete } \\
\text { conditionalities }\end{array}$ & $\begin{array}{l}\text { Short-term investment } \\
\text { on an annual base }\end{array}$ & $\begin{array}{l}\text { No long-term } \\
\text { financial } \\
\text { security, threat } \\
\text { of quick } \\
\text { eradication }\end{array}$ \\
\hline Incentive paying & $\begin{array}{l}\text { Economic } \\
\text { incentive when } \\
\text { conversion is } \\
\text { completed }\end{array}$ & $\begin{array}{l}\text { More deviations based } \\
\text { on GAEC }\end{array}$ & $\begin{array}{l}\text { MS can adapt } \\
\text { GAEC baseline } \\
\text { nationally }\end{array}$ \\
\hline $\begin{array}{l}\text { More farming-related } \\
\text { expenditure }\end{array}$ & $\begin{array}{l}\text { Smaller } \\
\text { beneficiary } \\
\text { range }\end{array}$ & $\begin{array}{l}\text { Possible more funding } \\
\text { of pollution sectors }\end{array}$ & VCS \\
\hline \multirow[t]{2}{*}{$\begin{array}{l}\text { More Young farmers } \\
\text { payment }\end{array}$} & $\begin{array}{l}\text { Youth is more } \\
\text { pro- } \\
\text { environmental }\end{array}$ & $\begin{array}{l}\text { Funding out of EU } \\
\text { MFF budget }\end{array}$ & $\begin{array}{l}\text { Higher EU } \\
\text { MFF } \\
\text { expenditure }\end{array}$ \\
\hline & & Individual approach & $\begin{array}{l}\text { More holdings- } \\
\text { based funding } \\
\text { possibly } \\
\text { covering fewer } \\
\text { ha }\end{array}$ \\
\hline
\end{tabular}




\section{\begin{tabular}{|l|l|l|}
\hline Overall increase in BPS & $\begin{array}{l}\text { BPS has no } \\
\text { environmental }\end{array}$
\end{tabular} effect}

Table 3: Effects of shifting funds from Pillar II to Pillar I, Source: own compilation based on finding of the previous chapters

Concluding this scenario, it can be said that each pillar of the CAP serves legitimate purposes and reveals advantages and disadvantages for the GHG reduction potential. Pillar I is better suited to maintain beneficial practices if market conditions and, most importantly, commodity prices remain somewhat stable. Pillar II, on the other hand, is more effective in initiating the change to beneficial practices by providing stable financing measures over a long time, thereby lowering or erasing the investment barrier of the change. As such, a simple shift from one pillar to the other is not expedient to foster beneficial practices and incentives. The conditionalities or details for granting the support schemes/measures are of higher importance, and possible funding reallocations should be based on the GHG reduction potential of each relevant measure and scheme. Hence, these details should be critically analyzed before making budget proposals, as the meaningful adaptation of the measures and schemes may affect the GHG reduction potential positively or negatively. The following subchapters suggest adaptations and considerations as a basis for the future budget allocation starting with the horizontal aspects.

\subsection{Horizontal Aspects Cross-Compliance}

The GAEC forming the basic requirements beneficial for the environment as outlined in Chapter 4 have been widely discussed amongst stakeholders in recent years. As a result, the EC has changed these standards significantly in its proposal for the CAP post-2020. To reflect these developments and the merits behind them, this chapter firstly focuses on possible drawbacks of the relevant GAEC standards, and secondly comments on the new enhanced conditionality in the proposal.

The first point frequently raised regarding the GAECs as a whole, is that MS have used their flexibility in some cases to limit the affected area, thus protecting farmers from possibly more costly management practices. One example of this is GAEC 4 on minimum soil cover. The variety of definitions, such as coverage of $20 \%$ of arable land by winter or perennial crops in winter (Romania), or a combination of ploughing restrictions and ground cover on nonproductive EFA zones (Germany), severely limits the scope of application and thus hampers the carbon sequestration of the soils. (Mottershead A., et al., 2019)

As for GAEC 5 regarding soil erosion: MS have opted to apply this rule to slopes which by itself is not to be seen negatively as erosion is more likely in mountainous areas. The deviation arises when MS such as Spain or Poland define the steepness of the slope $(>15 \%$ and $>20 \%$, 
respectively) in a way that does not reflect the geographic reality of the UAA. As a result, the vast majority of the UAA is not affected by this measure, which again significantly decreases the carbon sequestration potential. (Mottershead A., et al., 2019) In the case of Poland, an analysis by (Mottershead B., et al., 2019) has mapped the areas which would have been affected by different slope criteria definitions. Based on these results, a slope criterion between $15-25 \%$ would only have affected a relatively small part of land in the south, whereas a slope criterion between $8-15 \%$ would have affected a considerable part of the agricultural heartland of the country located in the central plains. Therefore, the Polish government presumably adopted the $>20 \%$ slope criterion to protect its holdings against costly adaptations resulting from the application of GAEC 5.

Regarding the GAEC 6 on the retention of soil organic matter and the ban on stubble burning, most MS have not defined additional requirements beyond the ban on burning plant stubble. This ignores the wide application potential of the GAEC for climate mitigation as it could be used to support incorporating crop residues into the soil, maintaining of winter stubble, minimum tillage practices etc. This result is further exacerbated by the fact that the negative management practice concerned had been largely out of fashion before the introduction of this GAEC in 2003. Hence this requirement was rather a result of changing agricultural practices than a driver of it. (Mottershead A., et al., 2019) Despite the overall limited effect of this basic requirement, some positive aspect in the case of Hungary and Romania should be mentioned. In these MS, the consecutive cultivation of sunflowers has been proven to be detrimental to soil organic matter, and thus the repeated cultivation of this crop on the same arable land has been restricted. (Mottershead A., et al., 2019).

The last climate mitigation-relevant Cross-compliance provision is GAEC 1 which obliges farmers to establish buffer strips along water courses. Depending on how the buffer strip is managed, it can be an efficient mitigation tool by improving the carbon stock in the soil and preventing soil erosion. (Mottershead A., et al., 2019). The allowed management practices are tied to the Council Directive 91/676/EEC of 12 December 1991, also called Nitrate Directive. It obliges MS and farmers to consider the ecological status and vulnerability of the water course when defining management practices as to a) reseeding of the buffer strips and b) fertilization of the land near water courses. These provisions must be further strengthened when the area is considered a vulnerable zone. (European Economic Community, 1991) Given these stringent provisions tied to the GAEC 1 it should be retained as is in the new CAP post-2020. In fact, this has been pursuit by the EC in its current proposal. (European Commission A., 2018) 
All these findings have let to the conclusion that a) the effect of the GAEC on climate change mitigation cannot be adequately modelled in most cases and b) that MS perceive the GAEC as rather undemanding. (Mottershead A., et al., 2019). Due to the latter point, there is room for the implementation of stricter basic requirements which has materialized in the current CAP post-2020 proposal of the EC. However, before elaborating on these, it should be noted that the following arguments on the proposals regarding the CAP post-2020 basic requirements are subject to the ongoing political decision-making process. Given that this process has not advanced beyond the first hearing in the Council of Europe and the European Parliament, it can be expected that amendments will change important details. (Jahr (Rapporteur European Parliament), 2020) (Müller (Rapporteur European Parliament), 2020)

The most notable change is the appropriate protection of wetland and peatland under the new GAEC 2. (European Commission A., 2018) As these areas are commonly considered carbon sinks, and provided that the word "appropriate" is not interpreted in a lax fashion by MS, this requirement will add a meaningful layer of protection. Research in the climate mitigation potential has found that damaged peatlands are a major source of GHG emissions, which provides a further reason for protecting them. (International Union for Conservation of Nature, 2017)

The second enhancement of the basic conditionality refers to the GAEC 4 which is now listed as GAEC 7. The new requirement demands covered soil in the most sensitive period(s) of the year. Thus- it specifies the timeframe of soil cover by possibly linking it to the seasons in which most soil erosion occurs. (European Commission A., 2018) Yet- the definition of "sensitive period(s)" seems to be under continuous discussion and in need of clarification by national stakeholders. (Deutscher Bauernverband e.V., 2020) At the time of writing one can only hope that the legislative stakeholders will adopt a narrow definition of the term to achieve an increased climate mitigation effect by decreasing soil erosion.

The third improvement regarding the limitation of soil erosion is the GAEC 6, which requires minimum tillage techniques for slope areas. (European Commission A., 2018). Provided that the slope criterion is set according to the MS' topography and does not exclude vulnerable agricultural areas, it would link a concrete beneficial management practice with the limitation of GHG released due to soil erosion. Under this assumption, the GAEC 6 should replace the current GAEC 5 and should be vigorously enforced by national authorities.

One possible addition to the Cross-compliance standards could be the restriction of mulching practices at field margins along country roads. If integrated, an equilibrium has to be found between ecological benefits (increase in biodiversity and carbon sequestration) on the one hand 
and traffic security (passing vehicles) on the other. One possible solution would be to have the margins only mulched once a year after the flowering season and only at a width that prevents the obstruction of traffic for the entire year leaving the non-obstructive land as a multi-year pasture. (Detsch, 2018) Given the focus of the current GAEC 7 on landscape features it should be integrated in this provision. The part that would not be mulched over a longer period might become eligible for PG support creating overlap in the legislation since they could be declared under GAEC 7 and as PG. This is why the new mulching practices should be specifically excluded in the PG declaration because this would give MS and farmers an easy way to circumvent the max 5\% reduction-of-PG clause in the regulation by simply declaring these areas to fall under the permanent grassland provision. At national level further limitations should be incorporated because flowering seasons vary in different climate zones and expressways require an increased amount of security precautions.

Despite the outlined improvement of the GAEC standards in the current proposal, some shortcomings may undermine the effective national implementation of environmental and climate provisions. The current proposal on the CAP strategic plans aims to integrate the three Greening requirements outlined in Chapter 4.1.1 into the GAEC and the basic requirements. This may seem advantageous at first glance since it would make them obligatory for all Pillar I payments (including now the SFC) and all area-based payments of Pillar II. (European Commission A., 2018) While in theory, this could improve the area managed under environmental provisions in MS willing to commit themselves to more ambitious targets, for reasons outlined in the previous paragraphs on the current GAEC 5 and 6 , this leaves room for deviations in the detailed definition of the provisions. An example is the new GAEC 9 which refers to the maintenance of non-productive areas similar to EFA zones. While the Greening framework sets a clear threshold of $5 \%$ of the agricultural area to be protected, the newly adapted version fails to do so. This could be utilized by MS to set the threshold as low as $1 \%$, effectively decreasing the area optimal for carbon sequestration (Matthews A. A., 2018). Apart from the possible weakening of the GHG reduction potential, this also constitutes a threat to the level playing field for all European farmers, as farmers in some MS would be obliged to dedicate more land towards non-productive purposes than those in other countries. In the context of environmental efforts, this could trigger a race to the bottom (within the range of EU law), favouring producers in the MS with the lowest requirements at the expense of farmers in nations with higher standards. 
To avert this, the EC has set a no-backsliding provision. The article in question states, "Member States shall aim to make, through their CAP Strategic Plan,... a greater overall contribution to the achievement of the specific environmental- and climate-related objective". (European Commission L., 2018) The approach of a strategic plan for all CAP payments is indeed an advancement since MS have to demonstrate greater coherence of the payments towards the defined goals based on the national agricultural situation; however, the formulation "shall aim" does not bind MS to concrete results. In the chosen qualitative approach MS need to explain how they aim to achieve GHG reductions and add environmental public goods. This is less effective than a quantitative approach based on numerical indicators. A straightforward example of the latter approach is to take the ha subject to beneficial practices i.e. organic farming practices $(\mathrm{N})$ and multiply it with a value $(\mathrm{X}<1)$ for the areas planned to be covered. By doing so, countries define their current situation regarding the practice and set an exact and measurable target to increase the amount of land under organic farming management. Contrarily, the former approach is more difficult to evaluate and enact by the EC once the strategic plans of the MS are approved. (Matthews A. B., 2018) Naturally, the definition of the added value $\mathrm{X}$ should reflect the environmental conditions (climate, soil etc.) and the structure of the industry in the MS. For instance, countries with a colder climate may have less potential for the cultivation of organic products than warmer countries. Another factor to consider is the current percentage of the organically-managed holdings in ha within the total UAA. Countries with an already high area coverage dedicated to organic farming are not supposed to increase the area in the same way as countries with a low area coverage. This reasoning is made on the assumption that it would be significantly easier to identify and convert areas to organic practices in the latter countries as more potential areas remain. Based on scientific evidence and industry data, the exact definition of the values $\mathrm{N}$ and, most importantly, $\mathrm{X}$, should be made by an expert committee. But as a considerable number of schemes and measures cannot be quantitively measured, the envisioned CAP post-2020 would rely on both quantitative and qualitative evaluation practices.

Summing up the findings on the integration of the Greening provisions into the GAEC baseline requirements for CAP support as outlined in the EC proposal, it can be argued that this would do more harm than good to the GHG reduction potential. This is reasoned in the assumption that both a strong basic conditionality and demanding additional Greening incentives are needed to maximize the GHG reduction potential. In the following chapters, this thesis will therefore continue to consider the Greening provisions as part of the Pillar I top-off payments and detail possible improvements. 
To conclude the analysis of the horizontal aspects, several general points should be considered in the new policy framework from 2020 on. For several GAEC, it was found that the legal wording has allowed for significant deviations in MS not usually in favour of environmental benefits. Consequently, the legislative stakeholders should concretize the formulations and thereby limit the room for deviations on a national level. The prime example for this would be the definition of slope criteria upon which certain soil-erosion-limiting practices have to be applied.

The second recommendation is to abstain from integrating the Greening provisions into the basic conditionality to avoid having them watered down in the national applications.

The third point regarding the planned CAP Strategic Plans of MS is a) to pursue the currently planned obligation to lay out a comprehensive national CAP plan and b) to apply a quantitative ex-ante and ex-post evaluations where possible, including numeric target indicators. All these aspects are summarized in Table 4 along with a brief comment.

\section{Relevant GAEC requirement based on Comment/adaptation}

\section{Regulation 1306/2013}

GAEC 1- Establishment of buffer strips To be retained as is

along water courses

GAEC 4 Minimum soil cover

To be replaced with GAEC 7 of CAP strategic plan regulation, strict definition of term most sensitive period(s)

\begin{tabular}{|c|c|}
\hline $\begin{array}{l}\text { GAEC 5- Minimum land management } \\
\text { reflecting site-specific conditions to limit } \\
\text { erosion }\end{array}$ & $\begin{array}{l}\text { Replaced by GAEC } 6 \text { of CAP strategic } \\
\text { plan regulation as it defines minimum } \\
\text { tillage techniques as preferred mitigation } \\
\text { measure }\end{array}$ \\
\hline $\begin{array}{l}\text { GAEC 6- Maintenance of soil organic } \\
\text { matter level through appropriate practices } \\
\text { including ban on burning arable stubble, } \\
\text { except for plant health reasons }\end{array}$ & $\begin{array}{l}\text { Although little effect is expected, it should } \\
\text { be retained }\end{array}$ \\
\hline $\begin{array}{l}\text { GAEC 7- Retention of landscape features, } \\
\text { including, where appropriate, hedges, } \\
\text { ponds, ditches, trees in line, in group or } \\
\text { isolated, field margins and terraces, and } \\
\text { including a ban on cutting hedges and trees } \\
\text { during the bird breeding and rearing }\end{array}$ & $\begin{array}{l}\text { Inclusion of mulching practices along } \\
\text { country side roads to create grassland. }\end{array}$ \\
\hline
\end{tabular}


season and, as an option, measures for

avoiding invasive plant species

Integration of Greening provisions as new Not to be pursuit and Greening maintained

GAEC requirements

as additional top-off incentive payment

Table 4: Summarized proposed changes to the GAEC based on classification in Regulation (EU) 1306/2013; Source: own compilation

\subsection{Pillar I Income Support}

As described in Chapter 4.1, the purpose of the seven Pillar I subsidies is to support farm holdings following a detailed intervention logic. Founded in this logic, this chapter will analyze the payments contributing towards the goal Provide environmental public goods and climate action, followed by subchapters regarding subsidies which have an indirect impact on GHG reductions. Since this analysis raises various detailed adaptation proposals regarding each relevant scheme, the reader is referred to Table 7 at the end of the Pillar I Income Support Chapter to obtain a summary.

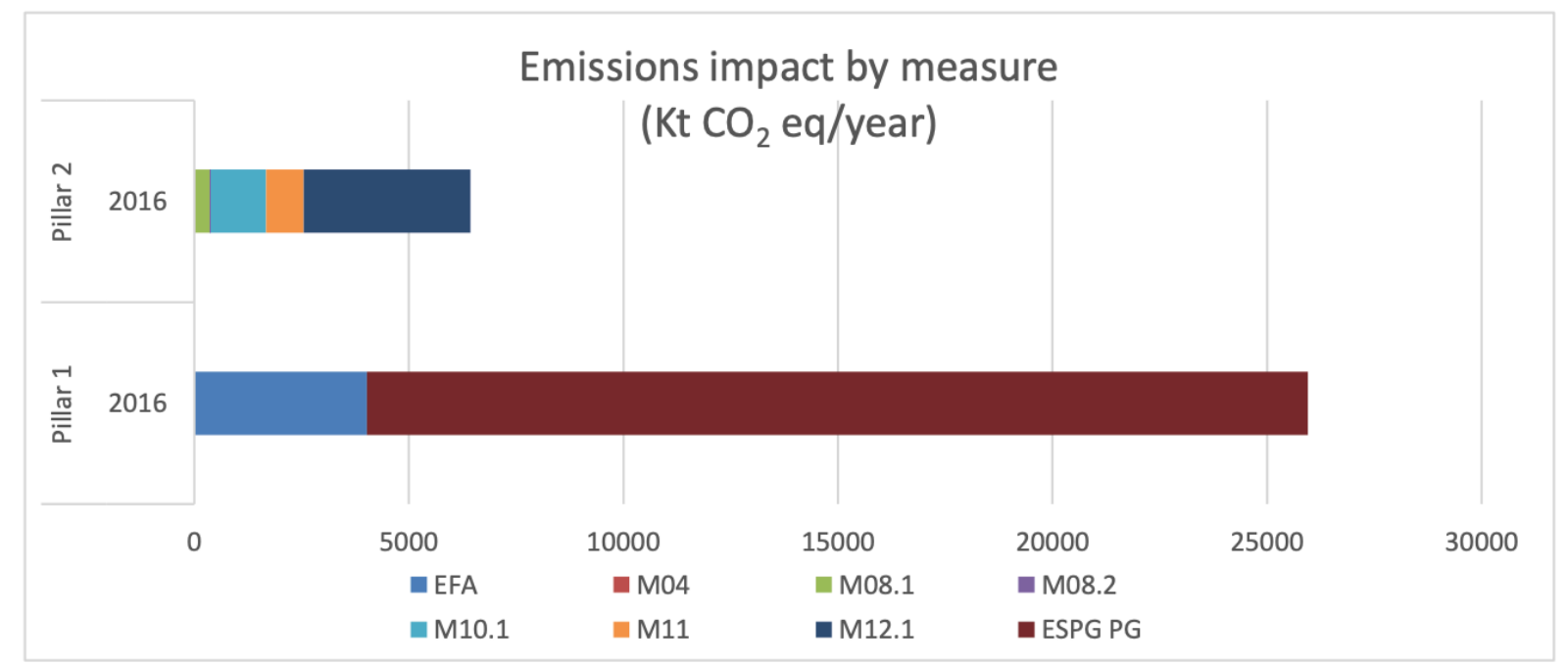

Figure 9: Simulated emission impact by measures Pillar I and II; Source: (Mottershead A., et al., 2019)

For the purpose of providing the reader with a high-level overview of the simulated effects of the relevant measures in terms of $\mathrm{Kt}$ of $\mathrm{CO} 2$ equivalent per year, Figure 9 details the GHG reduction effect compared to a baseline without a CAP policy in place. This shows that the Greening measures, especially EFA zones and ESPG/PG, are of particular importance within Pillar I. Nonetheless, these results should be interpreted with considerable care and only serve as a general orientation since the authors of the study point out that they were not able to include factors such as double counting between certain schemes and measures. 


\subsubsection{Greening-ESPG and PG}

Permanent grassland plays a significant role in carbon sequestration and the maintenance of carbon levels in soils, hence tackling GHG emissions from agricultural soils. Depending on the management practices, the soil type, the climate and additional factors, the soil can absorb between 500 and $1200 \mathrm{~kg} \mathrm{C} / \mathrm{ha} /$ year. (Soussana, et al., 2007) But this potential is diminished when the top layer soil is used for agricultural purposes, e.g., ploughing the field to prepare it for new cultivation. In order to give a perspective of the gain/loss of $\mathrm{kg} / \mathrm{C} / \mathrm{h} /$ year under local conditions the following table provides data for the most common soil types in the EU and the influence of management practices on the gain/loss.

\begin{tabular}{|c|c|c|c|c|c|}
\hline \multirow{2}{*}{$\begin{array}{l}\text { Soil type } \\
\text { and } \\
\text { climate }\end{array}$} & \multicolumn{5}{|c|}{ Annualised loss/gain of soil C over 20 years } \\
\hline & $\begin{array}{ll}\text { A. } & \text { No } \\
\text { plough } \\
\text { (t/ha) }\end{array}$ & $\begin{array}{l}\text { B. Plough and } \\
\text { reseed } \\
(\mathrm{t} / \mathrm{ha})\end{array}$ & $\begin{array}{l}\text { C. } \begin{array}{l}\text { Convert or } \\
\text { plough for } \\
\text { arable } \\
(\mathrm{t} / \mathrm{ha})\end{array} \\
\end{array}$ & $\begin{array}{l}\text { Difference A- } \\
\text { B per \% } \\
\text { permanent } \\
\text { grassland (kt } \\
\mathrm{CO}_{2} \text { eq) }\end{array}$ & $\begin{array}{l}\text { Difference A- } \\
\mathrm{C} \text { per \% } \\
\text { permanent } \\
\text { grassland (kt } \\
\mathrm{CO}_{2} \text { eq) }\end{array}$ \\
\hline $\begin{array}{l}\text { High activity } \\
\text { clay (NW } \\
\text { Europe) }\end{array}$ & 0.7 & -0.7 & -2.6 & 1853 & 4504 \\
\hline $\begin{array}{l}\text { Sandy (NW } \\
\text { Europe) }\end{array}$ & 0.5 & -0.8 & -2.3 & 1721 & 3710 \\
\hline $\begin{array}{l}\text { Low activity } \\
\text { clay } \\
\text { (Southern } \\
\text { Europe) }\end{array}$ & 0.2 & -0.3 & -0.7 & 664 & 1193 \\
\hline $\begin{array}{l}\text { Volcanic } \\
\text { (Southern } \\
\text { Europe) }\end{array}$ & 0.5 & -0.3 & -1.5 & 1061 & 2650 \\
\hline
\end{tabular}

Table 5: Soil carbon loss associated with a 1\% change in the area of permanent grassland converted or ploughed, ploughed and reseeded or maintained without ploughing; Source: (Mottershead A., et al., 2019)

To interpret the data in the table, the figures in A., B. and C. need to be multiplied by 1000 to convert them from tonnes to $\mathrm{kg}$. The negative numbers in Column B. and C. signal the release of GHG into the air when the soil is converted to productive fields or continuously used for agricultural purposes. The positive numbers in Column A. quantify the sequestration potential when the soil is neither converted nor ploughed. It thus becomes apparent that high activity clay soil and sandy soil in north-western Europe, and volcanic soil in southern Europe, are capable of sequestering the highest amounts of carbon.

Certain management practices of grassland largely affect the potential intake of carbon over time, representing the other type of constraint when designing climate mitigation policies. 
Besides the ploughing and reseeding fertilizations, irrigation as well as grazing intensity have an effect on the sequestration potential of the grassland in question. ${ }^{3}$

When distinguishing between ESPG and PG, these factors come into play and affect the potential GHG reduction as the two types of grassland diverge in various details and applications. Therefore, the following table lists the most important differences between them.

\begin{tabular}{|c|c|c|}
\hline Characteristics & ESPG & PG \\
\hline Intervention goal & $\begin{array}{l}\text { Aimed to protect } \\
\text { species, land of high } \\
\text { natural value, water } \\
\text { quality and to evade } \\
\text { soil erosion }\end{array}$ & $\begin{array}{l}\text { - Aimed to foster } \\
\text { carbon sequestration }\end{array}$ \\
\hline Land properties & $\begin{array}{l}\text { - Can only be declared } \\
\text { in environmentally } \\
\text { sensitive areas } \\
\text { chiefly within Natura } \\
2000 \text { areas by } \\
\text { farmers and national } \\
\text { authorities } \\
\text { - Include wet and peat } \\
\text { lands }\end{array}$ & $\begin{array}{l}\text { - Can be declared on } \\
\text { any areas and soil } \\
\text { complying with EU } \\
\text { and national } \\
\text { regulations by } \\
\text { farmers }\end{array}$ \\
\hline Threshold & $\begin{array}{l}\text { - } \\
\text { pet reduction }<5 \% \\
\text { per year compared to } \\
2012 \text { figures }\end{array}$ & $\begin{array}{l}\text { - } \\
\text { pet reduction }<5 \% \\
2012 \text { figures }\end{array}$ \\
\hline $\begin{array}{l}\text { Relevant management } \\
\text { practices influencing GHG } \\
\text { emission }\end{array}$ & $\begin{array}{ll}\text { - } & \text { Protected from } \\
\text { - } & \text { Reseeding prohibited } \\
\text { - } & \text { Grazing only if good } \\
\text { for conservation } \\
\text { and/or if traditional } \\
\text { in character } \\
\text { - Fertilization } \\
\text { prohibited }\end{array}$ & $\begin{array}{ll}\text { - } & \text { Ploughing allowed } \\
\text { every } 5 \text { years } \\
\text { - } & \text { Reseeding allowed } \\
\text { - } & \text { Grazing only if good } \\
\text { for conservation } \\
\text { and/or if traditional } \\
\text { in character } \\
\text { - } \quad \text { Fertilization allowed } \\
\text { - } & \text { Pesticides restricted }\end{array}$ \\
\hline
\end{tabular}

\footnotetext{
${ }^{3}$ Further details and practices are attached in Appendix J.
} 
Table 6: Differences between ESPG and PG (Hart, et al., 2017)

Out of the total grassland in Natura 2000 areas established in 2016 an average of 51\% or $15,058,820$ ha have been declared as ESPG with great disparities amongst MS. While Finland, Hungary or Italy declared all the grassland in these areas as ESPG, the share in such countries as Estonia (1\%), Portugal (1\%) or Ireland (4\%) was minimal. (Hart, et al., 2017). Presumably, these differences are due to the form of declaration of a Natura 2000 areas (just based on the Birds and Habitats Directive or beyond) and the legal interpretation of 'most sensitive' areas (implying the compulsory declaration as ESPG). (Hart, et al., 2017). It must, however, be pointed out that most of the ESPG grassland was declared by MS in land previously protected land under national law. This implies that the net change of land use for the establishment of ESPG is minimal and that the areas are at low risk of being converted into arable land or used otherwise in the future. (Mottershead A., et al., 2019) Only around 1.5\% of UAA in the EU have experienced a change in management practices as a result of ESPG. (European Court of Auditors, 2017)

Other aspects of importance in the analysis of the ESPG areas are the conservation status and the soil type protected in these areas. The conservation status is evaluated by assessing and weighting the composition (elements including species), structure (horizontal and vertical components of the land) and ecological functions (e.g., decomposition of plants). (Maciejewski, et al., 2016) This metric is largely unfavourable across the EU with $0 \%$ favourable status in Belgium, Denmark, Lithuania, the Netherlands etc., and 100\% in Cyprus, $76 \%$ in Romania and $50 \%$ in Estonia, suggesting overall lax enforcement. Furthermore, the proportion of carbon-rich soils protected by adequately managed ESPG cannot be clearly defined since data on the soil types of ESPG are lacking. (Hart, et al., 2017)

As shown in Table 6, the points ploughing and reseeding as well as fertilization and irrigation only apply to PG as they are prohibited in ESPG areas. As a result, areas under ESPG protection inside and outside Natura 2000 areas are well protected except for the unsatisfactory enforcement of conservation measures and the limited data available to quantify the effect of the GHG intake.

For areas declared as PG, several concerns come to mind regarding their management practices which in turn limit their capability of carbon sequestration. Firstly, the permission to plough PG hinders the soil to sequester GHG until the equilibrium is reached as the gas is released when turning the soil. As pointed out in Table 5 this effect is especially detrimental when the 
area is reseeded and fertilized in the process. On the other hand, some ploughing and reseeding are needed, for instance, when adapting the PG to new climate patterns that are excepted due to climate change or other relevant factors. (Ranner \& di Virgilio, 2020)

Secondly, the aforementioned threshold for the net reduction of $<5 \%$ has been exceeded by several MS and regions such as Romania, Cyprus and parts of France, suggesting that the enforcement of the rule is unsatisfactory. (Hart, et al., 2017)

Thirdly, the EC in its endeavour to create and protect high-value permanent grassland which fosters biodiversity and functions as an optimal carbon sink should encourage the seeding of deep-rooted grasses. Ideally, this could combine the farmers' need to grow potent grassland for their livestock with the maximization of carbon intake. (Hart, et al., 2017)

Furthermore, the scientific community possesses only insufficient data on many aspects of ESPG/PG, which hampers the concrete modelling of the carbon sequestration effects. This concerns the soil type covered by PG, the management practices and the conservation status, to name just a few. The groundwork for further reporting has been provided in many MS and beyond in the Land Use/Land Cover Area Frame Survey (LUCAS), which analyzed soil samples from over 23.000 locations. Thus the stakeholders should opt to include additional data in this database and mark ESPG and PG areas. (Hart, et al., 2017) (Tóth, Jones, \& Montanarella , 2013)

In the view of these findings several adaptions should be made to optimize the carbon intake of ESPG and PG areas:

- Stricter penalties for national authorities for not enforcing conservation measures on ESPG resulting in higher penalties for non-compliant areas.

- Enforcement of the $<5 \%$ rule and harder sanctions to MS, to avoid conversion of PG and recuperate PG.

- Reports of soil carbon content in LUCAS database in all declared ESPG areas to better estimate the intake of carbon.

- Reports in LUCAS database should detail which soil type is covered by ESPG/PG to better estimate carbon intake.

- Reports in the LUCAS database regarding management practices (fertilization of any type etc.) in PG areas.

- Reports in the LUCAS database regarding the types of habitats replaced by PG.

- Strict limits to unfavourable management practices as to ploughing and unnecessary reseeding of PG by establishing national/regional authorization systems. 
- Encouragement of deep-rooted grasses to be sown if applicable under climate and soil conditions.

However, these adaptations would certainly spark resistance among the stakeholders.

Firstly, there are the farmers who would have to work with stricter (applications of) provisions along with increased penalties if shortcomings in the management practices were found. Therefore, a firm resistance by the farmers' lobby groups can be expected, because the strengthening of the provisions is not accompanied by an increase in subsidy payments per ha for ESPG or PG.

Some resistance is also probable from the administrative side, given that severer penalties would affect national managing institutions, too. Furthermore, the stricter application of the $<5 \%$ provisions would presumably increase the monitoring efforts in selected MS to comply with the rule.

Lastly, enhancement reporting in the LUCAS database would require the joint effort of all (supra-)national and industry stakeholders probably resulting in a considerable and ongoing effort to widen and update the database. In order to increase the support for this adaptation, the EC should opt to provide MS with assistance and resources to conduct the survey of ESPG and PG areas.

\subsubsection{EFA}

The second subsidy with a direct effect on the reduction of GHG of agricultural soils is the Ecological Focus Area. As described in Chapter 4.1.1, MS and farmers have great flexibility when it comes to choosing types of EFA effecting the reduction potential of the subsidy. It has been calculated that about $2.4 \%$ of UAA have changed their management practices as a result of the application of EFA types. (European Court of Auditors, 2017)

In the following subchapters, the most familiar types will be analyzed and if possible, the reduction and areas of improvement will be given.

\subsubsection{EFA n-Fixing Crops}

The most commonly used EFA type n-fixing crops covered an area of 7,092,000 ha in 2015 . Close to $53 \%$ of the area was utilized growing leguminous fodder or green manure, followed by $30 \%$ covered by dry pulses. In the third place, and with a growing coverage over the last years, are soybeans covering ca. $13 \%$ of $n$-fixing crops, while another $4 \%$ is covered by fresh pulses. (Hart, et al., 2017) In general terms, the first category of leguminous plant is referred to as forage legumes whereas the latter three categories are grouped as grain legumes. 
In the growing cycle of farms, n-fixing crops provide twofold beneficial effects which are shown in Figure 10. Firstly, they barely require nitrogen fertilizer, and as they usually replace a cereal crop in growth patterns, a fertilizer saving of 100-200 $\mathrm{kg} \mathrm{N} / \mathrm{ha}$ can be achieved. (Bues, et al., 2013)

Secondly, the nitrate left in the ground via their residues, combined with secondary effects such as the reduction of root diseases, can be quantified as fertilizer nitrogen equivalent, bolstering the growth of the successive plant without the use of fertilizer which would cause nitrous oxide pollution. This effect can be as much as $120 \mathrm{~kg} \mathrm{~N} / \mathrm{ha}$ depending on the crop used. (Köpke \& Nemecek, 2009). However, there is no universally accepted scientific value that can be taken as a blueprint for the reduction linked to this EFA type. This is because it is extremely hard to measure, different studies obtaining variations of up to $500 \%$. Somewhat generalized modelling approaches are therefore needed to estimate the reduction potential on a large scale (Ranner \& di Virgilio, 2020)

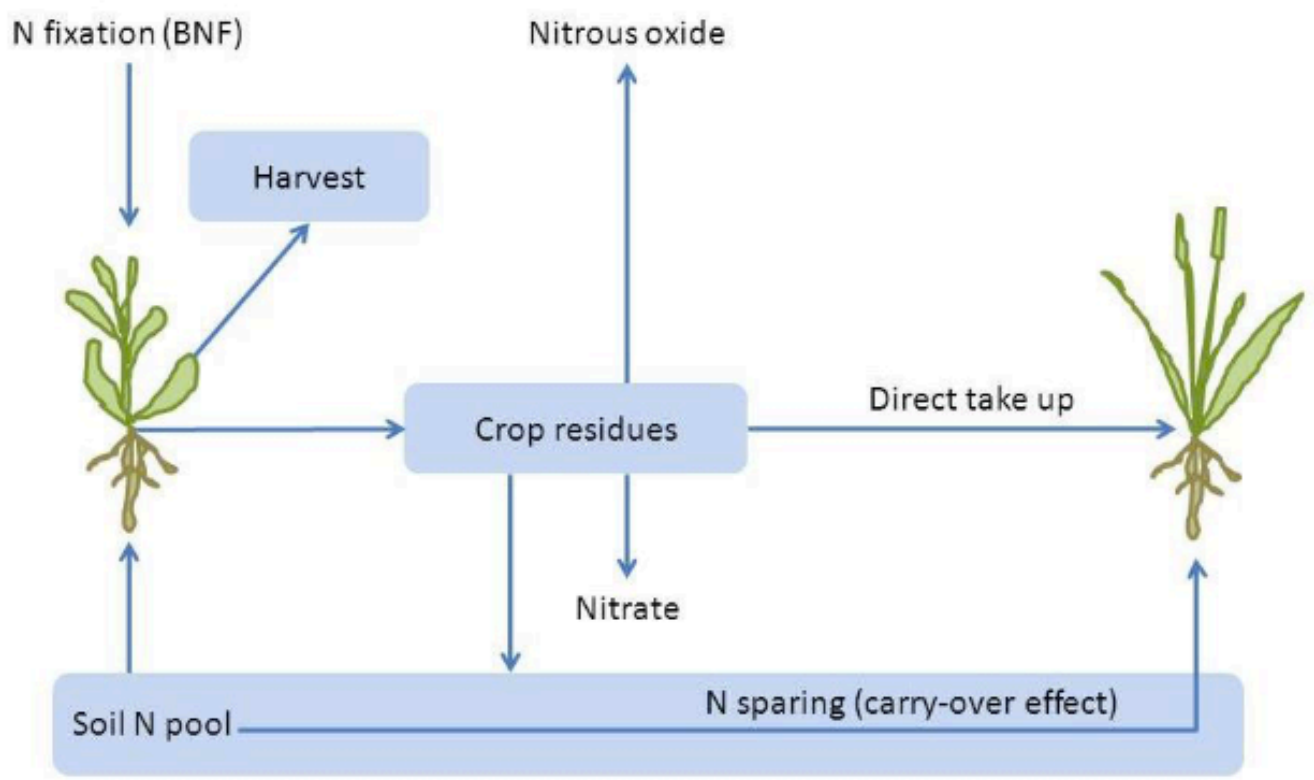

Figure 10: On-farm nitrogen cycle, showing the effect of legume pre-crops; Source (Bues, et al., 2013)

This reduction potential, however, was found not to be accurately utilized, as farmers fertilized their successive plants as they would have done without the n-fixing crop, thus taking the extra nitrogen in the soil as an additional boost for the yield. It should be pointed out that growing nfixing crops can have a lasting effect because $75 \%$ of the residue enters the soil reserve while only the remainder of $25 \%$ is consumed by the following plants. (Bues, et al., 2013)

Although n-fixing crops can lower the use of fertilizer and thus nitrous oxide pollution, the management of the residues has to be taken into consideration to avoid leaches into the air and groundwater. Thus, these crops should be followed by short-season catch-crops that use the 
nitrate in the residues, or some deep-rooting crops such as lupins should be grown. (Bues, et al., 2013)

Another important aspect to consider is that in general terms forage legumes fix more nitrogen than grain legumes due to their longer growing season and biomass production. Similarly, legumes grown for green manuring yield higher nitrogen in the ground than grain legumes harvested and processed. (Bues, et al., 2013)

Despite the clear evidence of the beneficial effect of the n-fixing crops, the increase in the use of these plants cannot be solely contributed to this EFA option. VCS subsidizes the main nfixing crops cultivated in many MS, and farmers have also utilized these crops to comply with the crop diversification requirement. Additionally, many of the crops were already a traditional part of the crop cycle before the introduction of Greening. Only in selected MS such as Latvia has a significant change in land use occurred. All this suggests that the EFA type was not the main drive for the use of n-fixing crops, but that the aforementioned subsidies along with market signals attribute more to the slight increase in their cultivation (Hart, et al., 2017) Based on this fact and the great variation of the reduction potential, it is impossible to establish a correlation between the public money spent on this type of EFA $\rightarrow$ change in land use, production, income $\rightarrow$ reduction of $\mathrm{x} t / \mathrm{ha}$ of $\mathrm{GHG}$.

Nonetheless, in the lights of these findings the EC should aim to establish the following adaptations to the cultivation of $n$-fixing crops in EFA zones:

- Limit the use of fertilizer on areas where n-fixing crops have been cultivated in the previous growing cycle or increase the VAT rates on nitrogen fertilizer

- Limit the choice of n-fixing crops to the most effective crops, i.e. forage legumes and legumes grown for green manuring or increase of VAT rates for ineffective n-fixing seeds

- Eliminate overlap between VCS and EFA n-fixing crops by excluding EFA n-fixing crops from VCS.

- Impose statutory management practices regarding the cultivation of catch crops to avoid nitrogen leaching into the groundwater and the air during the decomposition of the nfixing crops' residues

When it comes to the disadvantages of the proposed adaptations, three main areas are affected. On the farmers' side one can expect resistance because of the tightening of restrictions in the management of their holdings. Farmers' unions and their EU and national lobbies might actively try to prevent these changes. A more market-driven approach could therefore be an 
EU-wide increase of VAT rates on nitrogen fertilizer and seeds of ineffective $n$-fixing crops. This approach would make use of the steering effect a price increase would have in perfectly elastic markets, reducing the demand for these products. The question which of the options would yield more satisfying results considering the needs of farmers, should be subject to further research; only then could an adequate decision regarding these opposing approaches be made.

From the economic vantage point, both approaches would financially motivate farmers to increase/shift their production to the most effective n-fixing crops and bolster up their supply. In a perfectly elastic market this would lead to a price slump and possibly over-production with other species in short supply. As to the suggestion to limit the use of fertilizers, a sudden drop in demand for these products could have negative effects on the fertilizer producers. These producers would consequently decrease their production to stabilize the equilibrium price. With the now smaller market, less land, capital and labour would be required to satisfy the demand, probably leading, amongst others, to job losses. The concrete market effects of this proposal should therefore be subject to further research.

From the administrative perspective, each MS would need to define lists of n-fixing crops eligible for VCS and EFA subsidies. The result would be a higher administrative burden for the managing institutions and the industry alike. Furthermore, the enforcement of these rules may be challenging as an on-site visit to the farm is likely to be required to ensure compliance at a specific time. Whenever possible MS should resort to off-side revision capabilities such as the Copernicus programme. A promising development aiming to combine the development of sustainable practices with tangible advantages for farmers (water management, plant development analysis, soil analysis etc.) is the Farming by Satellite Prize. (Copernicus programme, 2016) (Copernicus programme, 2020)

\subsubsection{EFA Catch/Cover Crops}

The next type of EFA to be considered is the use of catch/cover crops which is already affected by the recommendations on the n-fixing crops making it obligatory to use. In 2015 a total of $33.2 \%$ or 2.7 million ha were declared as this EFA type with a slight increase to 2.92 million ha in 2016. The largest increases were noted in Bulgaria, Ireland and Croatia, which could be attributed to the spread of new practices via the application of EFA. (Hart, et al., 2017) Regarding the statutory management practices, MS have implemented a variety of regulations concerning the sowing period, the mandatory growing and the application of fertilizer or herbicides. Some MS such as the Czech Republic or Germany have integrated catch crops into 
their GAEC requirements or increased their spread by integrating them in the AECM. (Hart, et al., 2017) As a result of this integration, this EFA type has a significant overlap with other subsidies in several countries where catch crops can be declared under GAEC requirements for the BPS or the Single Area Payment Scheme (SAPS) as well as this EFA type. (European Court of Auditors, 2017) Notably, farmers in Austria have adopted the beneficial practice of leaving catch crops over the winter as required by national law. Yet catch crops are generally sown after the harvest of a cash crop in late summer and/or winter for a variety of economic and ecologic reasons relating to the soil quality. (Hart, et al., 2017)

The environmental benefits regarding the GHG reduction of these crops can be classified under three main effects. As pointed out in the previous part on n-fixing crops, catch crops prevent nitrate leaching into the ground, soil and air. The second effect is the enhanced carbon sequestration and storage in the soil accounting for an annual carbon intake of $0.32 \pm 0.08 \mathrm{Mg}$ per ha estimated to continue for 155 years until the equilibrium is reached. (Poeplaua \& Dona, 2015) Furthermore, catch/cover crops prevent soil erosion by fixing the ground with plant roots during the second growing period. This is considered to have a positive effect, as soil erosion usually releases GHG. (Poeplaua \& Dona, 2015) However, these benefits are diminished if the crops are not allowed to root deeply in the soil or if the residues are left to decompose on the ground rather than being incorporated in the biomass. (Hart, et al., 2017)

As there is evidence of GHG intake for this EFA type, a calculation based on the ha declared and the total GHG intake can be conducted; it can be enhanced further when applying a change in land use to this EFA type.

Given the variety of existing management practices, regulations and farming types, the EC should aim to harmonize certain aspects of this EFA type in order to maximize the uptake of GHG.

- Limit the choice of crops to be based on climate zones and local conditions to the most effective in carbon sequestration, i.e. annual ryegrass or cereal rye. (The Center for Agriculture, Food and the Environment (College of Natural Science), 2020)

- Establish minimum growing periods of the crops factoring in local climate conditions that allow the crops to root in the soil and create organic biomass.

- Limit the use of herbicides

- Eliminate overlap between catch crop EFA and GAEC requirements

With the envisioned CAP being primarily focused on the reduction of GHG, the catch/cover crops should be selected accordingly. Apart from their environmental effect many of these 
crops also have beneficial economic side effects. It is, however, out of the scope of this thesis to determine a concrete choice of crops for each climate zone and growing period. This should be done in an EU-wide expert panel.

In order to implement the suggested changes properly, the EU legislative stakeholders would need to overcome significant resistance from the farmers' side as the proposed changes in management practices would limit their freedom to cultivate their land at will. Additionally, the establishment of minimum growing periods could signify a loss of income because the successive crop would have to be sown later. Moreover, the limitation of the use of herbicides and the provision to keep the roots in the soil would increase the production cost.

From the MS' perspective, the definition of the most effective crop under local conditions could face resistance as it would doubtlessly consume resources and time to go through the process and implement the change in the respective part of the administration. The same argument can be made for the elimination of the overlap between the EFA type and the national GAEC.

\subsubsection{EFA Land Lying Fallow}

The last major EFA type applied widely throughout the EU (except in Romania and the Netherlands) is land lying fallow, accounting for 2.2 million ha or $25.9 \%$ of EFA types in 2015 and 2.03 million ha or $24 \%$ in 2016. (Hart, et al., 2017)

In order to be eligible for this EFA type, the land must have been out of production for the last five years, which does not exclude the voluntary sowing of grass to increase biodiversity. However, it cannot be classified as PG or ESPG due to the prohibition of double funding nor may it be extensively fertilized or sprayed with pesticides. (European Commission A., 2014) Regarding the management practices, MS have established a variety of regulations for the obligatory fallow period ranging from 5 to 9 months starting in mid-January in most MS. But these practices are insufficient to allow for sequestration to take up GHG. The only reduction in GHG is attributed to the lack of fertilization during this period. (Hart, et al., 2017)

Another negative aspect to consider is that fallow land can emit $\mathrm{N} 2 \mathrm{O}$ emission when residues of the previous crops decay. Hence, in the worst case, assuming that no grass cover grows or is sown, fallow land could even be a net contributor of GHG. (Wu, Kemmitt, $\mathrm{Xu}, \&$ Brookes, 2010) In dryer regions fallow land can also be susceptible to wind and water erosion when occasional storms cause heavy rainfall leading to nitrogen leaching and N2O emission. (Hart, et al., 2017) 
Given the varying effects of this EFA type, conclusive modelling of GHG uptake or emission cannot be established. As a whole, this EFA type only yields GHG uptake in the best scenario, which is unfertilized fallow land over a long period of time, covered by (wild) grass/flower vegetation. Therefore, it can be concluded that this EFA type should be abolished in the new CAP framework in order to motivate farmers for more aggressive land-use changes that are more beneficial for GHG reduction. This recommendation is based on the fact that possible changes apt to improve the GHG uptake, such as multi-annual fallow periods or mandatory green cover, would effectively convert the areas into grassland and could later be declared as PG. As this signifies an overlap with PG, it should be avoided for the sake of simplicity and coherence.

As for trade-offs resulting from the cancellation of this EFA type, one can expect resistance from MS with a high amount of fallow land declared, and from farmers. For the latter group, it is often the most inexpensive way to comply with the Greening provision, and an adaptation to other EFA types would result in transactional costs and higher maintenance costs. A farmer not capable or willing to change practices, would lose the subsidy and consequently some of his income. A more market-driven approach to regulate this EFA type would be welcomed by, e.g., binding the subsidy payment to the GHG sequestration potential or decreasing the price of maintenance for the remaining EFA types. Yet, the EC cannot weight the compliance and payment on GHG reduction potential of each EFA type. As they are coupled to the implementation of defined practices, no incentive can be put on a certain EFA type or Greening provision resulting in increased/decreased payments. Doing so would presumably cause international infringement procedures as it could violate the WTO Agreement on Agriculture. ${ }^{4}$ On the MS' side, abolishing this Greening practice would cause additional transactional costs, due to the obligation to control farmers' compliance with the new role and subsequently recategorize the patches in the IT-management systems.

\subsubsection{EFA General Adaptations}

For the EFA types as a bundle of measures some adaptations, along with the proposed adaptations of the specific EFA types, would significantly increase the GHG reduction effect. Firstly, given that as of today $14 \%$ of the UAA has been declared one type of EFA, more ambitious targets should be set. A new threshold of 15\% of arable land should therefore be established.

\footnotetext{
${ }^{4}$ Further details on this matter will be discussed in Chapter 6.3.4.1.
} 
Secondly, MS should be obliged to conduct studies as to which EFA types maximize the capture of GHG emissions from agricultural soils under local conditions with the aim of offering a shorter list of EFAs. This is because the nationally or locally offered EFA types are currently aimed at minimizing the administrative burden and effort for farmers. Although the Netherlands and Poland have previously conducted such studies, their recommendations and findings were not implemented in the respective EFA types. (European Court of Auditors, 2017) Therefore, MS should be obliged to take the result of these studies into account more forcibly.

Naturally, these two proposed changes would see some resistance from MS and farmers. Firstly, to conduct a study of the best EFA types under local conditions would cost money, and subsequent adaptations in the administration to manage the proposed types could be time- and resource-consuming. In the case of the farmer, it is quite conceivable that declassification of the applied EFA type would trigger resistance, again resulting as it would in transactional and maintenance costs or loss of income in case no action were initiated.

Summing up the recommendation for all EFA types, the legislative stakeholders should implement and enact several points. The first would be to limit certain management practices such as fertilizer use in order to allow $\mathrm{N} 2 \mathrm{O}$ to be sequestered into the ground and recycled during the growing periods. This goes along with the second point regarding the evaluation of the most capable n-fixing and catch crops under local conditions so that the sequestration can be maximized and the nitrogen leaching minimized.

The third recommendation is to establish minimum growing periods of these plants along with a provision to keep the plant residues in the soil. This would be of pivotal importance since even the most effective n-fixing and catch crops cannot deliver positive effects without having time to create biomass.

Lastly, the EFA type land lying fallow should be abolished because of its questionable climate effects. This would furthermore push farmers to opt for more climate-ambitious EFA types and thus increase the carbon sequestration of the industry.

\subsubsection{Crop Diversification}

Crop diversification as the third Greening obligation aims primarily at improving the soil quality of the agricultural land in the EU. It has been found that most farmers who had to diversify their crops, did so in rotation and planted leguminous plants instead of cereals. The areas most affected by this measure were Spain as a whole and certain regions in Poland, 
Lithuania, the Netherlands etc. where mono-cropping is the prevalent farming practice. (Hart, et al., 2017)

The reduction effect can be both positive and negative depending on how the crop diversification or rotation is managed. (Hart, et al., 2017) As previously pointed out in the EFA chapter, the cultivation of n-fixing crops, which leguminous plants are a part of, can lead to the reduction of $\mathrm{N} 2 \mathrm{O}$ pollution.

Despite the seemingly positive effect of this measure on GHG reduction, crop diversification has major flaws diminishing the impact. First and foremost, it has been found that only a small proportion of the farm holdings were subject to this requirement, namely five million farms or $31 \%$ of the EU farms. This is because of the various exceptions regarding the minimum size of the farm, and farms producing fodder crops. Bearing in mind that only $10 \%$ of affected farms are non-compliant with the measure, it becomes clear that the effective redistributed area represents not even $0.5 \%$ of the UAA. (Louhichi, et al., 2015) There seems to be some variation in these figures since another study has come to the conclusion that $0.8 \%$ of the UAA have been redistributed. (Hart, et al., 2017) When defining the effect by farming practices adapted by this measure, only $1.8 \%$ of EU farmland seems to be concerned. (European Court of Auditors, 2017) Other causes decreasing the effectiveness of the measure is the existence of equivalence schemes in five countries, and the switching of fields amongst neighbouring farmers to avoid real diversification. (Hart, et al., 2017) Given the named uncertainties and the negligible carbon sequestration effect, it is not possible to establish concrete GHG reduction rates per ha.

In view of the marginal and highly dependent positive effect as well as its negative impact, this measure is neither effective at tackling GHG emissions from agricultural soils nor consistent with the EFA type n-fixing crops and VCS. The latter can be explained by the fact that EFA nfixing crops and VCS induce the cultivation of protein crops more effectively; this, in turn, accumulates nitrate in the soil and thus provides GHG intake and improves soil organic matter. Additionally, this creates overlap between crop diversification and the other two subsidies resulting in $1.2 \%$ of UAA to be declared both under EFA and crop diversification. (European Court of Auditors, 2017) Hence, crop diversification should be abolished and replaced by a more capable approach which will be discussed the next subchapter.

The elimination of this Greening requirement may have favourable or unfavourable results for farmers, depending on their production and holdings. On the one hand, farmers would obtain more freedom to cultivate the same crop successively allowing them to further concentrate on the production of a specific agricultural commodity. This is underlined by the fact that most farmers already comply with the provision by rotating crops instead of diversifying them. 
On the other hand, the overlap in the policy allowing for a double declaration under EFA nfixing crops and at times VCS, would strip farmers from an easy practice to comply with several subsidy schemes. This may lead them to resist the changes.

The worst possible outcome would be that many farmers decided to mono-crop on a large scale leading to soil erosion and GHG emission. Despite this threat, this is not expected to happen as the vast majority of farms have already been compliant and the change of management due to crop diversification has been minimal.

\subsubsection{General Adaptations to the Greening Measures and the Greening Framework}

While the former chapters focused on the detailed analysis and possible improvements of the Greening measures themselves, this chapter explains the introduction of the Eco Scheme along with the intended intervention logic in the newly proposed CAP framework. Afterwards, an analysis of the strengths and weaknesses of the scheme will be conducted and on this basis of this, a meaningful integration of it into the current Greening architecture will be discussed.

The second subchapter focuses on changes regarding the areal allocation of the proposed architecture and its budgetary implications within the envisioned CAP. The third subchapter finally outlines general considerations regarding equivalent practices and organic farming.

\subsubsection{The Eco Schemes and the Greening Framework}

The newly introduced Eco Scheme replaces the Greening measures in Pillar I and is thus a direct payment, which can either be made based on the cost incurred and income forgone, or as an additional payment to the basic income payment. (European Commission B., 2018) Whereas the Greening requirements identify three concrete practices and areal thresholds under which they have to be applied, the Eco scheme is broadly aimed at commitments going beyond the basic requirements (GAEC \& SMR), and relate to one or several of the three CAP goals listed in the following:

- contribute to climate change mitigation and adaptation, as well as sustainable energy

- foster sustainable development and efficient management of natural resources such as water, soil and air

- contribute to the protection of biodiversity, enhance ecosystem services and preserve habitats and landscapes (European Commission C., 2018)

Also, implementing the Eco scheme is obligatory for MS, but voluntary at farm level, which reflects the increasing conditionality and subsidiarity of the new CAP proposal. This is further 
emphasized by the fact that the proposal does not define a financial ring-fence for the Eco scheme, as it did for the Greening framework. (European Commission B., 2018). In order to give the reader a high-level overview of the new CAP architecture in Pillar I and to contextualize the differences, Figure 11 compares the current and newly proposed building blocks.

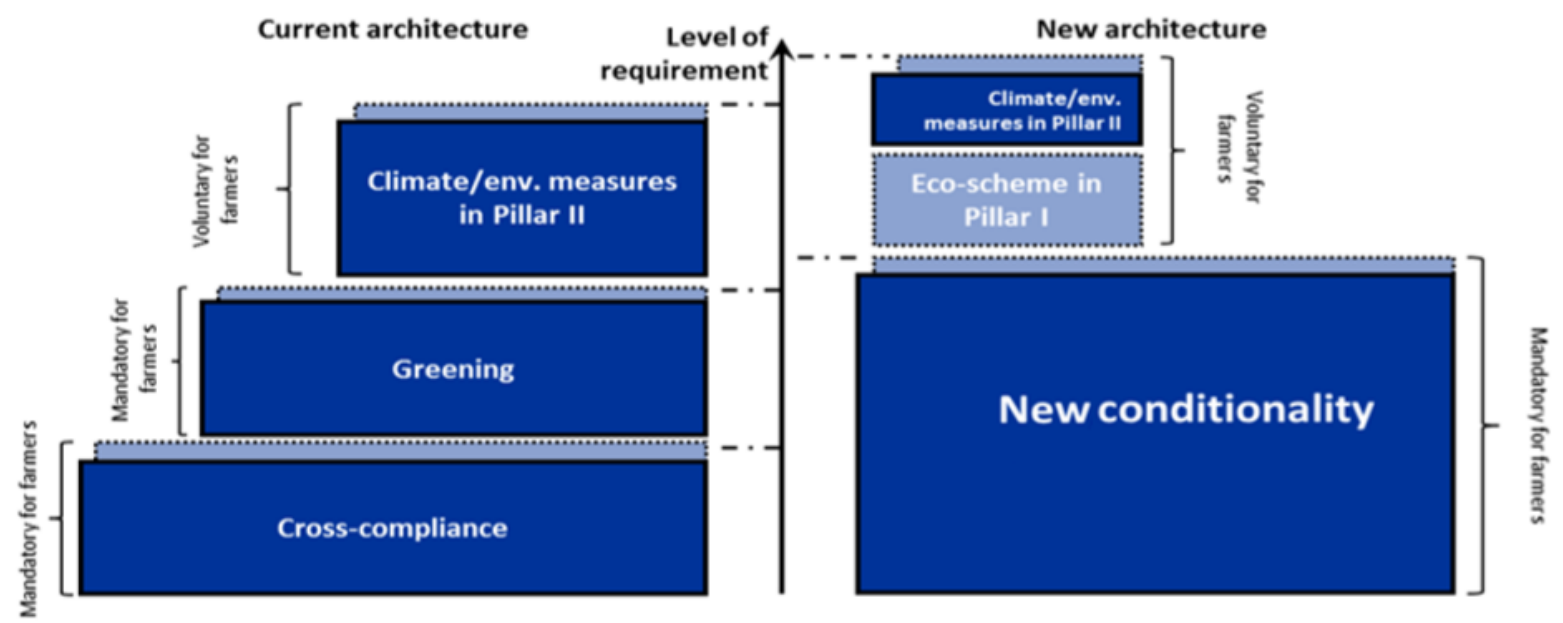

Figure 11:Comparison of the CAP's current and proposed new green architecture; Source: (Meredith \& Hart, 2019)

As outlined in Chapter 6.2, the EC has proposed to integrated the Greening requirements into the new conditionality, which it claims will enhance environmental provisions and thus the greenhouse gas reduction potential. But this is questionable. So this thesis proposes to retain the two Greening requirements deemed beneficial for the GHG reduction as described in Chapters 6.3.1 and 6.3.2, and adapt the additional Eco scheme layer in such a way that environmental payments for the continuation of climate mitigation, climate adaptation, or biodiversity-related to M10, M15 and M11 of Pillar II can be included in it.

The goal of adding them is to create consistency for climate mitigation, climate adaptation and biodiversity measures after the end of the maximum funding period of five to seven years under Pillar II. (European Parliament; Council of the European Union P., 2013) This is of great relevance as many beneficial practices and measures only yield tangible GHG reductions after a medium to a long timeframe. With the aim of providing this, the political stakeholder should amend Article 285 (d) of the current proposal by stating that the continuation of M10 AECM and M15 Forest Environment-Climate measures can be considered an eligible Eco scheme only after the successful termination of the project under Pillar II funding. Further details of what these projects should target while being under Pillar II funding, and further reasoning for their categorization in Pillar I, will be provided in the respective chapter. 
The envisioned changes to the Pillar I architecture described in the preceding paragraph along with some budgetary implications explained in the following chapter are displayed in Figure 12.

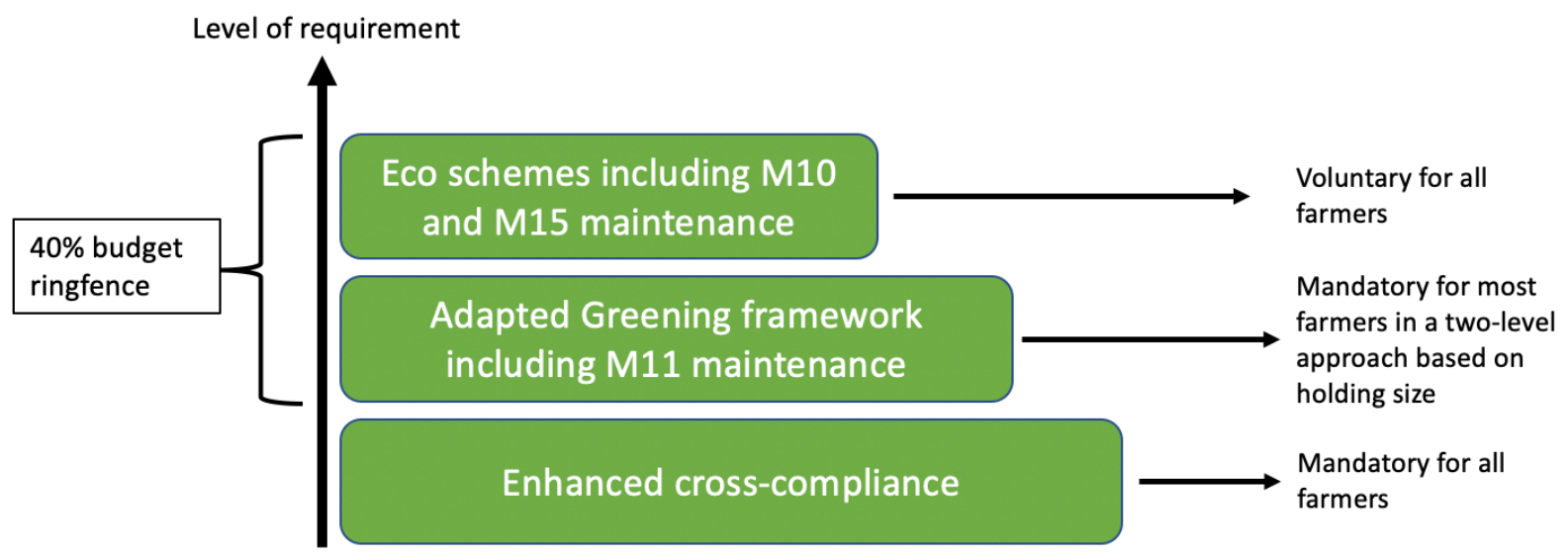

Figure 12: Proposed Pillar I architecture; Source: own compilation

From the financial perspective, the EC and MS need to make sure that farmers will not experience a reduction of their net income of the M10 or M15 project when continued in Pillar I. The straightest approach would be to cover income foregone plus cost incurred and an additional payment to set a financial incentive to initiate and continue a long-term commitment. This financial incentive, however, is strictly ruled out by the World Trade Organization's (WTO) Agreement on Agriculture. It only permits environmental support to comply with voluntary government programmes and the subsidy paid can solely cover the extra cost or loss of income. (World Trade Organization, 1995) On the basis of this legal definition, one has to elaborate which of the options would be more attractive to farmers and would thus set an effective economic incentive to maintain M10 or M15 practices. Depending on the product cultivated and the project employed on each holding, one or the other may grant a compensation motivating the farmer to continue the practice. But as this is, however, case-specific and bureaucratic to manage, it would put a high administrative burden on the agricultural industry, hence discouraging the continuation of the relevant M10 or M15 project via long and complicated approval processes for the farmers. From the economic perspective, the time spent for the approval process of the project is time lost for effectively managing the holding. Spending a considerable amount of time to receive the payment for the continuation of M10 or M15 in Pillar I may exceed the opportunity cost of the farmer, which is to say the additional revenue that the farmer could have generated if he or she had done farm work instead. (Mankiw N. , 2017)

However, there is a legal workaround for overcoming this dilemma; the granting of an i.e. flatrate payment on the basis of decoupled support. The legal interpretation of the WTO defines 
decoupled direct payments under environmental and regional assistance programmes as subsidies with minimal impact on trade. Consequently, they are part of the Green box subsidies which can be used without restrictions. (World Trade Organization , 2000) This has been recognized by the EC in its legal analysis of the compliance of the CAP proposal with the WTO Agreement on Agriculture. (European Commission D., 2018) As long as this payment is not based on any factor of production, volume of production or commodity prices, it is legally conceivable. Based on a commonly accepted methodology or past experiences, the managing authority determines the direct and indirect cost of a given Eco scheme instead. Henceforward this calculation serves as a basis for the subsidy payments. At this point, it would be in the hands of MS to offer the referred to measures as Eco schemes and compensate farmers on a national or local level as an i.e. flat-rate multiplied by the declared eligible ha under the scheme. Other methods of payment could be a Lump Sum payment or a Standard Scales of Unit Cost payment. These options all have positive and negative aspects, but it is not the subject of this thesis to elaborate on this extensively. (Directorate-General for Employment, Social Affairs and Inclusion (European Commission), 2014)

This is certainly the optimal solution regarding the just compensation and incentive setting for practices that increase the GHG reduction potential of the CAP. The international legal framework does not allow the EC nor the national authorities to weigh environmental commitments according to their GHG reduction potential. For this to happen the international community would have to renegotiate the WTO Agreement on Agriculture, which is highly unlikely and even less so to protect the climate. Another unlikely way to maximize the reduction potential of the Eco scheme would be to offer a limited amount of eligible practices targeted at GHG reduction EU-wide. The implausibility of this approach arises from the fact that the application of specialized Eco schemes would result in the exclusion of certain types of holdings, and possibly even entire farming sectors, or specific climate zones. As these schemes, and generally all CAP subsidies, cannot discriminate against certain parts of the industry, this would probably cause lawsuits and lead to the complete eradication of this practice. In that sense the EC only possesses limited power over MS as to which Eco schemes they deem beneficial for their environment and feasible for their agricultural industry.

This limited power is the cause for the first disadvantage of the proposed amendments because it leaves room for national deviations in the definitions of substitutable Eco schemes. Suppose that two fictional farmers cultivating the same product want to obtain the Eco scheme subsidy in their respective country. After conducting a cost-benefit analysis these farmers opt for the 
most cost-effective option. In country A this may be less expensive than in country B due to less demanding measures and practices. The farmer in country B would be disadvantaged since he or she would need to invest more to meet the national requirements without receiving a higher net subsidy rate.

The second negative is linked to the long timespan during which farmers would need to commit themselves to an environmental practice. Only after five+ years under Pillar II funding, farmers initiating a positive practice would become eligible for Pillar I support. This leaves them vulnerable to a possible failure of the M10 or M15 project during this time due to factors beyond their reach, such as extensive dry seasons or storm events. In these cases, the farmer should be granted an exceptional allowance to receive M10 or M15 support. If, for example, the project fails after three years due to the reasons outlined, the farmer should be granted an extension of three years to rebuild the damaged land and develop the climate-friendly project again. This would extend the total project length from five to eight years, eliminating the uncertainty farmers might face in this regard.

Another uncertainty lies in the political spectrum both on the supranational and national levels. On the first, the legislative stakeholders may decide to adapt or terminate the Eco schemes in the CAP after 2027, when the MFF along with the CAP will be renegotiated. In the case of adapting the Eco scheme's legal definition, some practices and measures could be included or excluded leading to the cancellation of the subsidy in the first case, or the opening of new, more cost-effective measures to comply with the second. The same case can be made on a national level when the responsible agencies decide to adapt their list of Eco schemes. In both cases, farmers that have started to implement the measures would lose out as they would suddenly disqualify for the subsidy, despite having invested in lasting assets; or they could have invested in less costly options now available.

The worst outcome would certainly be a sudden termination of the Eco scheme as a whole post2027. In this case, seven years of positive change would be made worthless and farmers would likely roll back the measures taken to cultivate more efficiently. In order to avoid this unwanted effect, the CAP post-2020 should provide a clause that grants farmers the right to receive the subsidy for a cancelled Eco scheme if they registered for it until a certain due date. For this group, the new Eco schemes would only gradually apply to allow them time to adapt.

Resuming the proposals on the Eco schemes, the main issues can be summarized in three points. The first one is that the Eco schemes are generally speaking a good idea to decrease GHG pollution in the agricultural industry and should thus be defined as the most superior level of 
environmental subsidies as presented in Figure 12. Secondly, the definition of them should include the continuation of AECM and Forest Environment-Climate projects funded in Pillar II. Thirdly, the compensation for farmers committing to subsidized voluntary actions should be compensated in the most unbureaucratic way possible. One option would be a flat-rate payment which has the potential to adequately reimburse farmers while at the same time decreasing the administrative burden and complying with international WTO agreements.

Fourthly, one should be aware that despite the best efforts by the legislative stakeholders, the proposed scheme is prone to deviations mainly via the definitions of Eco scheme measures and practices on a national level. Along with this, the concrete GHG reduction is highly depended on the selected measures and the willingness of farmers to initiate and continue them.

On the basis of this overall Greening architecture, the next chapter details adaptations concerning the areal threshold and its budgetary implications in the enhanced CAP.

\subsubsection{Areal Thresholds and Budgetary Implications of the Greening Architecture}

To widen the reach of the Greening framework and thus increase the reallocation of land to environmentally beneficial purposes, the CAP post-2020 should lower the threshold for all Greening requirements to commercial holdings larger than 5 ha and abolish the exemption of holdings under the SFS. ${ }^{5}$ While the SFS simplifies the payment procedure, a meaningful justification of why these holdings should not contribute to the fight against climate change cannot be found.

The new threshold ought to be a compromise between the maximization of land coverage dedicated to Greening and thus to GHG reduction on the one hand, and the administrative burden as well as the farms' capability to comply with the Greening provisions on the other. As pointed out in Chapter 3, about $65 \%$ of EU holdings are smaller than 5 ha providing a more limited space for reallocation, which would possibly make these farms economically unviable. Furthermore, adding this significant number of holdings to the administrative processes of the CAP on the national and supranational levels would drastically increase the workload of the institutions while yielding only a limited added value in terms of additional land under environmentally friendly management. Nonetheless, the new threshold would increase the area coverage necessary to combat GHG emissions from $88.5 \%$ to $93.9 \%$ of the total UAA in the EU.

Recognizing the limited space available to farmers in the 5 ha- 9.9 ha category, the Greening provisions EFA and the ESPG/PG should cover the percentage of land currently required

\footnotetext{
${ }^{5}$ Further details regarding this scheme is attached in Appendix B.
} 
accounting for 5\% of the declared land and the 95\% national reference value referring to 2012 values, respectively. Meanwhile, the specific adaptations to the Greening measures elaborated in Chapter 6.3 remain the same for every holding size. This would effectively create a two-level Greening approach accounting for the farmers' capability of reallocating land towards environmental purposes while ideally measuring the concrete effects in terms of GHG reduction, improvements in soil quality etc.

Based on the aforementioned new areal thresholds and the integration of the M10 and M15 projects as an additional layer of environmental incentives, the 30\% ring-fence of Pillar I currently enacted in the CAP does not constitute sufficient funding to adequately compensate farmers with an i.e. flat-rate per hectare. Therefore, a ring-fence of $40 \%$ of the Pillar I payments is advised for the new CAP. Although the EC has not defined a budget ring-fence for the Eco schemes nor other environmental payments. This step is apparently supported by a number of MS. (European Commission C., 2020) Within this ringfence, it should be up to the MS to elaborate the financial allocation between the obligatory Greening provisions and the payment towards the continuation of M10, M15 and Eco schemes.

Besides, the EC's proposal grants the MS the flexibility to transfer up to $15 \%$ of the financial allocations for the given timeframe between the two pillars. Another increase of up to $15 \%$ is permitted from Pillar I to Pillar II when these funds target the environmental CAP goals listed at the beginning of the previous chapter. (European Commission E., 2018) The two layers of flexibility and the link between the additional financial reallocation and environmental goals can be seen positively as they grant environmentally-motivated MS the financial means to initiate AECM projects, relevant investments and further measures which have a positive correlation with the GHG reduction. Nonetheless, some improvements should be made to maximize the reduction potential in question.

Firstly, any transfer within the first $15 \%$ range should not be at the expense of the Eco scheme or Greening payments in the first Pillar and, vice versa, not at the expense of environmental measures such as AECM or investment in non-productive assets or organic farming in the second Pillar. The definition of the payments and measures concerned could be based on the currently defined climate trackers. This budget tool is used to quantify how climate adaptationor mitigation-related a given subsidy or measure is by assigning a relevancy of $0 \%, 40 \%$ or $100 \%$ to it. By excluding the $100 \%$ climate-related schemes and measures from the budget transfer, unwanted cuts can be avoided. (European Commission F., 2018) This provision would close a possible loophole which might be exploited by MS not motivated to incentivize climate 
mitigation in their agricultural sector. At present they could defund, for instance, the Eco scheme in favour of Pillar II measures not related to environmental goals.

Secondly, MS should also be allowed to transfer an additional 15\% from Pillar II to Pillar I under the provision of further incentivizing Greening practices, organic farming or the continuation of AECM projects and Eco schemes as laid out in the preceding subchapter.

Concerning further possible trade-offs of the changes proposed in this chapter, the budgetary ring-fence and the restrictions on subsidy transfers between the pillars would possibly reduce the amount per ha paid in the EU by the BPS/SAPS schemes, thereby reducing income support. It would certainly provoke resistance by the farmers' unions and lobbies. (Deutscher Bauernverband e.V., 2020)

The second side effect would be a resistance of farmers currently under the SFS because many of these holdings would now be obliged to comply with all CAP provisions such as the GAEC etc. apart from the light Greening provisions.

The third effect regards the capability and willingness of the MS and EU institutions to enact the framework properly. The latter effect could be repealed with the argument that MS would obtain higher flexibility in their spending and could further localize their CAP. With this motivation, they would gradually increase their administrative capabilities. Despite this, some countries would be more capable than others to adapt, which would temporarily lead to varying levels of compliance across the EU.

Concluding the Greening threshold and budgets, the main changes proposed regard key factors in the application of the envisioned policy. In terms of areal thresholds, the stakeholders should establish a larger than 5ha threshold obliging as many holdings as possible to convert to practices beneficial for GHG savings. In order not to undermine the economic viability of small holdings, farms falling under this category should comply with less stringent provisions than larger ones.

As for the budgetary changes, it is advised to increase the Pillar I ring-fence to $40 \%$ of the budget for the covering of the new enhanced Greening framework and the Eco schemes. Additionally, MS should be granted increased budget transfer options between the two pillars so they can direct the funding according to the national needs without jeopardizing the environmental aim. 


\subsubsection{Further General Considerations}

The first point to be considered in this chapter regards the equivalence practices established by national governments. Although aimed at delivering the same result, these schemes may be designed to minimize the effects of change in terms of land use, production and management practices. Yet, without tangible changes in these categories, an increased uptake of GHG cannot be guaranteed. Additionally, these schemes significantly complicate the measurement of indicators and thus of the effectiveness of public money spent in terms of tonnes of GHG saving/EUR by widening the range of variables. Therefore, these practices should be subject to a rigorous evaluation process carried out by the responsible unit of the EC. In this forum the MS must present scientific proof that the resulting environmental effect of the practice is equal to the one it is supposed to replace.

Concerning organic farms and the automatic compliance of these holdings with the Greening provisions, no change should be made; for it has been found that management practices and land use yield positive results for the environment and GHG reduction. As the EC should further strengthen the position of organic farm products on the market, additional provisions would possibly weaken their economic viability and market position. Nonetheless, organic farms should be encouraged to part take in AECM etc. to further strengthen their environmental approach and receive additional subsidies in Pillars II and I.

Regarding the trade-off, the only possible resistance could come from the side of the MS and the farmers when specific equivalence schemes are cancelled because of the revised assessment. For the MS this would mean additional costs to adapt the administration, and for the farmers it would provoke transactional costs to comply with new Greening provision, or they would lose the subsidy payment and thus part of their income.

\subsubsection{Voluntary Coupled Support}

As pointed out in Chapter 4.1.2, the VCS scheme provides support chiefly to the meat and dairy industry, a branch associated with high methane emission in the form of enteric fermentation and manure management accounting for $4.32 \%$ and $1.48 \%$ of the EU pollution. (European Environmental Agency; Eurostat A.;, 2017) Bearing in mind that this accounts for more than $50 \%$ of the pollution of the agricultural industry and that due to these sources the pollution has increased over the last years, it seems clear that the biggest reduction potential lies in this sector. (European Environmental Agency; Eurostat B.; 2020)

But what is questionable is the effect of VCS on high density and intensive livestock farming, the main emitter in this category. This is because VCS, or more generally CAP support, is 
usually not granted to these holdings, which possess no eligible ha to declare. (Ranner $\&$ di Virgilio, 2020) VCS is only permitted to this sector in specific cases, and in remote areas of the EU, to keep the production alive, for the elimination of the subsidy would endanger the economic viability of these farms. Removing VCS could even harm the local ecosystems due to the absence of grazing animals maintaining the open grassland. (Ranner \& di Virgilio, 2020) Furthermore, Regulation (EU) 1307/2013, Article 52, gives MS some flexibility as to what sectors to support provided that they fit the description in terms of area and economic difficulties. This is important from an environmental standpoint as it also includes the coupled support for protein crops found to have a positive impact on carbon sequestration.

Nonetheless, an array of studies have concluded that the negative impact of the additional meat and dairy production outweighs the positive environmental impact of protein crops and landscape maintenance. (Mottershead A., et al., 2019) (Hayden, Adenaeuer, Jansson, Hoglind, \& Breen, 2019) (Janssona, et al., 2018)

Additionally, (Janssona, et al., 2018) conclude that with an eradication of VCS in the EU a 583 kt net-decrease of pollution in terms of $\mathrm{CO} 2$ equivalent would occur. The most affected sector would be the production of beef with a decrease of $4.47 \%$ (Hayden, Adenaeuer, Jansson, Hoglind, \& Breen, 2019) while the dairy, sheep, goat and crop sectors would see only marginal changes. (Janssona, et al., 2018)

Thus, a trade-off between economic factors for farmers along with biodiversity/landscape factors on the one hand and a mild decrease in GHG emission on the other exists in the VCS. It is, therefore, crucial to find a compromise between those factors. This is where the national implementations of the VCS come into play as a possible blueprint for successful enforcement. Within the set-out boundaries discussed in Chapter 4.1.2, MS have the liberty to link their support to certain criteria. One positive example in terms of linking the support to climaterelated factors can be found in France. Here the VCS for protein crops is only offered to livestock producers in applicable areas to increase their capability to feed their animals selfsufficiently. Vice versa, VCS is solely offered to crop producers that have a contract with livestock producers. Similarly, the support to produce forage seed is also indirectly linked to the goal of self-sufficiency. (French Ministry of Agriculture and Food, 2016). These linkages do not just have positive effects on the climate mitigation by decreasing the reliance on imported fodder to the French livestock industry, but additionally make farmers less depended on the increasing price volatility in the global markets. (Mottershead A., et al., 2019) Another decisive point in the French implementation is the introduction of digressive payment based on the size of the holding or the number of heads. (French Ministry of Agriculture and 
Food, 2016) This follows the logic of discouraging more intensive farming practices which by itself is positive for reducing GHG and nitrate related issues in the livestock industry with the possible disadvantage of soil erosion due to the abandonment of land. (Ranner \& di Virgilio, 2020) (Mottershead A., et al., 2019)

Keeping in mind these findings, the new CAP should aim to enhance and generalize the French approach on the EU level. While the complete reshifting of the VCS funds to other payments would only yield marginal positive effects due to the narrow application of the scheme and the resulting offset of GHG emissions to countries outside the EU when doing so, a meaningful linkage as pointed out in the French implementation could decrease the overall negative impact of GHG emissions. As livestock farmers would be financially supported to cultivate their own fodder, most notably by the production of protein crops, the balance of methane and nitrate emissions compared to the GHG intake of protein crops would shift towards a more positive result. Nonetheless, concrete calculations or models based on the French implementation are not currently available, which is why a reduction effect in terms of tonnes of GHG reduced/EUR spent cannot be conclusively specified.

One possible step towards the linkage of the VCS to GHG emissions based on the French implementation would be to connect it with other measures regarding farm development, the quality of the products and, most importantly, manure management and enteric fermentation. Since the CH4 emissions of the latter depend on the animals' fodder, the farmer could be obliged to use types of fodder that most effectively decrease this emission type, and ideally obtain the material from local producers. These could serve as conditions for granting VCS. The Pillar II measures M14 animal welfare, M03 quality scheme, M06 farm development along with the support of M02 farm advisory service, could be options to increase the environmental and economic impact.

Another relevant finding points to the utilization of seaweed as a potential additive to the animals' diet. An Australian case study claims to have reduced CH4 from enteric fermentation by more than $80 \%$ using this additive. (Commonwealth Scientific and Industrial Research Organisation, 2019) Although these figures must be interpreted with caution as the GHG footprint of European meat and dairy production differs from the Australian production, the EC and MS should instigate trial studies to examine the effect under local conditions. (Ranner \& di Virgilio, 2020) This innovative approach is underlined by another positive side effect: the increased cultivation of certain types of seaweed enlarges the overall carbon sequestration potential. (Hurlimann \& Zucker, 2019). 
Furthermore, efficient manure management may also be linked to VCS under certain conditions. Provided that the animals, and especially cattle, spend a considerable amount of time inside the barn, the manure can be efficiently collected, treated and converted into biogas. For this to happen, it would be advantageous to combine VCS with the Pillar II measure M04 Physical investment for the construction of adequate manure treatment facilities in each barn and possibly combine it with M16 cooperation to finance the construction of a biogas-refinery for the local community. As the holdings supported under the VCS are usually small, the biogas plant is aimed to be utilized by several farmers and furthermore fuelled by local organic waste, as a steady and high supply of organic matter is needed to produce energy efficiently. An ideal point for such a project would be farmers' cooperatives or small-scale farms with at least 100 livestock units. (Policy Department B Structural and Cohesion Policies, 2014) By utilizing the potential of biogas from animal manure, the holdings would gradually generate a new source of income while at the same time reducing their overall GHG emissions.

Concluding the analysis on VCS, it is evident that this payment certainly has a justification for most rural areas of the EU; abolishing it would have a detrimental effect on these areas while only marginally reducing the overall GHG emissions from the agricultural industry. Therefore, the CAP post-2020 should retain its current budget allocation, imposing stricter rules for the implementation of the scheme, considering the best practice of France, and enhancing it with meaningful links to the Pillar II measures. An overview of the linked Pillar II measures for this as well as the following Chapters 6.3.6 and 6.3.7 can be found in Figure 15 and Figure 16, listed in Appendix K.

Due to the scheme's limitations, other measures currently not considered in the CAP framework, as well as certain adjustments in relevant Pillar II measures, should be targeted at the high-density meat and dairy production. ${ }^{6}$

The main disadvantages associated with the proposed changes would affect the stakeholders in two ways. The first impact would be a higher compliance cost for farmers in order to receive the VCS due to the local sourcing of fodder and the optimization of the fodder mix. Two general facts must be considered when analyzing the disadvantages. Firstly, in the meat and dairy industry no single holding can influence the price of the produced good and, secondly, products are generally substitutable. This converts farmers into price takers. (Mankiw N. G., 2017) With the increased compliance cost and set market prices, the profit margins of the farms are sure to decrease, possibly leading to the closure of some holdings in vulnerable regions. Although this

\footnotetext{
${ }^{6}$ These will be elaborated in Chapter 6.4.4.
} 
may be offset by the new income stream from the production of biogas, the investment in the necessary equipment would only pay off over a long time leaving farmers in a delicate situation. As a result, one can expect a firm resistance of farmers' unions across the EU.

Furthermore, the adaptations would lead to higher administrative costs for national institutions as they would have to ensure that the holdings comply with the provisions for fodder and the combination with Pillar II measures. Therefore, it can be expected that some MS will be reluctant to adapt their schemes accordingly.

\subsubsection{Payments for Areas with Natural Constraint}

The ANC payment and its wide application via the three types of constraints provides some GHG reduction-favouring aspects but also opposing evidence of negligible or negative climate mitigation effect.

Other aspects to be considered are the heterogeneous national classification of ANC areas in MS and the fact that most of the subsidies were paid under Pillar II. Based on their climate and agricultural systems, MS developed 140 different indicators to define such areas leaving way for very different interpretations and ecosystem effects. (Hagyo, Terres, \& Paracchini, 2015) In the following analysis, a survey of these arguments and aspects will be linked with certain administrative and budgetary considerations.

The main argument in favour of the ANC scheme is its negative alternative: holdings closing down due to the constraints that increase land abandonment. In the case of abandoned fields, the lack of maintenance actions would result in a decrease of plant roots giving way to soil erosion caused by precipitation and wind. As a result, the stored carbon along with nitrous oxide would leach and cause a rise in GHG emissions. On abandoned grassland, especially rarely ploughed permanent grassland, the emissions would see an even steeper increase. (Mottershead A., et al., 2019) On the other hand, one has to consider the type of agricultural activity replaced by the abandoned land. The net GHG effect could be positive if, for instance, a high-density livestock holding ceased to exist because the GHG emissions post-abandonment described in the previous paragraph would be offset by the savings from the reduction in herd size. (Mottershead A., et al., 2019)

Besides the what-if scenario in the case of abandonment, the ecosystem services in the selected areas can be analyzed to estimate whether the ANC provides climate mitigation-related subsidies in areas where, for example, the carbon sequestration potential is high compared to non-ANC areas. Of the nine ecosystem effects elaborated by (Hagyo, Terres, \& Paracchini, 
2015), Mass stabilization and control of erosion rates as well as Global climate regulation have a direct link to GHG reduction.

For the former, the results are mixed as $25.2 \%$ of ANC have been classified as areas with low capacity for soil erosion control, while $32.1 \%$ and $42.5 \%$ are considered to have a medium and high capacity, respectively. These results stand somewhat in contrast to non-ANC areas where $43.7 \%$ are considered to have low capacity, $37.5 \%$ medium capacity, and only $18.8 \%$ high capacity. (Hagyo, Terres, \& Paracchini, 2015) It can therefore be said that ANC partially targets the areas with high soil erosion potential, but could ideally be extended to more affected zones. As for the second recorded ecosystem service, the classification was based on soil carbon content in the topsoil layer as an indicator of carbon sequestration. $16 \%$ of the ANC are situated in areas with a low capacity for climate regulation, $43.4 \%$ are classified as having a medium capacity, and the remainder of $40.6 \%$ are considered to a have high capacity. Compared to nonANC areas of which $13 \%, 55.8 \%$ and $31.2 \%$ are situated in low, medium and high capacity areas, respectively, it can be said that ANC more effectively targets areas of high capacity while falling short on the medium tier. (Hagyo, Terres, \& Paracchini, 2015)

In the evaluation of these ecosystem effects, the given data may have some limitations because MS had time to declare ANC areas and go through the fine-tuning process until 2019. (Matthews A. C., 2018) The ANC payments between 2014 and at least 2018 were made using the designation of Least Favoured Areas (LFA) from the previous programming cycle. This leaves possible changes in ANC areas disregarded in the analysis of the ecosystem services. Unfortunately, a more recent study has not been conducted or published to reflect the effects of the new ANC declaration method.

The application of the LFA criteria also affects the budgetary perspective of Pillar II, as the mapping of the areas concerned using fine-tuning and bio-physical criteria at the beginning of the current programming would probably have resulted in a shift in funding. Bearing this context in mind, the current funding of the M13 measure is overwhelmingly targeted at the Pillar II, Priority Restoring, Preserving and Enhancing Ecosystems implying a possible environmental focus. The difficulties in exactly determining the percentage of spending on this priority is further discussed in Chapter 6.4.1.

Leaving aside these issues and the debatable and case-specific effects of the ANC payments, roughly $€ 24.3$ billion have been relevantly spent under Pillar II, resulting in effective climaterelated targeting of $97.22 \%$ of the invested funds. In the context of all Pillar II spending, these measures attributed to $16.61 \%$ of the total spending and $16.15 \%$ of relevant climate spending. (Own calculations based on EAFRD data, 2020) 
Another budgetary issue elaborated by the European Court of Auditors is the insufficient climate tracking of the ANC payments considered to be $100 \%$ climate-related by the EC. Given all the uncertainties and the wide application potential previously outlined, it would make sense to amend this climate tracker. (European Court of Auditors, 2016)

Yet another point to consider is the administrative side of the ANC scheme. The introduction of fine-tuning along with the bio-physical criteria by the Directorate-General for Agriculture and Rural Development, and the Joint Research Center has provoked significant difficulties for MS and regions to map the areas concerned under the given three-layer constraint framework. (Matthews A. C., 2018) (Terres, et al., 2016) These difficulties, along with the allowance to continue the LFA designation approach until recently, made many MS and regions delay the mapping of the ANC areas or abstain from it altogether. (Directorate-General for Agriculture and Rural Development (European Commission) E., 2017) (Matthews A. C., 2018) As this implies a significant administrative burden, the new CAP should streamline this process.

Because of the aspects described above, a precise calculation of tonnes of GHG saved/EUR spent cannot be conducted. This is expected to persist into the future because the ANC payment is only partially aimed at climate issues and the new proposal is not likely to change the targeting. (European Commission G., 2018)

In the light of these findings, the political stakeholder should amend the ANC scheme in several ways.

- Payment solely managed under Pillar II M13

- Limit payment to $15 \%$ of Pillar II budget

- Push for the completion of the mapping process

- Amend climate tracker to $40 \%$ instead of $100 \%$ of the budget

In further elaboration of the proposed amendments, the first point would facilitate the management of the ANC by the EC as the institution would not have to revise payments under both pillars. The proposal for the new CAP has considered this criticism and consequently cites ANC as a Pillar II only measure. (European Commission G., 2018) It may free resources to help MS in the mapping process of the areas concerned, which should be given a high priority. It goes without saying that ANC funds should not be released by the EC if the mapping has not been approved, and no further extension should be granted to MS.

When discussing the actual effect of the ANC on the reduction of GHG emissions, they are low at best and negative at worst. Despite the case-specific effects elaborated in the part on land 
abandonment, the climate mitigation-related ecosystem services are likely to fluctuate depending on the exact declaration of ANC after the current guidelines. With the current data at hand, this is impossible to predict and hence puts a high level of uncertainty in the effectiveness of the ANC payments. Furthermore, the guidelines only partially consider climate mitigation as a reason for the declaration of an ANC area. This would become specifically apparent when MS would be able to pay ANC support to foster the touristic potential of a specific region with arguably no direct impact on GHG reductions.

All these considerations should result in two budgetary amendments. The first is the lowering of the budget's climate tracker to $40 \%$. This stems from the wide application criteria when defining an ANC, for not all definitions have environmental aspects as a main motivator for the declaration. Fortunately, this criticism has been acknowledged by the legislative stakeholders and the new proposal reflects this value. (European Commission M., 2018) Additionally, the new tracker would exclude ANC from the $15 \%+15 \%$ budget flexibility between the two Pillars mentioned in Chapter 6.3.4.2.

The second change refers to capping the maximum total spending on measure M13 at $15 \%$ of the Pillar II budget. This constitutes a rather small decrease which is why mountainous areas or areas otherwise constrained (by temperature, stoniness etc.) should not receive significantly less per ha. Possibly, this could mitigate the backlash of farmers and lobby groups advocating on their behalf. On the other hand, it would free financial resources which should be shifted to the Pillar II measures discussed in Chapter 4.3 as these have higher GHG reduction potential. ${ }^{7}$ To be implemented, the proposed changes would need to overcome two main obstacles.

The first hurdle is pushing MS to map their entire territory using the current declaration procedures. The EC should opt for constructive talks and, if necessary, technical assistance to complete this task. It should furthermore motivate MS to pursue the funding of areas with high value of the presented climate-related ecosystem effects. But it does not possess the power to force MS to carry out the mapping, if they do not wish to apply the scheme.

The second hurdle resulting from the new declaration of ANC is that some farmers used to receiving the payment would not classify anymore and therefore would provoke resistance and political pressure on the legislative stakeholders. As the ANC has been incorporated in Pillar II in the CAP post-2020 legislation, no significant resistance from MS currently using the Pillar I funds for this scheme is expected.

\footnotetext{
${ }^{7}$ One possible example discussed in Chapter 6.4.5 is M04 Physical investment.
} 


\subsubsection{Young Farmers Payment}

Although not directly linked to environmental goals in the intervention logic of Pillar I, the YFP is expected to have an indirect impact on the GHG emissions of the agricultural industry.

This connection derives from a more general correlation between young farmers having on average a higher education than old ones. This is numerically proven by the Pearson correlation coefficient between age and education which stands at 0.55 in line with the general massification of education globally. (Scherer, Verburg, \& Schulp, 2017) (Meyer, 2015) further argues that this leads to more pro-environmental behaviour. At farm level, it has led young farmers to become increasingly aware of negative environmental factors such as water scarcity and soil loss due to soil erosion. (Scherer, Verburg, \& Schulp, 2017) have come to the conclusion that well-educated farmers below the age of 35 owing a $>100$ ha farm, along with other farm parameters, have the highest opportunities for climate mitigation and adaptation actions. This is not to say that this group prefers to cultivate and earn less, but rather that they keep pursuing a sustainable intensification of their production. Therefore, the post-2020 CAP should strengthen the measure in several ways and increase the coherence of the YFP with other subsidies of Pillar II.

Hence, the new CAP should aim to provide a comprehensive starting package for young farmers consisting of the YFP and certain measures of Pillar II aimed at improving the GHG emissions of the industry. In this sense, measures M10 AECM, M11 Organic farming, M15 Forestenvironment-climate, M06 Farm development, M01 Knowledge transfer and, to a certain extent, M04 Physical investment of Pillar II would perfectly enhance the YFP. ${ }^{8}$

On the one hand, this could additionally motivate young, environmentally-minded people to initiate a career in farming by minimizing of the economic risks associated with it. On the other hand, it could push the conversion towards more sustainable agriculture along with the GHG reduction when a generation renewal occurs.

The coherence of the measures mentioned above with the YFP is further exacerbated by the fact that some relevant Pillar II measures are usually set as multi-annual approaches, perfectly complementing the five-year timeframe during which young farmers can receive support under this scheme.

All this should not exclude conventional young farmers from profiting from the scheme, as its focus does not discriminate against other types of farms. In this sense, the YFP can continue to be paid as a direct support Pillar I scheme without the attachment of the previously outlined Pillar II measures.

\footnotetext{
${ }^{8}$ Further analysis of the climate targeting of M04 can be found in Chapter 6.4.2.
} 
The EU should opt to increase the spending threshold of this scheme to a minimum of $3 \%$ of the Pillar I payments and oblige national paying agencies to set aside an adequate amount of Pillar II support to complement the YFP. Based on the currently planned public expenditure of $4.43 \%$ of the EAFRD for the FA $2 \mathrm{~b}$, MS should also aim for increased spending of Pillar II in this area. (Own calculations based on EAFRD data, 2020) As MS and the responsible management and paying agencies generally know the situation on the ground, the new CAP should grant these agencies flexibility concerning the exact combination of measures and the budget allocation to create the starter package.

As for a concrete link between tonnes of GHG saved/EUR spent, the new YFP will not be capable of yielding results to this extent. Despite the strengthening of the YFP and the envisioned enlargement to become a young farmer's starter package, the scheme aims to provide a menu of measures to young, possibly pro-environmental farmers. So it is ultimately the choice of the MS and beneficiaries which Pillar I and II measures to combine under local conditions to produce project-based results. Due to the expected variety of the focus and measures of these projects, exact GHG reductions cannot be generalized nor precisely measured.

Applying the proposed changes would cause some obstacles that would need to be overcome in the effort to implement the young farmers' starter package as intended.

The first difficulty resulting from the increase of the Pillar I funding and its combination with Pillar II measures, is that other farmers could face cuts in the BPS or the SAPS. A similar effect could occur in Pillar II as appropriate funds for measures would be put aside for the young farmers' package not benefiting other holdings.

Another backlash could come from MS managing institutions and farmers together, because a combination of measures and adequate planning would most certainly result in higher administrative costs.

Lastly, MS could simply circumvent the provision owing to the given flexibility to support young farmers by environmental measures and instead allocate the funding for conventional farming. The worst outcome would be that the generation renewal in the most polluting sectors would occur without changes beneficial to the GHG reduction.

To sum up to presented arguments, the legislative stakeholders and implementing authorities should become aware of the indirect, positive effect a generation renewal in the agricultural industry has on the GHG emissions. Therefore, a new young farmers' starter package consisting of the Pillar I scheme and relevant Pillar II measures is proposed. 
Furthermore, the budget of this package should reflect the increase in ambition and a meaningful combination of CAP tools. Thus, the budget in both pillars should be increased accordingly.

Concluding all proposed adaptation to the Pillar I schemes, Table 7 list the quantitative and qualitative changes and the links to Pillar II measures.

\begin{tabular}{|c|c|}
\hline Pillar I adaptation & Adaptation short description \\
\hline $\begin{array}{l}\text { Basic Payment Scheme/Single Area } \\
\text { Payment Scheme }\end{array}$ & $\begin{array}{l}\text { Decrease in total percentage of Pillar I } \\
\text { payments }\end{array}$ \\
\hline Greening general & $\begin{array}{l}\text { Area threshold to }>5 \text { ha, two- layer greening } \\
\text { provisions for small holdings, increase land } \\
\text { share to } 15 \% \text { of arable land for holdings }>10 \text { ha, } \\
\text { conduct and follow studies on most effective } \\
\text { EFA type under local conditions }\end{array}$ \\
\hline Greening budget & $\begin{array}{l}40 \% \text { of Pillar I budget, } 15 \%+15 \% \text { budget } \\
\text { flexibility between greening and Pillar II } \\
\text { climate measures }\end{array}$ \\
\hline Greening-ESPG/ PG & $\begin{array}{l}\text { Stricter enforcement of maintenance rules and } \\
\text { management practices, and higher penalties, } \\
\text { enhanced reporting, promotion of deep- rooted } \\
\text { grass }\end{array}$ \\
\hline Greening-Crop diversification & $\begin{array}{l}\text { Ineffective thus elimination in favour of more } \\
\text { demanding provisions }\end{array}$ \\
\hline Greening-EFA n-fixing crops & $\begin{array}{l}\text { Reduce use of fertilizer, target most effective } \\
\text { crops, erase possible deadweight with VCS, } \\
\text { require catch crops afterwards }\end{array}$ \\
\hline Greening-EFA catch crops & $\begin{array}{l}\text { Target most effective crops, minimum growing } \\
\text { period, limit use of herbicides }\end{array}$ \\
\hline Greening-EFA fallow land & $\begin{array}{l}\text { Ineffective thus elimination in favour of more } \\
\text { demanding EFA types }\end{array}$ \\
\hline Voluntary Coupled Support & $\begin{array}{l}\text { Mainstream French implementation model, } \\
\text { enhance this with combination of Pillar II } \\
\text { measures, maintain budget }\end{array}$ \\
\hline Eco Schemes & $\begin{array}{l}\text { Integrated as additional voluntary } \\
\text { environmental layer above greening, include }\end{array}$ \\
\hline
\end{tabular}


continuation of M10 and M15, e.g. flat-rate payments

\begin{tabular}{|l|l|}
\hline Areas with natural constraints & $\begin{array}{l}\text { Shift completely to Pillar II, limit to } 15 \% \text { of } \\
\text { Pillar II spending, adapt budget climate tracker } \\
\text { of } 40 \% \text {, urge completion of maps }\end{array}$ \\
\hline Young farmers' payment & $\begin{array}{l}\text { Increase Pillar I budget to } 3 \%, \text { create young } \\
\text { farmers' starter package in combination with } \\
\text { Pillar II measures }\end{array}$ \\
\hline
\end{tabular}

Table 7: Summary of Pillar I scheme adaptations; Source: own compilation

\subsection{Pillar II Rural Development}

This chapter on Pillar II aims to elaborate on the measures for climate mitigation and quantify the targeting of the funds. The relevant measures outlined in Chapter 4.3 will be examined based on the spending of the EU and the MS in the current 2014-2020 programming period. Due to the sometimes-vague definitions and applications of these measures, the current EAFRD spending and the budget of the MS' rural development plan will be critically assessed with regard to its factual targeting of GHG reduction.

In order to provide a second view on the targeting of Pillar II towards climate mitigation, Priorities Restoring, Preserving and Enhancing Ecosystems (Priority 4) and Resource-Efficient, Climate Resilient Economy (Priority 5) will be examined by looking at the participation of the focus areas with a direct links towards GHG reduction. Comparing the target setting of the relevant measures and the relevant priorities, the question will then be analyzed whether a climate mitigation ring-fence should be imposed based on these measures or rather on these priorities. With this two-step assessment at hand, quantitative and qualitative recommendations for a more climate mitigation-related Pillar II will be made whilst having regards for the currently discussed CAP proposal. As for Pillar I, the proposed adaptations are numerous and quite detailed. Therefore, the reader is invited to consult Table 11 at the end of the Pillar I Rural Development Chapter.

\subsubsection{Limitations and Considerations for the Analysis of the Pillar II Measures and Priorities for Climate Mitigation}

Before evaluating the effective targeting of each measure and priority towards the GHG reduction, some aspects of the approach and the data set need to be considered for the chosen approach as well as some data points pose limitations. 
As for the former, the selection of the total spending for each relevant measure has been made by filtering the EAFRD measures Code. This result has further been narrowed to climate mitigation relevance by selecting project funding based on the Focus area description. Whereas the first selection filters the data set for the relevant measure, the second cancels the support regarding the competitiveness of producer, water efficiency, risk management etc. as they do not have a direct link with GHG reduction. This approach was chosen to quantify the climate mitigation targeting of broad measures such as M04 Physical investment which can have a variety of goals.

With regard to Priorities 4 and 5 two slightly different approaches have been chosen because the data set provides the allocation of funds to the relevant FA for Priority 5, but fails to do so for Priority 4. For Priority 5, the first selection has been made on the EAFRD Area Code by first filtering all FAs of this section and then deselecting $5 \mathrm{~A}$ as it does not have a direct link with climate mitigation. For Priority 4, the first selection was based on the column Focus Area short description to select the funding of the relevant priority. The link with GHG reduction was made by selecting the relevant measures in the Measure short description which have been identified as having a clear link with climate mitigation in Chapter 4.3.

Furthermore, the absence of FA in Priority 4 may negatively affect the validity of the spending of the measures and thus alter the relevant targeted spending. This is because the FA $4 \mathrm{~b}$ mentions the improvement of the utilization of water, fertilizer and pesticides, which, at first glance, may make this FA seem relevant. However, in the detailed description of the FA, only water management is targeted. It is therefore irrelevant for climate mitigation, but cannot be adequately filtered out. Taking again the example of M04, the investment may be attributed to a more effective irrigation system under the FA 4 b yet counts as relevant because Priority 4 is considered entirely.

The first general consideration to keep in mind is that in this analysis both the MS's share of the funding and the EAFRD budget employed were subjects of the calculation. This is crucial for the investigation as MS provide a significant part of the funding along with the EAFRD. Another general consideration concerns the secondary effects of the Pillar II measures not included in the analysis. For instance, many projects under the Village renewal measure yield possible reduction potential. (European Network for Rural Development A., 2020) Despite the obvious gains, the projects are usually targeted at rural towns, and the participation of farmers is not always given. Consequently, they are disregarded in the calculations for the agricultural industry. 
A further general limitation is the date of the analysis. Since the data set used was last updated on June $15^{\text {th }}, 2020$, no subsequent adaptations can be considered. For all these reasons, the following analysis has to be interpreted with care and may be subject to change.

\subsubsection{Targeting the Relevant Measures Towards Climate Mitigation}

M02 Advisory services, at the top of the scale, is defined as a broad consulting measure for a variety of topics. Thus, it does not come as a surprise to see a wide allocation of the funds for this measure to many CAP goals. Nonetheless, Table 8, column IV, shows that an astonishing $42.2 \%$ of the funds has been allocated for climate mitigation advice which given its broad definition can be interpreted as an aspirational achievement. While the total spending on M02 makes up roughly $0.6 \%$, the relevant spending constitutes $0.25 \%$ of the multi-annual Pillar II budget.

One may, however, question this result as it was impossible to find out whether the advice on e.g. the GAEC or the Water Framework Directive was considered climate mitigation spending, or classified in other categories. Regardless, M02 is a key measure to educate farmers or in general people concerned with the exact application of the CAP and serves as a facilitator for compliance with environmental provisions.

\begin{tabular}{|c|c|c|c|c|c|}
\hline 1 & ॥ & IIII & IV & v & VI \\
\hline Relevant measure & total spending on measure & relevant spending on measure & $\begin{array}{l}\text { percentage of relevant } \\
\text { spending within measure }\end{array}$ & $\begin{array}{l}\text { pecentage of relevant spending } \\
\text { on measure of all pillar II } \\
\text { payments }\end{array}$ & $\begin{array}{l}\text { Percentage of total spending } \\
\text { on measure of all pillar II } \\
\text { payments }\end{array}$ \\
\hline M02 Advisory Services & $908.206 .268,83 €$ & $381.620 .018,83 €$ & 42,02 & 0,25 & 0,60 \\
\hline M04 Physical Investment & $34.731 .563 .476,49 €$ & $2.032 .233 .254,14 €$ & 5,85 & 1,35 & 23,09 \\
\hline M08 Forest Investments & $6.403 .717 .626,12 €$ & $5.812 .468 .064,91 €$ & 90,77 & 3,86 & 4,26 \\
\hline $\begin{array}{l}\text { M10 Agri Environmental } \\
\text { Climate Measures }\end{array}$ & $25.166 .590 .663,62 €$ & $25.126 .130 .450,97 €$ & 99,84 & 16,71 & 16,73 \\
\hline M11 Organic Farming & $11.457 .502 .961,34 €$ & $11.440 .169 .628,01 €$ & 99,85 & 7,61 & 7,62 \\
\hline $\begin{array}{l}\text { M12 Natura } 2000 \text { and Wat } \\
\text { Framework Directive } \\
\text { payments }\end{array}$ & $866.454 .429,77 €$ & $866.454 .429,77 €$ & 100,00 & 0,58 & 0,58 \\
\hline $\begin{array}{l}\text { M15 Forest Environment } \\
\text { Climate }\end{array}$ & $304.770 .205,70 €$ & $304.770 .205,70 €$ & 100,00 & 0,20 & 0,20 \\
\hline Sum (II,III)/ Aver (IV,V,VI) & $79.838 .805 .631,87 €$ & $45.963 .846 .052,33 €$ & 57,571 & 30,56 & 53,09 \\
\hline
\end{tabular}

Table 8: Results of the targeting of the individual Pillar II measures towards climate mitigation; Source: (Own calculations based on EAFRD data, 2020)

For the second relevant measure, M04 Physical investment, the total spending is considerable, making up $23.09 \%$ of Pillar II or more than $€ 34.7$ billion. As mentioned in Chapter 4.3, physical investment can be provided in many forms contributing to many goals. In spite of the great potential that M04 could yield for the GHG reduction by modernizing fuel-intensive machinery, the financing of biogas plants or more effective manure storage facilities, just to mention a few, only $5.85 \%$ is being spent directly on climate mitigation. For the percentage of relevant spending of this measure of all Pillar II payments, this yields $1.35 \%$ being spent effectively. One explanation of this is the high amount attributed to the FA 2A which aims to improve farm 
performance. In some isolated cases these investments may even contribute towards the reduction of GHG; for instance, when a holding would purchase new, more efficient machinery consuming, as a secondary effect, less fuel. However, the extent to which this is feasible cannot be determined, as secondary effects are not recorded in the data set.

The third measure, shown in Column VI, M08 Forest investments, accounts for $4.26 \%$ of the Pillar II funds or $€ 6.4$ billion. Column IV indicates that it is well targeted with $90.77 \%$ being spent on climate mitigation. Most notably, Carbon Conservation/Sequestration (Priority 5E) and Priority 4 are the aims of this investment category. As such, this measure constitutes $3.86 \%$ of the relevant spending. The few exceptions account for investment in the competitiveness of producers or diversification of Small \& Medium Enterprises and job creation.

The fourth measure, named M10 AECM, briefly touched on in Chapter 6.3.4.1, is by far the most effective in terms of total relevant spending. More precisely, Table 8, column IV, states that $99.84 \%$ of the AECM has a link with GHG reduction, which is also underlined by the more than $€ 25.1$ billion invested in these projects. The combination of the targeting and the total spending results in AECM accounting for $16.71 \%$ of the relevant climate mitigation funding; this makes it a cornerstone of the CAP environmental performance.

The next relevant measure is M11 Organic farming with a total investment sum of more than $€ 11$ billion or $7.62 \%$ of the Pillar II funding; it complements M10 in the ambition to save GHG. Column IV demonstrates that $99.84 \%$ of the M11 payments were made with the reduction of GHG in mind, which is a positive targeting to be maintained in the future. Compared to the overall spending in Pillar II, 7.61\% has been invested relevantly in this measure.

The most targeted measures with a climate linking of 100\% are M12 and M15. For the former, almost all spending is allocated for Priority 4 due to the mentioning of the Natura 2000 areas and Water Directive Compensation payments for farmers in FA 4a. Since the overall spending is comparatively low with about $€ 866$ million, the expected positive effects are limited. Despite this disadvantage, column V and VI show that the measure accounts for $0.58 \%$ of the Pillar II budget and acts as an effective deterrent to the destruction of the most sensitive natural areas and carbon-rich soils.

M15 with total spending of little over $€ 304$ million contributes $0.2 \%$ of the total and relevant EAFRD spending and is well targeted to climate-related purposes. Again, most of the money is spent under Priority 4 presumably in all FA as the target indicators for each mention forest land. (European Network for Rural Development C., 2017)

Summing up the effective targeting of these measures (dividing sum Column III by sum Column II), $57.57 \%$ of the funds contain a direct link towards climate mitigation. As for the 
total spending allocated for these measures when compared to the total spending of the EAFRD and the MS, Aver Column VI shows that $53.09 \%$ has been spent on these measures and that $30.56 \%$ of climate mitigation-related spending was conducted as a result.

To conclude: establishing a correlation between public money spent and GHG reduction, no measures, not even those with $100 \%$ target values offer a straight link; there is either an indirect link (M02) or the saving potential depends on the site-specific conditions such as climate or soil type. Given that the relevant data is currently not present on a European level and that it would be costly to gather them, only specific cases can be linked with concrete GHG savings.

\subsubsection{Targeting of Priorities 4 and 5 Towards Climate Mitigation}

For the analysis of the climate mitigation targeting of Priorities 4 and 5, Table 9 contains the compiled results classified into the relevant total spending or percentage of spending.

Priority 4's total spending accounts for $45.48 \%$ or $€ 68.4$ billion (Columns VI and II) making up a significant proportion of the total Pillar II budget. While this is certainly impressive, the targeting on GHG reduction is less so as only $56.87 \%$ was efficiently allocated, accounting for $25.87 \%$ of the relevant spending in the total Pillar II budget. This can be explained by the utilization of the measures cooperation, basic services or knowledge within the priority. In some cases, these measures could yield climate mitigation effects, but these are indirect and/or secondary and thus not quantifiable.

\begin{tabular}{|c|c|c|c|c|c|}
\hline 1 & ॥ & III & IV & $\mathbf{v}$ & V! \\
\hline Focus Area & total spending on FA & relevant spending on FA & $\begin{array}{l}\text { percentage of relevant } \\
\text { spending within FA }\end{array}$ & $\begin{array}{l}\text { percentage of relevant spending on } \\
\text { priority of all pillar II payments }\end{array}$ & $\begin{array}{l}\text { percentage of total spending on FA } \\
\text { of all pillar II payments }\end{array}$ \\
\hline Priority 4 & $68.400 .764 .506,13 €$ & $38.901 .739 .928,47 €$ & 56,87 & 25,87 & 45,48 \\
\hline Priority 5 & $9.919 .200 .289,83 €$ & $6.904 .962 .212,78 €$ & 69,61 & 4,59 & 6,60 \\
\hline Sum $(\mathrm{II}, \mathrm{III}) /$ Aver $(\mathrm{IV}, \mathrm{V}, \mathrm{VI})$ & 78.319.964.795,96€ & $45.806 .702 .141,25 €$ & 58,49 & 30,46 & 52,08 \\
\hline
\end{tabular}

Table 9: Results of the targeting of Priority 4 and 5 towards climate mitigation; Source: (Own calculations based on EAFRD data, 2020)

Priority 5 with total spending of $€ 9.9$ billion and a budget allocation of $6.6 \%$ plays a less significant role in the fight again climate change. Nonetheless, it is better targeted at climate mitigation with $69.61 \%$ of the spending being efficiently allocated, which results in $4.59 \%$ of the Pillar II budget spent on climate mitigation issues. The deviation of funding can be explained by the fact that FA 5a regarding water management does not contribute towards GHG reduction, which lowers the target percentage of the priority.

Concluding the analysis, it can be said that $58.49 \%$ of the spending on the two priorities has had a clear connection with GHG reduction. As six out of the eight FA have a clear link with the problem at hand, suggests that MS have used the priorities to invest and promote irrigation and water management rather than spending a higher amount of the funds on the climate mitigation-related FA. 
In this light, it becomes evident that while $52.08 \%$ of the Pillar II funds have been allocated for these priorities, this investment has only resulted in $30.46 \%$ climate mitigation-related funding. Despite this result, MS and the EC have reached their goal of allocating at least $30 \%$ of the investment for this issue, although they may claim to have assigned considerably more.

As for the individual measures, the correlation between the budget spent on the priorities and the saving of GHG cannot be made because of the inherent case-specific effects linked to the measure employed, the climate, the soil type etc.

\subsubsection{Qualitive Recommendations for Pillar II}

Based on the analysis of the MS' rural development plans and the EAFRD in the two previous chapters, the CAP post-2020 should aim to amend the current framework in several ways to concentrate its targeting on climate mitigation. Therefore, the following two chapters will outline first the qualitative recommendations regarding the framework and key measures and secondly focus on quantitative budgetary allocations.

When looking at the overall targeting of the relevant measures and Priorities 4 and 5, it becomes evident that the effective climate mitigation-related spending for both calculations lies a little over $30 \%$. Hence, it would not make a significant difference whether the measures or the priorities would be ring-fenced.

One general factor to be considered when adjusting Pillar II is the fact that this spending has to be increased to promote a way towards a more sustainable agricultural industry while at the same time preserving the industry from a decline due to increased climate and biodiversity regulations.

Other aspects to keep in mind are the budgetary constraints ${ }^{9}$ and the political willingness of all stakeholders to agree on, and enact a strictly regulated framework especially in the co-financed Pillar II, which focuses on a variety of EU priorities in the rural areas. The latter fact would hinder the ringfencing and thus strict targeting of (a group of) measures beneficial to GHG reduction. (Ranner \& di Virgilio, 2020)

Based on these considerations, the approach of combining relevant FA of Priorities 4 and 5 should be conducted in the new CAP. It would probably be more acceptable to MS to adapt priorities and funding rather than specific measures because it would leave MS more flexibilities as to what measures to utilize to address the priority. This new mandatory priority would adopt the FAs $4 \mathrm{a}, 4 \mathrm{c}, 5 \mathrm{~b}, 5 \mathrm{c}, 5 \mathrm{~d}$, and $5 \mathrm{e}$ and thus effectively combine all climate

\footnotetext{
${ }^{9}$ further discussed in Chapter 6.4.5
} 
mitigation spending. In order to avert irrelevant or partly relevant funding, the FA 4a should be slightly adapted by deleting the reference to areas facing natural or other specific constraints as it can be interpreted as a matter of climate adaptation or cohesion and social integration of the rural community.

Inspired by the CAP post-2020 proposal, the aspect of the newly proposed FA on societal demands which focuses on the limitation of pesticide use should be integrated, in order to tackle all sources of GHG emissions in the agricultural industry. (European Commission H., 2018). In essence, this would yield a potent priority with the sole targeting on climate mitigation whilst diverting funds for climate adaptation to another priority. The strict separation between these two climate aspects should be made based on the findings of Table 9, where it was demonstrated that spending in climate-related priorities does not necessarily result in climate mitigation investments. The exact FA are presented in the following list:

a. increasing efficiency in energy use in agriculture and food processing (current Focus Area 5B);

b. facilitating the supply and use of renewable sources of energy, of by-products, wastes and residues and of other non-food raw material, for the purposes of the bio-economy (current Focus Area 5C);

c. reducing greenhouse gas and ammonia emissions from agriculture (current Focus Area 5D);

d. fostering carbon conservation and sequestration in agriculture and forestry (current Focus Area 5E).

e. restoring, preserving and enhancing biodiversity, including in Natura 2000 areas, and high nature value farming, as well as the state of European landscapes (adapted Focus Area 4A);

f. preventing soil erosion and improving soil management (current Focus Area 4C).

g. limiting the use and leaching of pesticides on agricultural soils (newly proposed Focus Area)

Another attempt to increase the targeting of the new priority should focus on finding an adequate legal formulation concerning the funds. This regards specific FA targeted via adequate measures. This is, for instance, the case for the new FA $\mathrm{c}$ and $\mathrm{d}$ which would partially target the emissions from the meat and dairy industry. These are of key importance, as they are not adequately addressed in the current nor the envisioned Pillar I. 
The first step would be to actively include high-density meat and dairy farms with undeclared eligible ha under the current CAP as beneficiaries for these FA. This would open up the funding for the highly polluting sector and limit the access solely to climate mitigation action.

A possible formulation regarding the measures employed could be the following: Support regarding the climate-mitigation priority referred to in terms of Physical investment, AECM and Forest-environment-climate shall exceed these measures' planned public expenditure of the CAP 2014-2020 FAs, which have been grouped to become the priority. These increases shall not jeopardize the spending on organic farming while considering the need of the local industry. High-density livestock farms without declared ha shall be included in the FA $\mathrm{b}$. and c.

This approach seeks, firstly, to increase the effective spending of M04, M10 and M15 without cutting the funds for other relevant measures. Secondly, it directs the funding to the most polluting sector and, thirdly, it gives MS the flexibility to adapt the rule according to the local industry needs.

Having this priority settled, the EC should furthermore adapt some measures to integrate them in the intervention logic of both pillars. Thereby Pillar II acts as an initiating impulse by financing the conversion to beneficial practices, while Pillar I reimburses farmers for the maintenance of these practices. With this logic in mind M10 AECM should become an integral part of the two-pillar system, albeit remaining voluntary at farm level.

In the current system AECM are implemented as five+ years contracts ideally complying with the general principles outlined in the following:

- Clear objectives

- Evidence-based

- Clearly going beyond mandatory standards

- Targeted at specific problem/need and area

- Delivering clear results

- Controllable and verifiable. (Sulima, 2016)

On the basis of the WTO Agreement on Agriculture, AECM are declared as environmental subsidies only allowing the authorities to compensate for the cost incurred and the income foregone, depending on the fulfilment of specific conditions. (World Trade Organization, 1995) The formulation of the article allows for result-based payments depending on delivering clear results while prohibiting financial incentive payments. Nonetheless, AECM under Pillar II could act as a startup funding for environmental practices covering almost all costs, and upon 
successful completion could become a source of additional revenue per eligible ha under the previously outlined Pillar I AECM as part of the Eco schemes. This would combine long-term environmental effects with an economically attractive, long-term subsidy package for farmers. Unfortunately, this integrated approach has not been pursued by the EC in its current proposal as AECM is specifically meant to not be part of the Eco schemes, nor seen as an additional environmental layer. (European Commission B., 2018)

The second measure that should be amended in the context of the integrated intervention logic is M11 Organic farming. In the current framework, this measure can support both the conversion to, and the maintenance of, organic farming under Pillar II making it somewhat inconsistent with the envisioned intervention logic. (European Network for Rural Development D., 2017) Using the same conversion incentive under Pillar II and maintenance reimbursement under Pillar I of the AECM measure, the upkeep of organic farming should stay an alternative practice equivalent to the Greening measures and should be compensated in the same way.

The reasons for it not being considered an Eco scheme are of administrative, economical and motivational character. For the administrative side, it would arguably be easier to maintain the present organic farming support in the Greening framework, thus decreasing the administrative costs of the change. Secondly, organic farms usually produce profitably for a demanding market which allows them to put $25 \%-129 \%$ higher prices on their main products. This is reasoned in a) the consumer's willingness to pay more for these products and b) the lower volatility of organic products compared to conventional ones. When these two factors cause a price slump on the conventional market while the organic substitute sells at a stable or even increasing price, these significant price differences occur in the short term. This goes to say, that the M11 measure does not qualify in the proposed scope of the Eco schemes since these are meant to cover voluntary, non-profitable commitments going beyond the established (organic production) rules. This is not to say that organic farms usually have lower yields and higher production costs and risks. (Oekolandbau.de, 2017) (Directorate-General for Agriculture and Rural Development (European Commission) D., 2019)

The funds allocated to the current measure to maintain organic farming should consequently be transferred to the Greening payments. Additionally, the new Pillar I ring-fence should ensure additional funding to support the reimbursement.

Organic farmers should furthermore be motivated to partake in M10 and/or M15 given that these measures could generate an increased effect under the gentle management practices. Thereby, they would also profit from the Eco scheme payments increasing their income. 
The third measure to use the described intervention logic is M15 Forest-environment-climate. Similarly to M10, this measure aims to support forest holders to commit to long-term projects which enhance, amongst others, the absorption of atmospheric carbon while ideally establishing profitable mixed-used holdings. (European Network for Rural Development A., 2019) Upon completion, the holdings would receive support as an equivalence for Eco schemes and thus mirror the intervention logic of M10 in the forest sector.

In the currently discussed proposal, the number of Pillar II measures have been significantly lowered while the definitions of each measure are much broader. Nonetheless, all relevant measures analyzed in Table 8 including the conversion and maintenance of organic farming are retained in some form in the regulation. The envisioned intervention logic for the measures has not been considered in the current proposal (European Commission I., 2018).

To conclude the qualitative changes to Pillar II, three main adaptations have been proposed, the first being the creation of a climate mitigation priority with seven FA tackling each source of GHG in the agricultural industry. The second refers to the implementation of an integrated approach of key measures such as M10 or M04 to provide start up project funding under Pillar II and later on continue subsidizing the completed projects under Pillar I. This effectively utilizes the pros and cons of each pillar's legal and financial construct in order to maximize GHG reduction and the related spending. Lastly, the measures referred to in the previous paragraph should be opened up to high-pollution sectors such as high-density livestock farming. Thereby, the main emitters of the industry could finance the conversion towards a low carbon production and possibly reduce GHG significantly across the industry.

The disadvantages of the proposed qualitative adaptations to Pillar II are twofold. The first, resulting from the aim to invest more in M10, M11, and M15 measures, could be a resistance of MS that prefer to support their farms and sectors without attaching a climate-mitigation action to it. Generally speaking, this resistance could be especially pronounced in MS with low organic farming area coverage and low awareness of climate change in the farming communities.

The second drawback to expect is an increase of the administrative burden for the farmer and the responsible national agency. Whereas the farmer has to research, plan and calculate the cost of, e.g., an M10 project, the responsible agency has to define the exact implementations made available to farmers, revise the requested projects and inspect their success regularly. Obviously, this requires more effort than, for example, the administration of the BPS payments, which do not demand the same level of revision and inspections. 


\subsubsection{Budgetary Implications for Pillar II}

First and foremost, Pillar II should clearly state a spending ring-fence for the envisioned climate mitigation FA. Based on the relevant spending calculated in Table 9 for Priorities 4 and 5, a ring-fence of $30 \%$ of the Pillar II budget could easily be justified. But as this would be a simple continuation of the current funding allocation, it seems to be too low to reach the 2030 target set for the agricultural industry. This point is underlined by the fact that the meat and dairy industry currently not subsidized by the CAP is to be integrated for the purpose of environmental investments and AECM. Regarding the investment opportunities, one beneficial yet expensive type would be to promote new biogas plants serving the local communities. Given that in 2019 only 2 billion cubic meters were produced and some experts estimate this figure to skyrocket to 36 billion cubic meters by 2050 , the investment needs via the EAFRD and other funds would be significant. (Simon, 2019).

It is therefore proposed to increase the Pillar II ring-fence to $52.08 \%$ of the entire fund based on the finding of Table 9, column VI. Within this climate ring-fence, climate mitigation should receive $76.8 \%$ of the funds or $40 \%$ of the Pillar II spending dedicated to the newly envisioned priority and thereby increase the relevant spending by $9.54 \%$ compared to the current framework. The remainder would be dedicated to climate adaptation within (an)other FA. The reason behind incorporating climate adaptation into the ring-fence is the inherent connection between certain climate adaptation measures and the reduction of GHG. In total this would set aside little over $€ 78.3$ billion for the fight against, and the adaptation to, climate change as can be seen in Table 10, column II. The key difference in the new baseline is the expected increase in effective spending of the ringfenced budget due to the creation of a specific climate mitigation priority. Thereby the large sums invested in e.g. irrigation systems do not count as climate mitigation spending but are adequately marked as climate adaptation projects.

Recognizing MS' varying agricultural industries and the balance between climate mitigation and climate adaptation spending, national authorities should be allowed to shift up to $5 \%$ of the total funding between these goals with the aim to address local climate-related issues at its local core.

The envisioned total spending of $€ 78.3$ billion would, however, be somewhat outdated as the EU MFF is currently being negotiated effecting the potential monetary allocation to the EAFRD. As the EU is presently experiencing profound changes in the form of Brexit and the prioritization of new objectives such as digitalization or security, the new MFF is expected to decrease the overall funding of the EAFRD. (Massot A. \& Nègre, 2018) Besides the deductions 
of the payments to the United Kingdom and the reallocation to other funds, the EC has proposed a decrease in its budgetary participation thus lowering its overall co-finance rate by $10 \%$. It calls upon the MS to increase their participation in order to keep the overall support for rural areas largely unchanged. (European Commission J., 2018) (Matthews A. D., 2018)

Bearing these aspects in mind, three budgetary models have been calculated and are depicted in Table 10. Column II outlines the baseline in which the overall EAFRD budget and the cofinance rate are kept stable while applying the qualitative changes of the previous chapter and the $52.08 \%$ ring-fence proposal. The first scenario in Column III supposes that the co-finance rate is not adapted while the EU budget allocation to the EAFRD decreases. Column IV looks at the spending on condition that MS increase the allocation of national resources to the fund by $10 \%$ as suggested by the EC. Column $\mathrm{V}$ answers the question of how many financial resources MS would need to mobilize in order to keep the Pillar II budget constant and how this would affect the co-finance rate. In all models the potential spending on climate mitigation has been estimated by assuming that $40 \%$ of the Pillar II budget will be effectively allocated to this objective in the approach previously outlined.

The proposed EU budget has been calculated based on current prices to provide comparability with the calculations of the previous chapter, and the EU-budget allocation in $€$ is based on the budget proposal of the (Council of the European Union , 2019) and was adjusted for inflation using a $2 \%$ annual rate as done by the EC.

Despite there being an updated budget proposal allocating more resources to Pillar II as a result of the coronavirus relief package, the final amount to be spent is under ongoing negotiations and thus cannot be adequately considered. (European Commission D., 2020) (Streck, 2020) Another point one has to keep in mind is that the allocations have been calculated before the possible reallocations of funds by MS between Pillar I and II or between the climate-related goals.

\begin{tabular}{|c|c|c|c|c|}
\hline $\mathbf{I}$ & II & III & IV & $\mathbf{v}$ \\
\hline $\begin{array}{l}\text { EAFRD budget models in current } \\
2020 \text { prices }\end{array}$ & Pillar II 2014-2020 & $\begin{array}{l}\text { Pillar II 2021-2027 without } \\
\text { changes to co-financing rate }\end{array}$ & $\begin{array}{l}\text { Pillar II 2021-2027 with change to } \\
\text { co-financing rate }\end{array}$ & $\begin{array}{l}\text { Pillar II 2021-2027 co-finance } \\
\text { rate to keep EAFRD stable }\end{array}$ \\
\hline EU-budget spending in $€$ & $100.079 .494 .865,00 €$ & $83.062 .318 .563,00 €$ & $83.062 .318 .563,00 €$ & $83.062 .318 .563,00 €$ \\
\hline EU co-finance rate in \% & 66,55 & 66,55 & 56,55 & 55,23 \\
\hline National budget spending in $€$ & $50.310 .929 .258,32 €$ & $41.749 .580 .104,17 €$ & $63.820 .649 .718,17 €$ & $67.328 .105 .560,32 €$ \\
\hline National co-financing rate in \% & 33,45 & 33,45 & 43,45 & 44,77 \\
\hline Total estimated spending in $€$ & $150.390 .424 .123,32 €$ & $124.811 .898 .667,17 €$ & $146.882 .968 .281,17 €$ & $150.390 .424 .123,32 €$ \\
\hline Decrease in $€$ & & $-25.578 .525 .456,15 €$ & $-3.507 .455 .842,15$ & \\
\hline Decrease in \% & & 17,01 & 2,33 & \\
\hline $\begin{array}{l}\text { Potential spending on climate } \\
\text { mitigation in } € \text { with } 40 \% \text { ringfence }\end{array}$ & $60.156 .169 .649,33 €$ & $49.924 .759 .466,87 €$ & $58.753 .187 .312,47 €$ & $60.156 .169 .649,33 €$ \\
\hline $\begin{array}{l}\text { Potential spending on climate } \\
\text { adaptation in } € \text { with } 12.08 \% \\
\text { ringfence }\end{array}$ & $18.167 .163 .234,10 €$ & $15.077 .277 .358,99 €$ & $17.743 .462 .568,37 €$ & $18.167 .163 .234,10 €$ \\
\hline Sum of potential spending in $€$ & $78.323 .332 .883,43 €$ & $65.002 .036 .825,86 €$ & $76.496 .649 .880,83 €$ & $78.323 .332 .883,43 €$ \\
\hline
\end{tabular}

Table 10: EAFRD budget scenarios for 2021-2027; Source: (Own calculations based on EAFRD data, 2020) 
For the first scenario in Column III, the total estimated spending would be $€ 124.8$ billion resulting in a decrease of $€ 25.6$ billion or $17.01 \%$ of the budget. This result would have dramatic effects on the climate change mitigation spending, which despite representing $40 \%$ of the budget, would drop to $€ 49.9$ billion compared to the baseline. Because of this, the CAP's ability to increasingly tackle GHG emissions would certainly be hampered.

Nonetheless, when comparing Table 10, Column III to the results in Table 9 it is evident that more financial resources would be relevantly spent than under the currently enacted framework. In the second scenario in Column IV with an adjusted co-finance rate, the total estimated spending would lie at $€ 146.9$ billion resulting in an overall decrease of $€ 3.5$ billion or $2.33 \%$. When it comes to climate mitigation spending, this would signify a decrease to $€ 58.8$ billion compared to the baseline of $€ 60.2$ billion but constitute a significant increase compared to the $€ 45.8$ billion calculated in Table 9, Column III.

The third (quite unlikely) scenario assumes that MS would need to allocate $€ 67.3$ billion to the EAFRD to maintain the total estimated spending which would result in a co-financing rate of $44.77 \%$. While this would certainly produce the best outcome in terms of climate spending with $€ 60.2$ billion, it cannot be expected to materialize. Furthermore, it would be much harder for the $\mathrm{EC}$ to set concrete spending targets, i.e. the ring-fence on climate objectives, while only financing slightly over $55 \%$ of the spending. Therefore, this scenario would not necessarily have the best result. Considering the current status of the budget negotiations and the low probability of the third model, the most desirable outcome would be produced by the second model which increases effective climate mitigation spending by roughly $€ 13$ billion compared to the current framework.

Naturally, the overall decrease of Pillar II funds, while at the same time allocating a higher percentage of it towards climate mitigation goals, would leave fewer resources for the other Pillar II goals. Since the EU has become a net exporter of agricultural products thus somewhat lessening the need for increased food security, the most significant reduction should be made in the area of supporting productivity increases, especially in highly polluting sectors. Productivity increases may result in more agricultural goods being produced with less input hence possibly less GHG pollution. However, one can also argue that this would lead to a shift of the supply curve to the right; lowering the equilibrium price of the goods. In the case that the demand curve was perfectly elastic, an increase in consumption is to be expected. But as the supply of agricultural goods is usually not perfectly elastic in the short term, this sudden rise in demand would lead to rising prices. As a result, it would motivate more farmers to enter the market of the goods. In the end, the market size would expand and the efficiency increase would 
likely be offset by the increased market size leading to additional GHG pollution as a consequence of added production. This simplified scenario disregards key factors such as the substitution of imported by locally produced goods or inelastic consumer demand, but demonstrates that growth in productivity may not necessarily result in reduced GHG emissions when certain market conditions are met.

Other areas likely to receive less support would be social inclusion and disaster recovery. These are certainly difficult trade-offs and the responsible authorities are likely to resist budget cuts. Yet it can be argued that without a sustainable climate, many of the farms would lose their economic viability due to unpredictable weather patterns and extreme weather events. In this light, GHG reduction has indirect social and economic effects contributing to the livability of rural areas.

A general budgetary side effect of all the scenarios presented would be the gradual transfer of funds from Pillar II to Pillar I over time as a result of the integrated approach of M10, M11 and M15 in both pillars. The successive conversion of holdings using, for instance, AECM in Pillar II would trigger a shift towards the maintenance of AECM layer in Pillar I after the completion of the five-year period. This implies that the budgetary flexibility of $15 \%+15 \%$ as suggested in Chapter 6.3.4.2 is also relevant for the development of long-term climate mitigation and crucial for adjusting the funding to local conditions, as some MS may already dispose of a large number of climate-friendly farms while others need to invest more to adapt their industry. However, the time of the transfers to Pillar I in the envisioned CAP cannot be reliably predicted because it depends on the completion of the conversion projects.

For all these reasons some resistance can be expected to come from non-climate motivated MS wanting to further enhance their market share in the agricultural industry and from conventional farmers' unions and lobby groups that fear a net-loss of Pillar II funding in support of their holdings or projects unrelated to climate change.

Summing up the proposed adaptations, the following table provides and overview of the qualitative and quantitative recommendations sorted by thematic adaptation.

\begin{tabular}{|c|c|}
\hline Pillar II adaptation & Adaptation short description \\
\hline Climate Mitigation priority & $\begin{array}{l}\text { Combine relevant FAs of Priority } 4 \text { and } 5 \\
\text { with adapted or new FA }\end{array}$ \\
\hline $\begin{array}{l}\text { Ring-fence priority at } 52.08 \% \text { of which } \\
40 \% \text { is going towards climate mitigation } \\
\text { and } 12.08 \% \text { to adaptation }\end{array}$ & $\begin{array}{l}\text { Increase targeting of spending in restricted } \\
\text { overall budget, MS have 5\% flexibility }\end{array}$ \\
\hline
\end{tabular}




\begin{tabular}{|l|l|}
\hline $\begin{array}{l}\text { Integration of high-density livestock } \\
\text { farming for the purpose of climate }\end{array}$ & $\begin{array}{l}\text { Achieve reductions and enhance climate } \\
\text { footprint via feed additives, biogas energy } \\
\text { potential, }\end{array}$ \\
\hline $\begin{array}{l}\text { Double pillar approach for M10, M15 as } \\
\text { Eco schemes }\end{array}$ & $\begin{array}{l}\text { Create a conversion incentive via Pillar II } \\
\text { payment and continuation payments via } \\
\text { Pillar I Eco schemes }\end{array}$ \\
\hline $\begin{array}{l}\text { Double pillar approach for M11 as } \\
\text { greening equivalent }\end{array}$ & $\begin{array}{l}\text { Organic farming holding operate in a } \\
\text { profitable market, increase in greening } \\
\text { budget will (partly) make up for Pillar II } \\
\text { payment }\end{array}$ \\
\hline Young Farmers Package & $\begin{array}{l}\text { Combination of Pillar I YFP with Pillar II } \\
\text { measures to ensure GHG sensitive } \\
\text { generation change }\end{array}$ \\
\hline General budget & $\begin{array}{l}15 \%+15 \% \text { budget flexibility will shift funds } \\
\text { to Pillar I long term for maintenance of } \\
\text { practices, cuts to productivity increase, } \\
\text { social inclusion funding }\end{array}$ \\
\hline
\end{tabular}

Table 11: Summary of Pillar II measure adaptations; Source: Own compilation

\section{Policy Proposals outside of the current CAP framework}

As discussed in several parts of the thesis, the CAP is a collection of partly nationally-defined standards and EU regulations intertwining to a legal framework. This exposes the CAP to external factors and regulations which are likely to influence the climate mitigation potential of the agricultural industry. Therefore, this chapter will briefly touch upon the external effects and suggest changes beneficial for the reduction of GHG.

The most decisive regulation possibly bolstering the CAP climate achievements is the ETS regulation discussed in Chapter 5. In order to enhance the positive effect, stakeholders should consider amending the allowed mitigation threshold of 280 million tonnes of CO2 equivalent that can be set off with environmental measures by the agricultural industry.

Along with the common certification scheme for sequestered GHG which the EC plans to roll out under the F2F strategy, it would open up the ETS allowance market for many farmers and could provide an attractive revenue stream for the industry. Given that the market stays somewhat more stable than in previous years, farmers could plan long-term and cost-efficient 
projects to store GHG and reckon with a reliable income likely exceeding the income foregone and cost of maintenance.

Another proposal currently discussed to decrease the livestock sector's emissions is a VAT rate adjustment or an EU meat tax. The Netherlands and Germany have raised this issue and proposed two different tax solutions. In Germany, the continuing infringement of the nitrate directive and the current Covid-19 outbreaks in slaughterhouses have triggered a discussion about raising the price of meat by 40 cents per $\mathrm{kg}$ in order to redress shortcomings in animal welfare. (European Commission C., 2019) (Mitteldeutscher Rundfunk Aktuell, 2020) Provided that the surtax would flow into often costly GHG-saving investments, it could shift the industry towards a lower GHG per kg footprint. Nonetheless, it would not address the overconsumption of meat in the EU as even a VAT increase from $7 \%$ to $19 \%$ is unlikely to pose a sufficient incentive for many consumers to cut back on these products. (Grefe, 2019)

Therefore, the Netherlands in cooperation with the True Animal Protein Price Coalition (TAPP) adopted a proposal for a fair meat price which aims to internalize all environmental costs while simultaneously decreasing the VAT rates for fruit, vegetables as well as meat and dairy alternatives from 9\% to the lowest allowed EU VAT rate of 5\%. (True Animal Protein Price Coalition, 2020). Calculating the exact costs to be internalized, the coalition has proposed to raise prices per 100 grams of beef/veal, pork and chicken by 47-, 36- and 17-euro cents by 2030. The proposed increases reflect the externalities of the animal's lifecycle which explains e.g., the higher price increase for beef. (True Animal Protein Price Coalition, 2020)

The expected $€ 32$ billions of annual tax revenue is proposed to be reinvested in farms (31\%$46 \%$ ), used to finance lower VAT rates on healthy food (22-36\%) and compensation payments to low-income households (19\%). The remainder of $12 \%$ would finance the development of nature reserves and climate mitigation. It is further estimated that if all MS were to adopt this approach, an EU-wide reduction of up to 120 million tonnes of $\mathrm{CO} 2$ equivalent could be expected. (True Animal Protein Price Coalition, 2020)

As for imported meat from third countries, an import tariff would level the playing field for all producers. A climate-related import tax could furthermore motivate importers to comply with the stringent new EU-regulations by applying best practices to their entire production to be granted access to the single market tariff-free. This would extend the Brussels Effect to a wider meat production industry and force producers to comply with the future EU standards. One example where this is currently undertaken is the organic food market. By abolishing the mutual recognition of laxer organic farming practices in countries such as the United States of America, the new organic regulation will establish the practice of the principle of conformity from 2021 
on. (European Parliament; Council of the European Union D., 2018) (True Animal Protein Price Coalition, 2020) Thereby the regulation will tentatively apply the European organic standards extraterritorially and raise the standards in the relevant markets.

While all these are ambitious plans, it remains to be seen whether they materialize on an EUlevel. Although the approach towards climate-related VAT rates has been integrated into the F2F strategy as mentioned in Chapter 5, the MS retain the authority over tax matters. This complicates an EU-wide harmonization even just based on the VAT and even more so for the case for the climate-related tax based on externalities. (Schulz, 2020)

Another relevant initiative is the EC proposal for the establishment of a $€ 7.5$ billion Just Transition Fund with the aim of financing the way to a climate-neutral economy. If applied to agriculture and the production of food in general, it could trigger beneficial projects and initiatives. One possible use could be for instance the promotion of urban community gardens which provide a sustainable food supply and decrease emissions from logistics. (European Commission E., 2020)

Concerning the international trade of agricultural products, the EU and the Mercosur countries have reached an agreement in principle which is in the process of being finalized. (European Parliament, 2020) Based on this version, the expected impact on GHG emissions is going to be a net surplus. A considerable part is expected to come from increased imports of agricultural products, mainly soya and beef, presumably leading to increased deforestation and biodiversity loss. (Dr. Ghiotto \& Dr. Echaide, 2019)

Another issue raised in the trade agreement is the accountability of the parties involved regarding the designated environmental provisions. While they commit themselves to the Paris Agreement and pledge to fight deforestation, illegal wildlife trade etc., the vague language and the interpretation of the relevant chapters as soft law severely weakens its compliance capabilities upon infringements. Although an infringement procedure based on government consultations and expert recommendations is provided, the enforcement is not believed to be sufficient. Therefore, the EC should include treating these infringements as part of the state-tostate dispute resolving mechanisms commonly applied in trade disputes. (Dr. Ghiotto \& Dr. Echaide, 2019) (Erthal Abdenur, 2019). (European Commission F., 2020)

It would thus pursue a treaty-based harmonization of the environmental regulatory framework. By enforcing these standards, it would also show its assertiveness and its strong mandate in competition policy vis-à-vis the Mercosur countries.

Apart from the political spectrum, researchers have started to implement cutting-edge projects at farm level which promise high mitigation and adaptation potential. One example is the 
concept of Agrophotovoltaics where solar panels are installed above a field. Besides producing renewable energy, the panels provide shade for the growing plants thus increasing their drought resistance. If further improved and adapted to the variety of agricultural production, this and other developments can provide a boost to the climate resilience of the industry. (Trommsdorff, 2020)

The most promising way to effectively implement the political initiatives and reach the targets mentioned in this chapter and in the proposed CAP, would be to agree on (a) package deal(s), i.e. the compensation of concessions made in one regulation by advantages received in another, to harness support from often disagreeing parties. Given the depth of the proposed initiatives and the cross-cutting manner of climate change, this approach may be feasible in this instance. (Bradford A. B., 2020) In this sense, MS opposing, for example, tax harmonization of meat products could be persuaded to agree in exchange for increased contributions by the EAFRD for negatively affected rural areas.

\section{Conclusion}

Throughout the analysis of the CAP and the external factors, this thesis has proposed tangible changes to the policy itself and the inherently connected circumstances.

The first category focuses on stricter regulations of management practices, larger areal thresholds etc. as a baseline to receive support under the Pillar I schemes. One example in which and already beneficial practice has been proposed to be improved is putting limits on fertilization of PG grassland and EFA-catch crops. This will inevitably reduce the N2O pollution resulting from an agricultural land management in favour of nitrogen-balanced soils as a result of cultivating n-fixing crops and catch crops.

One scheme that has been left almost unchanged in budgetary terms is the ANC payment. Nonetheless, currently enacted best practices along with recent scientific findings demand stricter conditions for receiving the subsidy payment. To extend the expected positive effects of GHG-capturing animal fodder (protein crops) supplied to livestock farmers by local providers, the proposals aim to reduce the fodder import from third countries. Thereby, the demand for e.g. soya beans would be reduced consequently lowering the need for conversion of natural habitats into farmland in vulnerable regions such as the Amazon Rainforest.

Furthermore, it has been found that some schemes and options in Pillar I do not yield tangible GHG-reducing effects and should be eliminated in order to motivate farmers to adopt more stringent practices. This refers to the Crop diversification scheme as well as the EFA-fallow 
land option. All these changes are likely to cause increased compliance costs for agricultural holdings. These costs are reflected in the increased Pillar I budget ring-fence of $40 \%$ earmarked for environmental subsidies. Doubtlessly this increases the amount paid per ha to complying farms and additionally motivates non-compliant holdings to adapt.

As for Pillar II, the budgetary analysis has resulted in proposals for the qualitative and quantitative aspects of the measures and FA. For the former, it is of key importance to a) implement a new FA solely focused on climate mitigation and b) open up the funding for climate mitigation funding for high-density livestock farms currently not considered.

As for the quantitative proposals, Pillar II should get an $40 \%$ ring-fence for climate mitigation adaptation purposes. With the aim to effectively pay out the subsidy for the envisioned Eco schemes, which includes the continuation of key Pillar II schemes, the MS should pursue a e.g. flat-rate payment method to decrease the bureaucratic burden on the stakeholders and adequately reimburse farmers for their commitment.

Combined, the changes aim to increase overall spending on the issue while limiting the room for deviation of funds in order to finance, for instance, irrigation systems.

Another pivotal building block that should be considered in the new CAP is the seamless integration of GHG reduction measures under Pillar II with Eco schemes or the Greening provision in Pillar I. Thereby, start-up investment for e.g. M10 AECM would later qualify the holding for the Eco scheme subsidy as part of Pillar I to maintain the implemented practice. Other meaningful changes and integrations have been proposed for certain Pillar II measures in combination with the ANC or the YFP scheme in Pillar I.

As important as all these changes would be for the CAP framework, some pitfalls remain. The first is the possible overlap of fund eligibility between some subsidy forms. For instance, it has been pointed out that VCS may overlap with EFA-n-fixing crops as both schemes support the cultivation of the same crop type. Therefore, the stakeholders involved should initiate a discussion as to which types of crops should be funded under these schemes and avoid double declaration in the future.

Furthermore, it has not been possible to determine a correlation between EUR spent on a selected scheme or measure and the resulting GHG reduction effect. Although for some practices like EFA-catch crops the sequestering factors are known under certain circumstances, these are hard to generalize for the entire European agricultural industry because of the greatly varying conditions regarding soil, climate and fodder, to name but a few. Therefore, a clear pathway showing which subsidy has to adapt, and how to budget it to meet the 2030 Green 
New Deal reduction target could not be established. Nevertheless, the proposed adaptations of the CAP should yield tangible reductions and offer an incentive to low-carbon food production in the long run. As to why it is difficult for the industry to reach a net-zero emission point, the unavoidable emissions associated with the production need to be considered. For instance, as long as all Europeans are not miraculously becoming vegans, the demand for animal products will be satisfied by raising animals, which in turn causes $\mathrm{N} 2 \mathrm{O}$ and methane emissions.

When it comes to other policies that influence the GHG emissions of the agricultural industry, the EC along with other stakeholders have initiated leading policies, such as the ETS regulation, which puts a price on carbon emission and indirectly includes carbon removal in the industry. Other options mentioned in the F2F strategy as well as the proposed change in VAT based on environmental externalities can positively influence the demand side of the market.

Extraterritorially, the currently finalized trade agreement with the Mercosur countries puts some emphasis on the climate mitigation of imported agricultural goods. As a further improvement it should interpret environmental provision as hard law, and the EC should become aware of the Brussel Effect which could globally expand EU environmental provisions based on treaties or market forces.

In essence, the proposed CAP policy bolstered by external policies and developments provides the political stakeholders with an integrated, long-term framework to address the pressing issue of GHG reductions. All factors considered, it has been shown that combined stricter management practices, new areal thresholds, and integrated, two-pillar subsidy incentives, all supported by an increased environmental CAP budget, have great potential to lead the agricultural industry to comply with the 2030 Green New Deal reduction targets. 


\section{List of references}

Angileri, V., Fasbender, D., Van Eupen, C., Tzilivakis, J., Warner, D., Devos, W., ... Terres, J.-M. (2017). Using the Ecological Focus Area (EFA) calculator to assess the potential impact of EFA implementation on biodiversity and ecosystem services. Geel. Belgium: Joint Research Center (European Commission).

Bradford, A. A. (2020). Theory- What is the Brussels Effect. In A. Bradford, The Brussels Effect- How the European Union rules the world (p. 2). New York, USA: Oxford University Press.

Bradford, A. B. (2020). Theory- Promoting Europes Integration via Regulation. In A. Bradford, The Brussels Effect- How the European Union rules the world (pp. 14-15). New York, USA: Oxford University Press.

Bues, A., Preißel, S., Reckling, M., Zander, P., Kuhlman, T., Topp, K., . . . Murphy-Bokern, D. (2013). The environmental role of the protein crops in the new Common Agricultural Policy. Luxembourg: Publication Office of the EU.

Commonwealth Scientific and Industrial Research Organisation. (2019, 03 21). csiro. Retrieved from Case Study Future Feed: https://www.csiro.au/en/Research/AF/Areas/Food-security/FutureFeed

Copernicus programme. $(2016,1101)$. https://www.copernicus.eu. Retrieved from Impact of Copernicus- Agriculture: https://www.copernicus.eu/en/about-copernicus/impactcopernicus/agriculture

Copernicus programme. (2020, 03 16). https://land.copernicus.eu. Retrieved from Farming by Satellite Prize 2020 is now open for applications: https://land.copernicus.eu/news/farming-by-satellite-prize-2020-is-now-open-forapplications

Council of the European Union . (2019). Multiannual Financial Framework (MFF) 20212027: Negotiating Box with figures 14518/1/19 REV 1. Brussels : Council of the European Union .

Detsch, U. (2018, 06 22). Youtube Kanal-Bayrischer Rundfunk . Retrieved from Mähen und mulchen: Warum "rasiert" man Wegränder ab? | Unser Land | BR | Artenschutz | Insekten: https://www.youtube.com/watch?v=z-EEa7_JtJg

Deutscher Bauernverband e.V. (2020). Green Architecture and Eco-Schemes-Key features of a future CAP Strategic Plan for Germany. Berlin, Germany: Deutscher Bauernverband e.V.

Directorare-General for Agriculture and Rural Development (European Commission) A. (2016, 11). Redistributive payment. Retrieved from Envelopes: https://ec.europa.eu/info/sites/info/files/food-farmingfisheries/key_policies/documents/ds-dp-redistributive-payment_en.pdf

Directorate-General for Agriculture and Rural Development (European Commission) A. (2015). GUIDANCE DOCUMENT ON THE IMPLEMENTATION BY MEMBER STATES OF PERMANENT GRASSLAND PROVISIONS IN THE CONTEXT OF THE PAYMENT FOR AGRICULTURAL PRACTICES BENEFICIAL FOR THE CLIMATE AND THE ENVIRONMENT (GREENING)Direct support D.2. Greening, crosscompliance... Brussels: Directorate- General Agriculture and Rural Development.

Directorate-General for Agriculture and Rural Development (European Commission) A. (2017). TECHNICAL HANDBOOK ON THE MONITORING AND EVALUATION FRAMEWORK OF THE COMMON AGRICULTURAL POLICY 2014 - 2020.

Brussels: The Official Journal of the European Union.

Directorate-General for Agriculture and Rural Development (European Commission) A. (2018, 03 19). Publication Office of the European Union. Retrieved from Publication 
Office of the EU: https:/op.europa.eu/en/publication-detail/-/publication/541f0184-

759e-11e7-b2f2-01aa75ed71a1/language-en/format-PDF/source-130283942

Directorate-General for Agriculture and Rural Development (European Commission) A. $(2019,10)$. Voluntary coupled support Review by the Member States of their support decisions. Retrieved from VCS REVIEW APPLICABLE FROM CLAIM YEAR 2019 - OVERVIEW: https://ec.europa.eu/info/sites/info/files/food-farmingfisheries/key_policies/documents/voluntary-coupled-support-note-revisedaug2018_en.pdf

Directorate-General for Agriculture and Rural Development (European Commission) B. $(2017,06)$. Common monitoring and evaluation framework. Retrieved from TECHNICAL HANDBOOK ON THE MONITORING AND EVALUATION FRAMEWORK OF THE COMMON AGRICULTURAL POLICY 2014 - 2020: $\mathrm{https} / / /$ ec.europa.eu/transparency/regexpert/index.cfm?do=groupDetail.groupDetailDo c\&id $=21095 \&$ no $=3$

Directorate-General for Agriculture and Rural Development (European Commission) C. (2019). Voluntary Coupled Support Informative Note September 2019. Brussels: Directorate-General Agriculture and Rural Development.

Directorate-General for Agriculture and Rural Development (European Commission) D. (2019). EU Agricultural Markets Briefs- Organic farming in the EU A fast growing sector. Brussels: Directorate General Agriculture and Rural Development (European Commission).

Directorate-General for Agriculture and Rural Development (European Commission) E. (2017). CAP CONTEXT INDICATORS 2014-2020 32. LESS FAVOURED AREAS / AREAS FACING NATURAL AND OTHER SPECIFIC CONSTRAINTS. Brussels: Directorate-General for Agriculture and Rural Development (European Commission).

Directorate-General for Argiculture and Rural Development (European Commission) C. (2017, 05). The Small Farmers Scheme. Retrieved from Financial aspects: https://ec.europa.eu/info/sites/info/files/food-farmingfisheries/key_policies/documents/small-farmers-scheme_en.pdf

Directorate-General for Argiculture and Rural Development (European Commission) D. (2017, 05). The Small Farmers Scheme. Retrieved from Financial aspects: https://ec.europa.eu/info/sites/info/files/food-farmingfisheries/key_policies/documents/small-farmers-scheme_en.pdf

Directorate-General for Climate Action (European Commission). (2015). EU ETS Handbook. Brussels: European Commission.

Directorate-General for Communcation (European Commission) D. (2020). The redistributive payment. Retrieved from The redistributive payment explained: https://ec.europa.eu/info/food-farming-fisheries/key-policies/common-agriculturalpolicy/income-support/additional-optional-schemes/redistributive-payment_en

Directorate-General for Communication (European Commission) A. (2016). Income Support explained. Retrieved from Why farmers need support: https://ec.europa.eu/info/foodfarming-fisheries/key-policies/common-agricultural-policy/income-support/incomesupport-explained_en

Directorate-General for Communication (European Commission) A. (2019). Young farmers. Retrieved from Young people in farming: https://ec.europa.eu/info/food-farmingfisheries/key-policies/common-agricultural-policy/income-support/young-farmers_en

Directorate-General for Communication (European Commission) A. (2020, 05 04). Market Measures explained. Retrieved from Rules and measures to regulate and support the marketing of agricultural products.: https://ec.europa.eu/info/food-farmingfisheries/key-policies/common-agricultural-policy/market-measures/market-measuresexplained_en 
Directorate-General for Communication (European Commission) B. (2016, 03). The Young Farmer Payment under Pillar I of the Common Agricultural Policy. Retrieved from NOTIFICATIONS OF THE POLICY CHOICES RELATED TO THE IMPLEMENTATION OF THE YOUNG FARMER PAYMENT: https://ec.europa.eu/info/sites/info/files/food-farmingfisheries/key_policies/documents/young-farmer-payment_en.pdf

Directorate-General for Communication (European Commission) B. (2020). Common agricultural policy. Retrieved from The common agricultural policy is about our food, the environment and the countryside: https://ec.europa.eu/info/food-farmingfisheries/key-policies/common-agricultural-policy_en

Directorate-General for Communication (European Commission) C. (2020, 04). Rural Development. Retrieved from European agricultural fund for rural development: https://ec.europa.eu/info/food-farming-fisheries/key-policies/common-agriculturalpolicy/rural-development_en

Directorate-General for Employment, Social Affairs and Inclusion (European Commission). (2014). Guidance on Simplified Cost Options (SCOs). Luxembourg: Publications Office of the European Union.

Dr. Ghiotto, L., \& Dr. Echaide, J. (2019). Summary of the Analysis of the agreement between the European Union and the Mercosur Summary based on the study. Berlin, Buenos Aires, Brussels: Anna Cavazzini MEP, The Greens/EFA,.

Erthal Abdenur, A. (2019, 08 20). Climate Diplomancy. Retrieved from A double-edged sword: The climate politics of the Mercosur-EU Agreement: https://www.climatediplomacy.org/news/double-edged-sword-climate-politics-mercosur-eu-agreement

European Commission A. (2014). COMMISSION DELEGATED REGULATION (EU) No 639/2014. In European Commission, supplementing Regulation (EU) No 1307/2013 of the European Parliament and of the Council establishing rules for direct payments to farmers under support schemes within the framework of the common agricultural policy and amending Annex X to that Regulation (p. 7). Brussels, Belgium: The Official Journal of the European Union.

European Commission A. (2017, 03 29). eur-lex.europa.eu. Retrieved from REPORT FROM THE COMMISSION TO THE EUROPEAN PARLIAMENT AND THE COUNCIL on the implementation of the ecological focus area obligation under the green direct payment scheme: https://eur-lex.europa.eu/legalcontent/EN/TXT/HTML/?uri=CELEX:52017DC0152\&from=EN

European Commission A. (2018). Annex III RULES ON CONDITIONALITY PURSUANT TO ARTICLE 11. In European Commission, Annexes to the Proposal for a REGULATION OF THE EUROPEAN PARLIAMENT AND OF THE COUNCIL $\{S E C(2018) 305$ final $\}$ - \{SWD(2018) 301 final $\}$ (pp. 13-16). Brussels: The Official Jounal of the European Union.

European Commission A. (2019, 12 05). Cross- compliance. Retrieved from Good agricultural and environmental conditions: https://ec.europa.eu/info/food-farmingfisheries/key-policies/common-agricultural-policy/income-support/crosscompliance_en

European Commission A. (2020). European Commission Climate Action. Retrieved from 2030 climate \& energy framework: https://ec.europa.eu/clima/policies/strategies/2030_en

European Commission B. (2017, 11 03). ec.europa.eu. Retrieved from Areas of natural or other specific constraints (ANCs): https://ec.europa.eu/info/food-farmingfisheries/key-policies/common-agricultural-policy/income-support/additionaloptional-schemes/anc_en 
European Commission B. (2018). Article 28 Schemes for the climate and the environment. In E. Commission, Proposal for a REGULATION OF THE EUROPEAN PARLIAMENT AND OF THE COUNCIL \{SEC(2018) 305 final $\}$ - $\{$ SWD(2018) 301 final $\}$ (p. 52).

Brussels: The Official Journal of the European Union.

European Commission B. (2019, 12 11). https://eur-lex.europa.eu. Retrieved from COMMUNICATION FROM THE COMMISSION TO THE EUROPEAN PARLIAMENT, THE EUROPEAN COUNCIL, THE COUNCIL, THE EUROPEAN ECONOMIC AND SOCIAL COMMITTEE AND THE COMMITTEE OF THE REGIONS The European Green Deal COM/2019/640 final: https:/eurlex.europa.eu/resource.html?uri=cellar:b828d165-1c22-11ea-8c1f01aa75ed71a1.0002.02/DOC_1\&format=PDF

European Commission B. (2020). Farm to Fork Strategy For a fair, healthy and environmentally-friendly food system. Brussels: European Commssion.

European Commission C. (2018). Article 6- Specific objectives. In E. Commission, Proposal for a REGULATION OF THE EUROPEAN PARLIAMENT AND OF THE COUNCIL $\{S E C(2018) 305$ final $\}-\{S W D(2018) 301$ final $\}$ (p. 41). Brussels: The Official Journal of the European Union.

European Commission C. (2018, 05 12). Common Monitoring and Evaluation Framework. Retrieved from CMEF reports: https:/ec.europa.eu/info/sites/info/files/food-farmingfisheries/key_policies/documents/report-implementation-cmef_december2018_en.pdf

European Commission C. (2019, 11 28). https://www.ombudsman.europa.eu. Retrieved from Decision in case 1802/2019/EWM on the European Commission's refusal to provide access to a letter to Germany in an infringement procedure for non-respect of the Nitrates Directive: https://www.ombudsman.europa.eu/en/decision/en/122116

European Commission C. (2020). COMMISSION STAFF WORKING DOCUMENT Analysis of links between CAP Reform and Green Deal. Brussels: European Commission.

European Commission D. (2018). ANNEX II WTO DOMESTIC SUPPORT PURSUANT TO ARTICLE 10. In E. Commission, ANNEXES to the Proposal for a REGULATION OF THE EUROPEAN PARLIAMENT AND OF THE COUNCIL \{SEC(2018) 305 final $\}$ - $\{S W D(2018) 301$ final $\}$ (pp. 8-12). Brussels: The Official Journal of the European Union.

European Commission D. (2020, 05 27). COMMUNICATION FROM THE COMMISSION TO THE EUROPEAN PARLIAMENT, THE EUROPEAN COUNCIL, THE COUNCIL, THE EUROPEAN ECONOMIC AND SOCIAL COMMITTEE AND THE COMMITTEE OF THE REGIONS. Retrieved from MULTIANNUAL FINANCIAL FRAMEWORK 2021-2027 (IN COMMITMENTS):

https://ec.europa.eu/info/sites/info/files/about_the_european_commission/eu_budget/1 _en_act_part1_v9.pdf

European Commission E. (2018). Article 90- Flexibility between direct payments allocations and EAFRD allocations. In European Commission, Proposal for a REGULATION OF THE EUROPEAN PARLIAMENT AND OF THE COUNCIL \{SEC(2018) 305 final\} $\{S W D(2018) 301$ final\} (pp. 92-93). Brussels: The Official Journal of the European Union.

European Commission E. (2020, 01 14). European Green Deal-Just Transition Fund. Retrieved from Proposal for a REGULATION OF THE EUROPEAN PARLIAMENT AND OF THE COUNCIL establishing the Just Transition Fund: https://ec.europa.eu/info/law/better-regulation/have-your-say/initiatives/12113-Fasttrack-interservice-consultation-on-the-SEIP-including-a-JTM-and-the-JTF-

European Commission F. (2018). Article 87- Tacking Climate Expenditure. In European Comission, Proposal for a REGULATION OF THE EUROPEAN PARLIAMENT AND 
OF THE COUNCIL \{SEC(2018) 305 final $\}$ - $\{$ SWD(2018) 301 final $\}$ (pp. 91-92).

Brussels: The Official Journal of the European Union.

European Commission F. (2020, 07 21). https://trade.ec.europa.eu. Retrieved from EU-

MERCOSUR* TRADE AGREEMENT TRADE AND SUSTAINABLE

DEVELOPMENT:

https://trade.ec.europa.eu/doclib/docs/2019/june/tradoc_157957.pdf

European Commission G. (2018). Article 66 Natural or other area-specific constraints. In

European Comission, Proposal for a REGULATION OF THE EUROPEAN

PARLIAMENT AND OF THE COUNCIL \{SEC(2018) 305 final $\}$ - \{SWD(2018) 301

final\} (pp. 78-79). Brussels: The Official Journal of the European Union.

European Commission G. (2020, 03 11).www.eur-lex.europa.eu. Retrieved from

COMMUNICATION FROM THE COMMISSION TO THE EUROPEAN

PARLIAMENT, THE COUNCIL, THE EUROPEAN ECONOMIC AND SOCIAL

COMMITTEE AND THE COMMITTEE OF THE REGIONS A new Circular

Economy Action Plan For a cleaner and more competitive Europe: https://eur-

lex.europa.eu/resource.html?uri=cellar:9903b325-6388-11 ea-b735-

01aa75ed71a1.0017.02/DOC_1\&format=PDF

European Commission H. (2018). ANNEX I IMPACT, RESULT AND OUTPUT

INDICATORS PURUSANT TO ARTICLE 7. In European Commission, ANNEXES

to the Proposal for a REGULATION OF THE EUROPEAN PARLIAMENT AND OF

THE COUNCIL $\{$ SEC(2018) 305 final $\}$ - $\{$ SWD(2018) 301 final $\}$ (pp. 1-7). Brussels:

The Official Journal of the European Union.

European Commission I. (2018). CHAPTER IV TYPES OF INTERVENTIONS FOR

RURAL DEVELOPMENT. In European Commission, Proposal for a REGULATION

OF THE EUROPEAN PARLIAMENT AND OF THE COUNCIL \{SEC(2018) 305

final $\}-\{S W D(2018) 301$ final $\}$ (pp. 77-86). Brussels: The Official Journal of the

European Union.

European Commission J. (2018). ESTIMATED FINANCIAL IMPACT OF THE

PROPOSAL. In European Commission, Proposal for a REGULATION OF THE

EUROPEAN PARLIAMENT AND OF THE COUNCIL \{SEC(2018) 305 final\} -

$\{S W D(2018) 301$ final $\}$ (pp. 133-134). Brussels: The Official Journal of the European Union.

European Commission K. (2018). Pretext (22). In E. Commission, Proposal for a REGULATION OF THE EUROPEAN PARLIAMENT AND OF THE COUNCIL $\{S E C(2018) 305$ final $\}$ - $\{S W D(2018) 301$ final (pp. 20-21). Brussels: The Official Journal of the European Union.

European Commission L. (2018). Article 92- Increased ambition with regard to environmental- and climate-related objectives. In European Commission, Proposal for a REGULATION OF THE EUROPEAN PARLIAMENT AND OF THE COUNCIL $\{S E C(2018) 305$ final $\}$ - \{SWD(2018) 301 final $\}$ (p. 94). Brussels: The Official Journal of the European Union.

European Commission M. (2018). Article 87 Tracking climate expenditure. In European Commission, Proposal for a REGULATION OF THE EUROPEAN PARLIAMENT AND OF THE COUNCIL \{SEC(2018) 305 final $\}$ - \{SWD(2018) 301 final $\}$ (pp. 9192). Brussels: The Official Journal of the European Union.

European Commission; Council of the European Union. (2013). Article 31 Payments to areas facing natural or other specific constraints \& Article 32 Designation of areas facing natural and other specific constraints. In E. Parliament, \& C. o. Union, REGULATION (EU) No 1307/2013 OF THE EUROPEAN PARLIAMENT AND OF THE COUNCIL of 17 december 2013 (pp. 513- 514). Brussels: The Official Journal of the European Union. 
European Court of Auditors. (2016). Special Report: Spending at least one euro in every five from the EU budget on climate action: ambitious work underway, but at serious risk of falling short. Luxembourg : European Court of Auditors.

European Court of Auditors. (2017). Greening: a more complex income support scheme, not yet environmentally effective. Luxembourg: Publication Office of the European Union.

European Economic Community. (1991). ANNEX II CODE(S) OF GOOD

AGRICULTURAL PRACTICE. In European Economic Community, COUNCIL

DIRECTIVE of 12 December 1991 concerning the protection of waters against pollution caused by nitrates from agricultural sources (p. 6). Brussels: The Official Journal of the European Communities.

European Envionmental Agency. (2020). Annual European Union greenhouse gasinventory 1990-2018and inventory report 2020. Copenhagen, Denmark: European

Environmental Agency.

European Environmental Agency; Eurostat A. (2020, 06 09). Eurostat Data Explorer. Retrieved from Grenhouse gas emissions by source sector (source: EEA): https://appsso.eurostat.ec.europa.eu/nui/submitViewTableAction.do

European Environmental Agency; Eurostat A.;. (2017, 12 20). Eurostat statistics explained. Retrieved from Agriculture - greenhouse gas emission statistics: https://ec.europa.eu/eurostat/statisticsexplained/index.php?title=Archive:Agriculture _greenhouse_gas_emission_statistics\&oldid $=367927$

European Environmental Agency; Eurostat B.;. (2020, 02 24). Eurostat. Retrieved from Eurostat greenhouse gas emissions by source sector: https://appsso.eurostat.ec.europa.eu/nui/submitViewTableAction.do

European Network for Rural Development A. (2017, 05 01). https://enrd.ec.europa.eu/. Retrieved from RDP measure analysis: https://enrd.ec.europa.eu/rdp-measuresanalysis_en

European Network for Rural Development A. (2019, 04 03). https://enrd.ec.europa.eu. Retrieved from Promoting sustainable forest management: https://enrd.ec.europa.eu/projects-practice/promoting-sustainable-forestmanagement en

European Network for Rural Development A. (2020,05). https://enrd.ec.europa.eu. Retrieved from Stakeholder reflections Smart Villages and the European Green Deal: making the connections: https://enrd.ec.europa.eu/sites/enrd/files/enrd_publications/tg6_smartvillages_sv-green-deal-bill-slee.pdf

European Network for Rural Development B. (2017, 04 07). https://enrd.ec.europa.eu. Retrieved from Priority \& Focus Area Summaries: https://enrd.ec.europa.eu/policy-inaction/rural-development-policy-figures/priority-focus-area-summaries_en

European Network for Rural Development C. (2017, 04 07). Priority \& Focus Area Summaries. Retrieved from Priority 1: Knowledge Transfer and Innovation: https://enrd.ec.europa.eu/policy-in-action/rural-development-policy-figures/priorityfocus-area-summaries en

European Network for Rural Development D. (2017, 05 01). RDP Mesure Analysis. Retrieved from M11- Organic Agriculture: https://enrd.ec.europa.eu/rdp-measures-analysis_en

European Network for Rural Development E. (2017, 12 09). Policy framework. Retrieved from Policy priorities and implementation: https://enrd.ec.europa.eu/policy-inaction/policy-framework_en

European Parliament. (2020, 06 20 4). https://www.europarl.europa.eu. Retrieved from LEGISLATIVE TRAIN SCHEDULE A BALANCED AND PROGRESSIVE TRADE POLICY TO HARNESS GLOBALISATION EU-MERCOSUR ASSOCIATION AGREEMENT: https://www.europarl.europa.eu/legislative- 
train/theme-a-balanced-and-progressive-trade-policy-to-harness-globalisation/file-eumercosur-association-agreement

European Parliament; Council of the European Union A. (2013). REGULATION (EU) No 1306/2013 OF THE EUROPEAN PARLIAMENT AND OF THE COUNCIL of 17 December 2013. In European Parliament, \& Council of Europe, Article 110 Monitoring and evaluation of the CAP (pp. 597-598). Brussels: Official Journal of the European Union.

European Parliament; Council of the European Union A. (2017). Regulation (EU) 2017/2393. In European Parliament, \& Council of Europe, REGULATION (EU) 2017/2393 OF THE EUROPEAN PARLIAMENT AND OF THE COUNCIL of 13 December 2017 amending Regulations (EU) No 1305/2013 on support for rural development by the European Agricultural Fund for Rural Development (EAFRD), (EU) No 1306/2013 on the $f$ (p. 35). Brussels: Official Journal of the European Union.

European Parliament; Council of the European Union A. (2018). ANNEX I MEMBER STATE GREENHOUSE GAS EMISSION REDUCTIONS PURSUANT TO ARTICLE 4(1). In European Parliament, \& Coucil of the EU, REGULATION (EU) 2018/842 OF THE EUROPEAN PARLIAMENT AND OF THE COUNCIL of 30 May 2018 (pp. 39-40). Brussels: The Official Journal of the European Union.

European Parliament; Council of the European Union AA. (2013). RULES ON CROSSCOMPLIANCE PURSUANT TO ARTICLE 93. In E. I. 1306/2013, REGULATION (EU) No 1306/2013 OF THE EUROPEAN PARLIAMENT AND OF THE COUNCIL (pp. 602- 603). Brussels: Offical Journal of the European Union.

European Parliament; Council of the European Union B. (2013). Article 92 Beneficiaries concerned. In European Parliament , \& Council of the European Union, REGULATION (EU) No 1306/2013 OF THE EUROPEAN PARLIAMENT AND OF THE COUNCIL of 17 December 2013 (p. 592). Brussels: Offical Journal of the European Union.

European Parliament; Council of the European Union B. (2018). Article 2 Scope. In European Parliament, \& Coucil of Europe , REGULATION (EU) 2018/841 OF THE EUROPEAN PARLIAMENT AND OF THE COUNCIL of 30 May 2018 (p. 7). Brussels: The Official Journal of the European Union.

European Parliament; Council of the European Union C. (2013). Article 4(1) and article 17 monthly payment. In European Parliament, \& Council of the European Union, REGULATION (EU) No 1306/2013 OF THE EUROPEAN PARLIAMENT AND OF THE COUNCIL of 17 December 2013 (p. 567). Brussels: The Official Journal of the European Union.

European Parliament; Council of the European Union C.;. (2018). Pretext- (22). In E. Parliament, \& C. o. Union, REGULATION (EU) 2018/842 OF THE EUROPEAN PARLIAMENT AND OF THE COUNCIL of 30 May 2018 (p. 30). Brussels: The Official Journal of the European Union.

European Parliament; Council of the European Union D. (2013). Article 110 Monitoring and Evaluation of the CAP. In European Parliament, \& Council of the European Union, REGULATION (EU) No 1306/2013 OF THE EUROPEAN PARLIAMENT AND OF THE COUNCIL of 17 December 2013 (pp. 597-598). Brussels: The Official Journal of the European Union.

European Parliament; Council of the European Union D. (2018). Article 48 Equivalence under Regulation (EC) No 834/2007. In European Parliament, \& Coucil of Europe, REGULATION (EU) 2018/848 OF THE EUROPEAN PARLIAMENT AND OF THE COUNCIL of 30 May 2018 on organic production and labelling of organic products and repealing Council Regulation (EC) No 834/2007 (p. 51). Brussels: The Official Journal of the European Union. 
European Parliament; Council of the European Union E. (2013). Article 47 Fianacila provisions. In European Parliament, \& Council of the European Union, REGULATION (EU) No 1307/2013 OF THE EUROPEAN PARLIAMENT AND OF THE COUNCIL of 17 december 2013 (pp. 642-643). Brussels: The Offical Journal of the European Union.

European Parliament; Council of the European Union F. (2013). REGULATION (EU) No 1307/2013 OF THE EUROPEAN PARLIAMENT AND OF THE COUNCIL of 17 december 2013. In European Parliament, \& Council of Europe, Paragraph 44 (p. 7). Brussels: Official Journal of the European Union.

European Parliament; Council of the European Union G. (2013). Article 52- General Rules. In E. Parliament, \& C. o. Union, (Directorate General for Agriculture and Rural Development (European Commission), 2018) (pp. 645-646). Brussels: The Official Journal of the European Union.

European Parliament; Council of the European Union H. (2013). Article 53 Voluntary Coupled Support. In European Parliament, \& Council of Europe, REGULATION (EU) No 1307/2013 OF THE EUROPEAN PARLIAMENT AND OF THE COUNCIL of 17 december 2013 establishing rules for direct payments to farmers under support schemes within the framework of the common agricultural policy (pp. 645-646). Brussels: Official Journal of the European Union.

European Parliament; Council of the European Union I. (2013). REGULATION (EU) No 1307/2013 OF THE EUROPEAN PARLIAMENT AND OF THE COUNCIL of 17 december 2013. In European Parliament, \& Council of Europe, CHAPTER 5 Payment for young farmers (pp. 643-645). Brussels: Official Journal of the European Union.

European Parliament; Council of the European Union J. (2013). Article 31-32 Payments for Areas with Natural contraints. In European Parliament, \& Council of Europe, REGULATION (EU) No 1305/2013 OF THE EUROPEAN PARLIAMENT AND OF THE COUNCIL of 17 december 2013 (p. 643). Brussels: Official Journal of the European Union.

European Parliament; Council of the European Union K. (2013). Payment for areas with natural constraints Article 48 General rules \& Article 49 Financial provisions. In European Parliament, \& Coucil of Europe, REGULATION (EU) No 1307/2013 OF THE EUROPEAN PARLIAMENT AND OF THE COUNCIL of 17 december 2013 (pp. 663-664). Brussels: The Official Journal of the European Union.

European Parliament; Council of the European Union L. (2013). Article 15 Advisory services, farm management and farm relief services. In E. Parliament, \& C. o. Union, REGULATION (EU) No 1305/2013 OF THE EUROPEAN PARLIAMENT AND OF THE COUNCIL of 17 december 2013 (pp. 504-505). Brussels: The Official Journal of the European Union.

European Parliament; Council of the European Union M. (2013). Article 17 Investments in physical assets. In European Parliament, \& Council of Europe, REGULATION (EU) No 1305/2013 OF THE EUROPEAN PARLIAMENT AND OF THE COUNCIL of 17 december 2013 (pp. 506-507). Brussels: The Official Journal of the European Union.

European Parliament; Council of the European Union N. (2013). Annex II Amount and Support Rates. In European Parliament, \& Council of the European Union, REGULATION (EU) No 1305/2013 OF THE EUROPEAN PARLIAMENT AND OF THE COUNCIL of 17 december 2013 (pp. 537-540). Brussels: The Official Journal of the European Union.

European Parliament; Council of the European Union O. (2013). Article 34 Forestenvironmental and climate services and forest conservation. In European Parliament, \& Council of Europe, REGULATION (EU) No 1305/2013 OF THE EUROPEAN 
PARLIAMENT AND OF THE COUNCIL of 17 december 2013 (pp. 515-516).

Brussels: The Official Journal of the European Union.

European Parliament; Council of the European Union P. (2013). Article 28 Agri-

environment-climate. In European Parliament , \& Council of Europe, REGULATION (EU) No 1305/2013 OF THE EUROPEAN PARLIAMENT AND OF THE COUNCIL of 17 december 2013 (pp. 511-512). Brussels: The Offical Journal of the European Union.

European Parliament; Council of the European Union Q. (2013). Article 28 Agrienvironment climate \& article 29 Organic farming. In European Parliament, \& Council of the European Union, REGULATION (EU) No 1305/2013 OF THE EUROPEAN PARLIAMENT AND OF THE COUNCIL of 17 december 201 (pp. 511 513). Brussels: The Official Journal of the European Union.

European Parliament; Council of the European Union R. . (2013). REGULATION (EU) No 1307/2013 OF THE EUROPEAN PARLIAMENT AND OF THE COUNCIL of 17 december 2013. In European Parliament, \& Council of Europe, Small Farmers Scheme (pp. 648-650). Brussels: Official Journal of the European Union.

European Parliament; Council of the European Union S. (2013). Article 4 Objectives. In European Parliment, \& Council of Europe, REGULATION (EU) No 1305/2013 OF THE EUROPEAN PARLIAMENT AND OF THE COUNCIL of 17 december 2013 (p. 499). Brussels: Official Journal of the European Union.

European Parliament; Council of the European Union T. (2013). Article 41(1-8) of Regulation (EU) No 1307/2013. In E. Parliament, \& C. o. Union, REGULATION (EU) No 1307/2013 OF THE EUROPEAN PARLIAMENT AND OF THE COUNCIL of 17 december 2013 establishing rules for direct payments to farmers under support schemes within the framework of the common agricultural policy and repealing Council Regulation (p. 637). Brussels: Official Journal of the European Union.

European Parliament; Council of the European Union U. (2013). I. ANNEX IX List of equivalent practices referred to in Article 43(3). In E. Parliament, \& C. o. Union, REGULATION (EU) No 1307/2013 OF THE EUROPEAN PARLIAMENT AND OF THE COUNCIL of 17 december 2013 (p. 662). Brussels: Official Journal of the European Union.

European Parliament; Council of the European Union V. (2013). Article 21 Investments in forest area development and improvement of the viability of forests. In E. Paraliament, \& C. o. Union, REGULATION (EU) No 1305/2013 OF THE EUROPEAN PARLIAMENT AND OF THE COUNCIL of 17 december 2013 (pp. 509-511). Brussels: The Official Journal of the European Union.

European Parliament; Council of the European Union W. (2013). Article 28 Agrienvironment-climate. In E. Parliament, \& C. o. Union, REGULATION (EU) No 1305/2013 OF THE EUROPEAN PARLIAMENT AND OF THE COUNCIL of 17 december 2013 (pp. 511-512). Brussels: The Official Council of the European Union.

European Parliament; Council of the European Union X. (2013). Article 29 Organic farming. In E. Parliament, \& C. o. Union, REGULATION (EU) No 1305/2013 OF THE EUROPEAN PARLIAMENT AND OF THE COUNCIL of 17 december 2013 (pp. 512513). Brussels: The Official Journal of the European Union.

European Parliament; Council of the European Union Y. (2013). Article 30 Natura 2000 and Water Framework Directive payments. In E. Parliament, \& C. o. Union, REGULATION (EU) No 1305/2013 OF THE EUROPEAN PARLIAMENT AND OF THE COUNCIL of 17 december 2013 (p. 513). Brussels: The Official Journal of the European Union.

European Parliament; Council of the European Union Z. (2013). ANNEX IX List of equivalent practices referred to in Article 43(3). In E. Parliament, \& C. o. Union, 
REGULATION (EU) No 1307/2013 OF THE EUROPEAN PARLIAMENT AND OF THE COUNCIL of 17 december 2013 (pp. 662-663). Brussels: The Official Journal of the European Union.

European Space Agency. (2017, 03 19). News. Retrieved from Sentinels help monitor grasslands for agricultural subsidy checks in Europe:

https://sentinel.esa.int/web/sentinel/missions/sentinel-2/news/-/article/sentinels-helpmonitor-grasslands-for-agricultural-subsidy-checks-in-europe

Eurostat A. (2016). https://ec.europa.eu/eurostat. Retrieved from Farmers and the agricultural labour force - statistics: https://ec.europa.eu/eurostat/statisticsexplained/index.php/Farmers and the agricultural labour force - statistics

Eurostat A. (2017). Agri-environmental indicator - greenhouse gas emissions- Statistics Explained. Brussels: Eurostat.

Eurostat A. (2018, 02 21). https://ec.europa.eu. Retrieved from Agri-environmental indicator - greenhouse gas emissions: https://ec.europa.eu/eurostat/statisticsexplained/index.php?title=Archive:Agri-environmental_indicator__greenhouse_gas_emissions

Eurostat A. (2019, 01). https://ec.europa.eu. Retrieved from Agri-environmental indicator specialisation: https://ec.europa.eu/eurostat/statistics-explained/index.php/Agrienvironmental_indicator_-_specialisation

Eurostat A. (2020, 24 02). Eurostat Data Explorer. Retrieved from Farm indicators by agricultural area, type of farm, standard output, legal form and NUTS 2 regions: https://appsso.eurostat.ec.europa.eu/nui/submitViewTableAction.do

Eurostat B. (2016). https://ec.europa.eu/eurostat. Retrieved from Agriculture statistics family farming in the EU: https://ec.europa.eu/eurostat/statisticsexplained/index.php?title=Agriculture_statistics_family_farming_in_the_EU\#Structural_profile_of_farms_-_analysis_for_the_EU

Eurostat B. $(20 \overline{1} 8,1231)$. Eurostat statistics explained. Retrieved from Organic farming statistics: https://ec.europa.eu/eurostat/statisticsexplained/index.php/Organic_farming_statistics

Eurostat B. (2019, 11). https://ec.europa.eu/eurostat/. Retrieved from Performance of the agricultural sector: https://ec.europa.eu/eurostat/statisticsexplained/index.php/Performance_of_the_agricultural_sector

Eurostat B. (2020,04). https://ec.europa.eu/eurostat/. Retrieved from From farm to fork - a statistical journey: https://ec.europa.eu/eurostat/statisticsexplained/index.php?title=From_farm_to_fork_a_statistical_journey\#Farm_production_stage

Eurostat C. (2020, 05 29). Eurostat Data Explorer. Retrieved from Economic accounts for agriculture - values at current prices: https://appsso.eurostat.ec.europa.eu/nui/show.do?dataset=aact_eaa01\&lang=en

Food and Agriculture Organization of the United Nations. (2019, 1127$)$. http://www.fao.org/faostat/. Retrieved from FAOSTAT- Emission intensities: http://www.fao.org/faostat/en/\#data/EI

French Ministry of Agriculture and Food. (2016, 03 17). Décret $n^{\circ}$ 2016-330 du 17 mars 2016 relatif aux régimes de soutien couplé du domaine végétal dans le cadre de la politique agricole commune et modifiant le code rural et de la pêche maritime. Retrieved from www.legifrance.gouv.fr: https://www.legifrance.gouv.fr/affichTexte.do?cidTexte=JORFTEXT000032259591\& dateTexte $=20160328$

Grefe, C. (2019, 08 08). https://www.zeit.de. Retrieved from Fleischsteuer : Wer hat das Menschenrecht auf dreimal täglich Fleisch ausgerufen?: 
https://www.zeit.de/wirtschaft/2019-08/fleischsteuer-tierwohl-steuererhoehungfleischpreise

Hagyo, A., Terres, J., \& Paracchini, M. (2015). Assessment of capacity for ecosystem services in agricultural areas, focusing on areas with natural constraints (ANC). Ispra, Italy: JRC Science Hub.

Hart, K., Mottershead, D., Tucker, G., Underwood , E., Maréchal, A., Menet, L., . . Klages, S. (2017). Evaluation study of the payment for agricultural practices beneficial for the climate and the environment. Luxembourg: Publications Office of the European Union,.

Hayden, A., Adenaeuer, L., Jansson, T., Hoglind, L., \& Breen, J. (2019). The potential Impact of Changes to Voluntary Coupled Beef Support Payments on EU beef production: A Regional Analysis . England : Agricultural Economics Society, University of Warwick.

Hurlimann, S., \& Zucker, H. (2019, 07 04). SITN Harvard University. Retrieved from How Kelp Naturally Combats Global Climate Change:

http://sitn.hms.harvard.edu/flash/2019/how-kelp-naturally-combats-global-climatechange/\#: :text=Coastal\%20ecosystems $\% 20$ sequester $\% 20$ away $\% 20$ surprisingly,seagr ass $\% 2 \mathrm{C} \% 20$ live $\% 20 \mathrm{in} \% 20$ rich\%20soil.

International Union for Conservation of Nature. (2017, 11). IUCN Issue Brief. Retrieved from Peatlands and climate change: https://www.iucn.org/resources/issues-briefs/peatlandsand-climate-change

Jahr (Rapporteur European Parliament), P. (2020, 09 04). https://www.europarl.europa.eu/legislative-train. Retrieved from LEGISLATIVE TRAIN SCHEDULE PROPOSAL FOR RULES ESTABLISHING COMMON AGRICULTURAL POLICY STRATEGIC PLANS:

https://www.europarl.europa.eu/legislative-train/theme-new-boost-for-jobs-growthand-investment/file-mff-cap-strategic-plans-regulation

Janssona, T., Nordina, I., Wilhelmson, F., Manevska-Tasevskaa, G., Weiss, F., \& Witzke, P. (2018). Coupled agricultural subsidies in the EU undermine climate efforts Agrifood Economics Centre working paper. Uppsala, Sweden: Agri Food economics center.

Köpke, U., \& Nemecek, T. (2009). Ecological services of faba bean. Bonn, Germany: Institute of Organic Agriculture, University of Bonn.

Lampkin , N., Stolze, M., Meredith, S., de Porras, M., Haller, L., \& Mészáros, D. (2020). USING ECO-SCHEMES IN THE NEW CAP-A GUIDE FOR MANAGING AUTHORITIES. Brussels: International Federation of Organic Agriculture Movements.

Loudjani, P., Angileri, V., \& Milenov, P. (2015). Technical guidance for the On-The-Spot check of Ecological Focus Areas (EFA) requirements. Geel, Belgium: Joint Research Center (European Commission).

Louhichi, K., Ciaian, P., Maria, E., Colen, L., Perni, A., Gomez, S., \& Paloma. (2015). The Impact of Crop Diversification Measure: EU-wide Evidence Based on IFM-CAP Model. Milan: Joint Research Center (European Commission).

Müller (Rapporteur European Parliament), U. (2020, 09 04). https://www.europarl.europa.eu/legislative-train. Retrieved from LEGISLATIVE TRAIN SCHEDULE PROPOSAL FOR A REGULATION ON THE FINANCING, MANAGEMENT AND MONITORING OF THE COMMON AGRICULTURAL POLICY (CAP HORIZONTAL REGULATION):

https://www.europarl.europa.eu/legislative-train/theme-new-boost-for-jobs-growthand-investment/file-mff-cap-horizontal-regulation

Maciejewski, L., Lepareur, F., Viry, D., Bensettiti, F., Puissauve, R., \& Touroult, J. (2016). https://ec.europa.eu/. Retrieved from HABITAT CONSERVATION STATUS: 


\section{PROPOSED DEFINITIONS AND CONCEPTS FOR ASSESSMENT AT THE NATURA 2000 SITE LEVEL:}

https://ec.europa.eu/environment/nature/natura2000/platform/documents/extended_su mmary_by_ctebd_maciejewski_et_al_2016_en.pdf

Mankiw, N. (2017). Principle 2: The Cost of Something is What You Give Up to Get It. In N. Mankiw, Principles of Economics- Eight Edition (pp. 5-6). Boston, USA: Cengage Learning.

Mankiw, N. G. (2017). 4-1 Markets and Competition. In N. Mankiw, Principles of Economics (pp. 66-67). Boston, USA: Cengage Learning.

Massot A., A., \& Nègre, F. (2018, 09). Research4committees.blog. Retrieved from Towards the Common Agricultural Policy beyond 2020: comparing the reform package with the current regulations: https://research4committees.blog/2018/09/19/towards-thecommon-agricultural-policy-beyond-2020-comparing-the-reform-package-with-thecurrent-regulations/

Massot, A. (2020, 02). Fact Sheets of the European Union. Retrieved from Financing of the CAP: https://www.europarl.europa.eu/factsheets/en/sheet/106/financing-of-the-cap

Matthews, A. A. (2018, 06 20). capreform.eu. Retrieved from The greening architecture in the new CAP: http://capreform.eu/the-greening-architecture-in-the-new-cap/

Matthews, A. B. (2018, 06 30). capreform.eu. Retrieved from The Article 92 commitment to increased ambition with regard to environmental- and climate-related objectives: http://capreform.eu/the-article-92-commitment-to-increased-ambition-with-regard-toenvironmental-and-climate-related-objectives/

Matthews, A. C. (2018, 02 01). capreform.eu. Retrieved from The ANC delimitation controversy continues: http://capreform.eu/the-anc-delimitation-controversycontinues/

Matthews, A. D. (2018, 09 23). capreform.eu. Retrieved from CAP spending in the next MFF: http://capreform.eu/cap-spending-in-the-next-mff/

Meredith, S., \& Hart, K. (2019). CAP 2021-27: Using the eco-scheme to maximise environmental and climate benefits. Brussels: International Federation of Organic Agriculture Movements and Institute for European Environmental Policy .

Meyer, A. (2015, 08). Does education increase pro-environmental behavior? Evidence from Europe. Ecological Economics, pp. 108-121.

Mitteldeutscher Rundfunk Aktuell. (2020, 02 07). https://www.mdr.de/. Retrieved from Neue Fleischsteuer- 40 Cent fürs Tierwohl?: https://www.mdr.de/nachrichten/politik/inland/kloeckner-fleisch-steuer-100.html

Mottershead A., D., Marécha, A., Allen, B., Keenleyside, C., Lórànt, ,. A., Bowyer, C., . . . A., C. (2019). Evaluation study of the impact of the CAP on climate change and greenhouse gas emissions. Luxembourg: Publications Office of the European Union.

Mottershead B., D., Marécha, A., Allen, B., Keenleyside, C., Lórànt, ,. A., Bowyer, C., . . . A., C. (2019). Annexes 3.2-Evaluation study of the impact of the CAP on climate change and greenhouse gas emissions. Luxembourg: Publication Office of the European Union.

Mottershead C., D., Marécha, A., Allen, B., Keenleyside, C., Lórànt, ,. A., Bowyer, C., . . . Coulon. (2019). Annexes- Evaluation study of the impact of the CAP on climate change and greenhouse gas emissions. Luxembourg: Publications Office of the European Union.

Nègre A., F. (2020, 02). Fact Sheet on the European Union. Retrieved from Second pillar of the CAP: rural development policy: https://www.europarl.europa.eu/factsheets/en/sheet/110/second-pillar-of-the-cap-ruraldevelopment-policy 
Nègre B., F. (2020). SECOND PILLAR OF THE CAP: RURAL DEVELOPMENT POLICYMEASURES ON THE 'EUROPEAN MENU'. Brussels: European Parliament.

Oekolandbau.de. (2017, 08 27). Ökolandbau.de Das Informationsportal. Retrieved from Preisaufschläge für Bioprodukte:

https://www.oekolandbau.de/handel/marketing/preis/preisaufschlaege-fuerbioprodukte/

Own calculations based on EAFRD data. (2020, 08). 2014-2020 EAFRD Budget Calculation. please refer to file on USB Stick, Berlin, Germany.

Poeplaua, C., \& Dona, A. (2015, 02 01). Carbon sequestration in agricultural soils via cultivation of cover crops - A meta-analysis. Agriculture, Ecosystems \& Environment(200), 33-41.

Policy Department B Structural and Cohesion Policies. (2014). Measures at farm level to teduce GHG emissions from EU Agriculture. Brussels: European Parliament .

Rafferty, J. P. (2019, 04 08). Encyclopedia Britanica. Retrieved from Paris Agreement international treaty [2015]: https://www.britannica.com/topic/Paris-Agreement-2015

Ranner, H., \& di Virgilio, N. (2020, 05 20). please refer to USB stick file "Transcript Interview Herwig Ranner, Nicola di Virgilio Master Thesis". (P. Kowas, Interviewer)

Scherer, A., Verburg, P., \& Schulp, C. (2017). Opportunities for sustainable intensification in European agriculture. Amsterdam, The Netherlands : Elsevier .

Schulz, F. (2020, 01 10). https://www.euractiv.de. Retrieved from Kommt es noch zur Fleisch-Steuer?: https://www.euractiv.de/section/landwirtschaft-undernahrung/news/kommt-es-noch-zur-fleisch-steuer/

Simon , F. (2019, 10 01). Euractiv.com. Retrieved from The future of Biogas in Europe: it's a local affair: https://www.euractiv.com/section/energy/news/the-future-of-biogas-ineurope-its-a-local-affair/

Soussana, J. F., Allard, V., Pilegaard, K., Ambus, P., Amman, C., Campbell, C., . . Ree. (2007). Full accounting of the greenhouse gas (CO2, N2O, CH4) budget of nine European grassland sites. Agriculture, Ecosystems \& Environment, 121-134.

Statista.com. (2018, 09). Statista.com. Retrieved from Preisvergleich zwischen biologischen und konventionellen Lebensmitteln 2017 :

https://de.statista.com/statistik/daten/studie/943059/umfrage/preisvergleich-zwischenbiologischen-und-konventionell-erzeugten-lebensmitteln-in-deutschland/

Streck, R. (2020, 06 22). heise.de. Retrieved from EU: Die 750-Milliarden-Euro-Fragen: https://www.heise.de/tp/features/EU-Die-750-Milliarden-Euro-Fragen4791055.html?fbclid=IwAR0L79H9fjA75eLuH6N3wHAjb0B2S8QRQ95O18G1QVn kUpdi2b4kx8H-D-Q

Sulima, K. (2016, 07 12). ENRD Workshop on Agri-environment-climate Measures.

Retrieved from Agri-environment-climate measures: support for results, controllability and the way to go?: https://enrd.ec.europa.eu/sites/enrd/files/w12_measure10_sulima.pdf

Terres, J.-M., Toth, T., Wania,, A., Hagyo, A., Koeble, R., \& Nisini, L. (2016). Updated Guidelines for Applying Common Criteria to Identify Agricultural Areas with Natural Constraints. Luxembourg: Publication Office of the European Union .

The Center for Agriculture, Food and the Environment (College of Natural Science). (2020). New England Vegetable Management Guide. Retrieved from Cover Crops and Green Manures: https://nevegetable.org/cultural-practices/cover-crops-and-green-manures

Trommsdorff, M. (2020). https://www.ise.fraunhofer.de. Retrieved from Agrophotovoltaik: https://www.ise.fraunhofer.de/de/geschaeftsfelder/photovoltaik/photovoltaischemodule-und-kraftwerke/integrierte-pv/agrophotovoltaik.html 
True Animal Protein Price Coalition. (2020). Aligning food pricing policies with the European Green Deal True Pricing of meat and dairy in Europe, including CO2 costs. Brussels : True Animal Protein Price Coalition.

Tóth, G., Jones, A., \& Montanarella , L. (2013). https://esdac.jrc.ec.europa.eu. Retrieved from LUCAS Topsoil Survey methodology, data and results: https://esdac.jrc.ec.europa.eu/ESDB_Archive/eusoils_docs/other/EUR26102EN.pdf

United Nations A. (2016). Article 6. In United Nations, Paris Agreement-United Nations Framework Convention on Climate Change (pp. 7-8). New York, USA: United Nations.

United Nations B. (2016). Article 4. In United Nations, Paris Agreement-United Nations Framework Convention on Climate Change (pp. 4-6). New York, USA: United Nations.

United Nations C.;. (2016). Article 2. In U. Nations, Paris Agreement-United Nations Framework Convention on Climate Change (p. 3). New York, USA: United Nations.

United Nations D. (2016). Article 5. In United Nations, Paris Agreement-United Nations Framework Convention on Climate Change (p. 6). New York, USA: United Nations.

World Bank . (2018, 07). https://de.statista.com/. Retrieved from Europäische Union: Anteile der Wirtschaftssektoren am Bruttoinlandsprodukt (BIP) von 2008 bis 2018: https://de.statista.com/statistik/daten/studie/249078/umfrage/anteile-derwirtschaftssektoren-am-bruttoinlandsprodukt-bip-der-eu/

World Resources Institute . (2016, 05). https://www.wri.org. Retrieved from Paris Agreement Tracker: https:/cait.wri.org/source/ratification/\#?lang=en\&ratified=AF,AL,DZ,AD,AG,AR,A M,AU,AT,AZ,BH,BD,BB,BY,BE,BZ,BJ,BT,BO,BA,BW,BR,BN,BG,BF,BI,KH,CM, $\mathrm{CA}, \mathrm{CV}, \mathrm{CF}, \mathrm{TD}, \mathrm{CL}, \mathrm{CN}, \mathrm{CO}, \mathrm{KM}, \mathrm{CK}, \mathrm{CR}, \mathrm{HR}, \mathrm{CU}, \mathrm{CY}, \mathrm{CZ}, \mathrm{CD}, \mathrm{DK}, \mathrm{DJ}, \mathrm{DM}, \mathrm{DO}, \mathrm{EC}, \mathrm{EG}, \mathrm{S}$ V,GQ,EE,ET,EU,FM,FJ,FI,FR,GA,GM,GE,DE,GH,GR,GD,

World Trade Organization . (2000, 03). https://www.wto.org. Retrieved from Domestic support: some you can, some you can't: https://www.wto.org/english/thewto_e/whatis_e/tif_e/agrm3_e.htm

World Trade Organization. (1995, 01 01). Agreement on Agriculture. Retrieved from Article 12 (b) Annex II Domestic Support - The Basis for Exemption from The Reduction Commitments: https://www.wto.org/english/docs_e/legal_e/14-ag_02_e.htm\#annII

Wu, Y., Kemmitt, S., Xu, J., \& Brookes, P. (2010). Effects of Soil Management from Fallow to Grassland on Soil Microbial and Organic Carbon Dynamics. In J. Xu, \& P. Huang, Molecular Environmental Soil Science at the Interfaces in the Earth's Critical Zone (pp. 20-22). Berlin, Heidelberg, Germany: Springer. 


\section{Appendix}

\section{Appendix A}

\section{Pillar I-Basic Payment Scheme}

Within the Income Support pillar, the Basic Payment is the most significant financial support. It has no fixed ceiling since the figure is calculated by subtracting the five payments that require cross-compliance from the overall national ceiling. (European Parliament; Council of the European Union T., 2013) Therefore, the participation of the payment averages at $52 \%$ of the Pillar I subsidies, yet varies between 12\% in Malta and 68\% in the Netherlands or Luxembourg when excluding the minor expenditure for the small farmers scheme. (Directorate-General for Agriculture and Rural Development (European Commission) A., 2018) As shown in Figure 4, basic payment is connected to the goal Enhance farm income of Pillar I and to the Viable food production goal regarding the CAP general objectives.

Given that farmers comply with the requirements mentioned, they are eligible to receive a basic payment which can be provided in two forms. The most commonly used is called the Basic Payment Scheme (BPS); it bases the amount paid each year on the payment entitlements distributed to farmers. These entitlements are in turn based on the eligible hectares of arable land declared by farmers and each entitlement has the same value, although some MS opted to set a maximum number of entitlements per farmer or decrease their value after surpassing a nationally declared threshold. (Directorate-General for Agriculture and Rural Development (European Commission) A., 2018)

In the MS that joined the EU in 2004 and 2007 the SAPS is used instead of the BPS. The only notable differences are that it is not based on entitlements, but rather directly on declared hectares and that the level of support for all hectares is the same. (Directorate-General for Agriculture and Rural Development (European Commission) A., 2018)

\section{Appendix B}

\section{Pillar I-Small Farmers Scheme}

The voluntary Small Farmers Scheme (SFS) targets specifically small holdings which make up the majority of the overall agricultural holding in the EU. Although a concrete threshold in terms of hectares is not given, the maximum payment per annum is set at $€ 1.250$ thereby excluding larger holdings that would receive higher amounts when applying for subsidies in the BPS or SAPS. Consequently, farmers receiving this subsidy are excluded from all other subsidies of Pillar I and do not have to comply with the Greening rules and Cross-compliance. 
Thereby, the administrative procedure is simplified, lowering the administrative burden for the farmers and the MS. (European Parliament; Council of the European Union R. , 2013) Unsurprisingly, the scheme has a strong connection to the Pillar I goals Enhance farm income as well as Maintain agricultural diversity, although to a lesser extent. Hence, the measure mainly contributes to the CAP general objective Viable food production and, on a lesser scale, Balanced territorial development. (Directorate-General for Agriculture and Rural Development (European Commission) B., 2017)

The scheme has been activated by 15 MS that have the freedom to choose between two ways of calculating the amount per farmers. For the purpose of the theoretical introduction to the scheme, it is important to mention that the Lump-sum calculation method limits the maximum expenditure to $10 \%$ of the MS's financial envelope, while the payment due-to-each-year method does not impose a maximum expenditure. This results in significant differences between such MS as Malta spending 30\% on this scheme, and Bulgaria or Germany less than $1 \%$. The EU average spending lies at slightly over $5 \%$ of all Pillar I payments. (DirectorateGeneral for Argiculture and Rural Development (European Commission) C., 2017)

\section{Appendix C}

\section{Pillar I-Redistributive Payment}

With the introduction of the optional scheme Redistributive Payment (RP) the MS recognized the fact that the majority of farms in the EU is smaller than 28ha, excluding them from the economy of scale advantages. (Directorate-General for Communcation (European Commission) D., 2020) In order to compensate this disadvantage, MS may use up to $30 \%$ of their national ceiling for direct payments to these farms with a threshold of 30ha. Furthermore, payments may not exceed $65 \%$ of the average national amount of direct payment per hectare. Despite the limitations set by the regulation, MS have flexibility in establishing a graduation system per hectare and may opt to base the amount paid on regional averages. (European Parliament; Council of the European Union T., 2013)

Regarding the allocation of the scheme towards the Pillar I goals and the CAP general objectives, the classification is equivalent to the SFS. (Directorate-General for Agriculture and Rural Development (European Commission) B., 2017) For the current programming period, nine countries or regions have implemented the measure making use of the flexibility options mentioned. For the years 2019 and 2020, France and Lithuania have allocated the highest amounts of their national envelope to RP with $20 \%$ and $15 \%$ respectively. On average EU MS spend $3.1 \%$ of the Pillar I support utilizing this scheme, not counting the 19 countries that do 
not apply it. (Directorare-General for Agriculture and Rural Development (European Commission) A., 2016)

\section{Appendix D}

List of equivalent practices referred to in Article 43(3)

\section{Practices equivalent to crop diversification:}

1. Crop diversification

Requirement: at least three crops, the main crop covering a maximum of $75 \%$, and any one or more of the following applying:

- there are at least four crops,

- lower maximum thresholds apply

- there is a more appropriate selection of crops, such as, for example, leguminous protein crops, crops not requiring irrigation or pesticide treatments, as appropriate

- regional varieties of old, traditional or endangered crop types are included on at least 5 $\%$ of the rotated area

2. Crop rotation

Requirement: at least three crops, the main crop covering a maximum of $75 \%$, and any one or both of the following applying:

- a more environmentally beneficial multiannual sequence of crops and/or fallow is followed

- there are at least four crops

3. Winter soil cover

4. Catch crops

\section{Practices equivalent to maintenance of permanent grassland:}

1. Management of meadows or pastures

Requirement: maintenance of permanent grassland and any one or more of the following: 
- Cutting regime or appropriate mowing (dates, methods, limits)

- Maintenance of landscape features on permanent grassland and control of scrub

- Specified grass varieties and/or seeding regime for renewal depending on the grassland type, with no destruction of high nature value

- Evacuation of forage or hay

- Appropriate management for steep slopes

- Fertiliser regime

- Pesticide restrictions

2. Extensive grazing systems

Requirement: maintenance of permanent grassland and any one or more of the following:

- Extensive grazing (timing, maximum stocking density)

- Shepherding or mountain pastoralism

- Using local or traditional breeds for grazing the permanent grassland III.

\section{Practices equivalent with ecological focus area}

Requirement: application of any of the following practices on at least the percentage of the arable land set pursuant to Article 46(1):

- Ecological set-aside

- Creation of "buffer zones" for high nature value areas, Natura 2000 or other biodiversity protection sites, including along hedgerows and water courses

- Management of uncultivated buffer strips and field margins (cutting regime, local or specified grass varieties and/or seeding regime, re-seeding with regional varieties, no use of pesticides, no disposal of manure and/or mineral fertilisers, no irrigation, no soil sealing)

- Borders, in-field strips and patches managed for wildlife or specific fauna (herbaceous border, protection of nests, wildflower strips, local seed mix, unharvested crops)

- Management (pruning, trimming, dates, methods, restoration) of landscape features (trees, hedgerows, riparian woody vegetation, stone walls (terraces), ditches, ponds)

- Keeping arable peaty or wet soils under grass (with no use of fertilisers and no use of plant protection products) 
- Production on arable land with no use of fertiliser (mineral fertiliser and manure) and/or plant protection products, and not irrigated, not sown with the same crop two years in a row and on a fixed place $(*)$

- Conversion of arable land into permanent grassland extensively used (European Parliament; Council of the European Union Z., 2013)

\section{Appendix E}

Pillar II-Food Chain Organization and Risk Management

This priority is also aimed at the achievement of the CAP general objective Viable food production by enabling producers to reach the ultimate goal of a better market position in the global commodity markets. (European Network for Rural Development B., 2017) The FA of the measure are defined as follows:

a. improving the competitiveness of primary producers by better integrating them into the agri-food chain through quality schemes, adding value to agricultural products, promotion in local markets and short supply circuits, producer groups and organizations and inter-branch organizations (Focus Area 3A);

b. supporting farm risk prevention and management (Focus Area 3B). (European Network for Rural Development B., 2017)

The total spending for this priority lies at $€ 14.9$ billion or slightly over $9.9 \%$ of the Pillar II budget. The main measures employed are M04 Physical investment followed by M17 Risk management and M14 Animal welfare. (Own calculations based on EAFRD data, 2020) (European Network for Rural Development B., 2017)

Although some aspects of the measure, such as supply chains and quality schemes, are loosely linked to the reduction of GHG, it is unlikely that this priority as a whole contributes significantly to the potential reduction of GHG.

\section{Appendix F}

\section{Pillar II-Social Inclusion and Economic Development}

The priority contributes to the attainment of the CAP general objective 1 Balance territorial development; it is structured into three FA:

a. facilitating diversification, creation and development of small enterprises, as well as job creation (Focus Area 6A) 
b. fostering local development in rural areas (Focus Area 6B)

c. enhancing the accessibility, use and quality of information and communication technologies (ICT) in rural areas (Focus Area 6C). (European Network for Rural Development B., 2017)

This priority has a total budget of $€ 22.1$ billion making up $14.72 \%$ of the Pillar II budget. The most prevalent measure employed in this priority were M19 LEADER, M07 Basic services \& village renewal, and M06 Farm and business development. (Own calculations based on EAFRD data, 2020) (European Network for Rural Development B., 2017)

From the aspect of GHG reduction potential, the FA 6C has a loose link to the improvement of pollution. This is because a broadband internet connection is a crucial tool for implementing innovations such as precision agriculture. Although not being specifically expressed, the FA $6 \mathrm{~B}$ offers another reduction potential because the measure Village renewal could be used to decrease local energy consumption by erecting more energy-efficient structures. (European Network for Rural Development B., 2017) Yet, this is likely not to reduce the agricultural GHG emissions which is why it can be discarded, as mentioned in the delimitation.

\section{Appendix G}

\section{Pillar II-Farm Viability and Competitiveness}

The priority Farm Viability and Competitiveness is aimed at the achievement of the CAP general objective Viable food production. Furthermore, it focuses on the sustainable management of forests and the promotion of innovative farm technologies with two defined FA:

a. improving the economic performance of all farms and facilitating farm restructuring and modernization, notably with a view to increasing market participation and orientation as well as agricultural diversification (Focus Area 2A);

b. facilitating the entry of adequately skilled farmers into the agricultural sector and, in particular, generational renewal (Focus Area 2B). (European Network for Rural Development B., 2017)

Roughly $€ 30.9$ billion has been spent by both stakeholders, which accounts for $20.57 \%$ of all spending; the main measures employed were M04 Physical investment and M06 Farm and business development. (Own calculations based on EAFRD data, 2020) (European Network for Rural Development B., 2017) 
As a whole, this priority puts some focus on the forest development, but chiefly addresses competitive improvements at farm level and has thus a limited effect on the reduction of GHG emissions. However, some measures employed may have great potential to support GHG reduction efforts.

\section{Appendix $\mathrm{H}$}

Pillar II- European Menu of Measures

- M01: Transfer of knowledge and information measures (training, information campaigns, etc.);

- M02: Advisory services, farm management and farm relief services

- M03: Quality systems applicable to farm produce and foodstuffs (new ways for farmers to participate in quality systems)

- M04: Physical investment (processing of farm products, infrastructure, improving the performance and sustainability of farms, etc.)

- M05: Restoring agricultural production potential damaged by natural disasters and catastrophic events and introducing appropriate prevention actions

- M06: Development of farms and businesses (business start-up aid for young farmers, non-farm business operations in rural areas, etc.)

- M07: Basic services and revitalisation of villages in rural areas (broadband, cultural activities, tourist facilities, etc.)

- M08: Investment in the development of forests and improving their viability (afforestation and creation of woodland; establishment of agro-forestry systems, prevention and restoration of damage to forests from forest fires, natural disasters and catastrophic events, including parasite infestations and diseases, as well as threats from climate change; investment to improve the resilience and environmental value of forest ecosystems and their potential for mitigating climate change; investment in forestry technologies and in processing, mobilisation and marketing of forest products);

- M09: Setting-up of producer groups and organisations

- M10: Preservation of farming practices which have a beneficial effect on the environment and climate and foster the necessary changes (agri-environment- climate measures). These measures have to be included in rural development programmes. Commitments must go beyond the mandatory standards

- M11: Subsidies for organic farming (conversion or support payments);

- M12: Payments linked to Natura 2000 and the Water Framework Directive 
- M13: Payments for areas facing natural or other specific constraints

- M14: Animal welfare payments

- M15: Payments for forest, environmental and climate services and forest conservation;

- M16: Encouragement of cooperation between farmers and forestry operators and those involved in the food production chain (establishment of centres and networks, operational groups of the European Innovation Partnership for Agricultural Productivity and Sustainability (EIP))

- M17: 'Risk management toolkit': crop, livestock, and plant insurance; mutual funds for adverse climate events, animal and plant diseases, pest infestations and environmental incidents; income stabilisation tool, in the form of financial contributions to mutual funds, providing compensation to farmers for a severe drop in their income

- M19: LEADER

- M20: Technical assistance (Nègre B., 2020) 


\section{Appendix I}

\begin{tabular}{|c|c|c|c|c|c|}
\hline EU level objective & \multicolumn{2}{|c|}{ Emission reductions } & \multirow{2}{*}{$\begin{array}{l}\text { Increasing } \\
\text { removals } \\
\mathrm{N}\end{array}$} & \multirow{2}{*}{$\begin{array}{l}\text { Replacing } \\
\text { emissions } \\
\mathrm{N}\end{array}$} & \multirow{2}{*}{$\begin{array}{l}\text { Climate } \\
\text { adaptation } \\
\mathrm{N}\end{array}$} \\
\hline $\begin{array}{lr}\text { Direct } & \text { payments } \\
\text { (excluding } & \text { cross- } \\
\text { compliance }- \text { see below) }\end{array}$ & $\mathrm{N}$ & $\mathrm{N}$ & & & \\
\hline $\begin{array}{ll}\text { Voluntary } & \text { redistributive } \\
\text { payment } & \\
\end{array}$ & $\mathrm{N}$ & $\mathrm{N}$ & $\mathrm{N}$ & $\mathrm{N}$ & $\mathrm{N}$ \\
\hline $\begin{array}{ll}\text { Greening } & \text { (crop } \\
\text { diversification) }\end{array}$ & $P$ & $\mathrm{~N}$ & $\mathrm{~N}$ & $\mathrm{~N}$ & $\mathrm{P}$ \\
\hline Greening (PG ratio) & $\mathrm{N}$ & $\mathrm{N}$ & $\mathrm{R}$ & $\mathrm{N}$ & $\mathrm{N}$ \\
\hline Greening (ESPG) & $\mathrm{N}$ & $\mathrm{N}$ & $\mathrm{R}$ & $\mathrm{N}$ & $\mathrm{N}$ \\
\hline Greening (EFA) & $P$ & $\mathrm{~N}$ & $\mathrm{P}$ & $\mathrm{N}$ & $\mathrm{P}$ \\
\hline Voluntary payment ANC & $\mathrm{N}$ & $\mathrm{N}$ & $\mathrm{P}$ & $\mathrm{N}$ & $\mathrm{N}$ \\
\hline Voluntary coupled support & $\mathrm{P}$ & $\mathrm{N}$ & $\mathrm{N}$ & $\mathrm{N}$ & $\mathrm{N}$ \\
\hline Small farmers' scheme & $\mathrm{N}$ & $\mathrm{N}$ & $\mathrm{N}$ & $\mathrm{N}$ & $\mathrm{N}$ \\
\hline Cross-compliance & $P$ & $\mathrm{~N}$ & $\mathrm{P}$ & $\mathrm{N}$ & $P$ \\
\hline Farm Advisory Systems & $P$ & $\mathrm{~N}$ & $\mathrm{P}$ & $\mathrm{N}$ & $\mathrm{R}$ \\
\hline M1: Knowledge \& info & $P$ & $\mathrm{P}$ & $P$ & $\mathrm{P}$ & $\mathrm{P}$ \\
\hline M2: Advisory services & $\mathrm{R}$ & $\mathrm{R}$ & $\mathrm{R}$ & $\mathrm{R}$ & $\mathrm{R}$ \\
\hline M3: Quality schemes & $P$ & $\mathrm{~N}$ & $\mathrm{~N}$ & $\mathrm{~N}$ & $\mathrm{~N}$ \\
\hline M4: Physical assets & $\mathrm{R}$ & $\mathrm{R}$ & $\mathrm{P}$ & $\mathrm{R}$ & $\mathrm{R}$ \\
\hline M5: Disaster risk reduction & $\mathrm{N}$ & $\mathrm{N}$ & $\mathrm{P}$ & $\mathrm{N}$ & $\mathrm{R}$ \\
\hline M6: Farm business and dev & $P$ & $P$ & $\mathrm{~N}$ & $P$ & $P$ \\
\hline M7: Basic services & $P$ & $\mathrm{P}$ & $\mathrm{P}$ & $\mathrm{R}$ & $\mathrm{P}$ \\
\hline M8: Forest investments & $\mathrm{R}$ & $\mathrm{R}$ & $\mathrm{R}$ & $\mathrm{R}$ & $\mathrm{R}$ \\
\hline M10: Agri-Env-Climate & $\mathrm{R}$ & $\mathrm{R}$ & $\mathrm{R}$ & $\mathrm{N}$ & $\mathrm{R}$ \\
\hline M11: Organic Farming & $P$ & $\mathrm{~N}$ & $\mathrm{P}$ & $\mathrm{N}$ & $\mathrm{P}$ \\
\hline M12: N2000 \& WFD & $\mathrm{N}$ & $\mathrm{N}$ & $\mathrm{P}$ & $\mathrm{N}$ & $\mathrm{P}$ \\
\hline M13: ANC & $\mathrm{N}$ & $\mathrm{N}$ & $\mathrm{N}$ & $\mathrm{N}$ & $P$ \\
\hline M14: Animal welfare & $\mathrm{N}$ & $\mathrm{N}$ & $\mathrm{N}$ & $\mathrm{N}$ & $P$ \\
\hline M15: Forest-Env-Climate & $\mathrm{R}$ & $\mathrm{N}$ & $\mathrm{R}$ & $\mathrm{N}$ & $\mathrm{R}$ \\
\hline M16: Cooperation & $\mathrm{P}$ & $P$ & $\mathrm{P}$ & $P$ & $P$ \\
\hline M17: Risk Management & $\mathrm{N}$ & $\mathrm{N}$ & $\mathrm{P}$ & $\mathrm{N}$ & $\mathrm{R}$ \\
\hline M19: Leader & $P$ & $P$ & $\mathrm{P}$ & $\mathrm{P}$ & $P$ \\
\hline
\end{tabular}

Figure 13: Relevance of CAP instruments and measures to EU Climate needs; Source: (Mottershead A., et al., 2019) 


\section{Appendix J}

- Grazing intensity, timing and type of livestock - although the exact amounts of $\mathrm{C}$ sequestered are very variable and depend on the grazing practices employed and the diversity of plant species, soils, and climates involved (Schils et al,, 2008). In general, C sequestration per unit area is favoured by extensive management provided that nutrients are not limiting (Allard et al., 2007; Klumpp et al., 2007, Soussana et al., 2007).

- Improving the productivity of pastures through practices such as fertilisation and irrigation can improve carbon storage in pastures. However, some of these gains can be offset by $\mathrm{N}_{2} \mathrm{O}$ emissions from $\mathrm{N}$ fertilizers and the energy used in irrigation (O'Mara, 2012; Soussana et al; 2010, Ammann et al., 200; Jones et al., 2006). However the intensification of nutrient-poor grasslands on organic soils may lead to large $\mathrm{C}$ losses.

- Enhancing grass species diversity, in particular, introducing new deep-rooted grasses with greater productivity can increase soil carbon, particularly on low-productivity pastures (Tilman et al., 2006).

- Age of permanent grassland: After a certain length of time a carbon equilibrium is reached after which there is no further increase in C storage. O'Mara (2012) reported the time-scale to range from 30 to 40 years, although other studies have shown that grasslands may continue to act as a carbon sink for longer periods of time (Poeplau et al., 2011).

Ploughing and reseeding: ploughing (and re-seeding) permanent grassland increases GHG emissions $\left(\mathrm{CO}_{2}\right.$ and $\left.\mathrm{N}_{2} \mathrm{O}\right)$ :

- The conversion of permanent grassland into cropland (through ploughing) leads to a loss of carbon twice as fast as the rate of storage of carbon when cropland is converted into permanent grassland. In semi-natural grasslands where the initial levels of organic matter for decomposition are high, the ploughing and subsequent fertilisation releases 50-70 per cent of the soil organic carbon pool (Soussana et al., 2004; Turbé et al., 2010).

- Ploughing and reseeding of permanent grassland lead to significant releases of $\mathrm{N}_{2} \mathrm{O}$ into the atmosphere (Necpálová, Casey and Humphreys, 2013), Vellinga et al., 2004), these decrease over time once the grass cover is re-established. The Dutch study suggested that $\mathrm{N}_{2} \mathrm{O}$ emissions could be reduced by undertaking renovation in the spring (Vellinga et al., 2004).

Figure 14: Effect of Management practices on the GHG reduction potential of permanent grassland; Source: (Hart, et al., 2017)

\section{Appendix K}

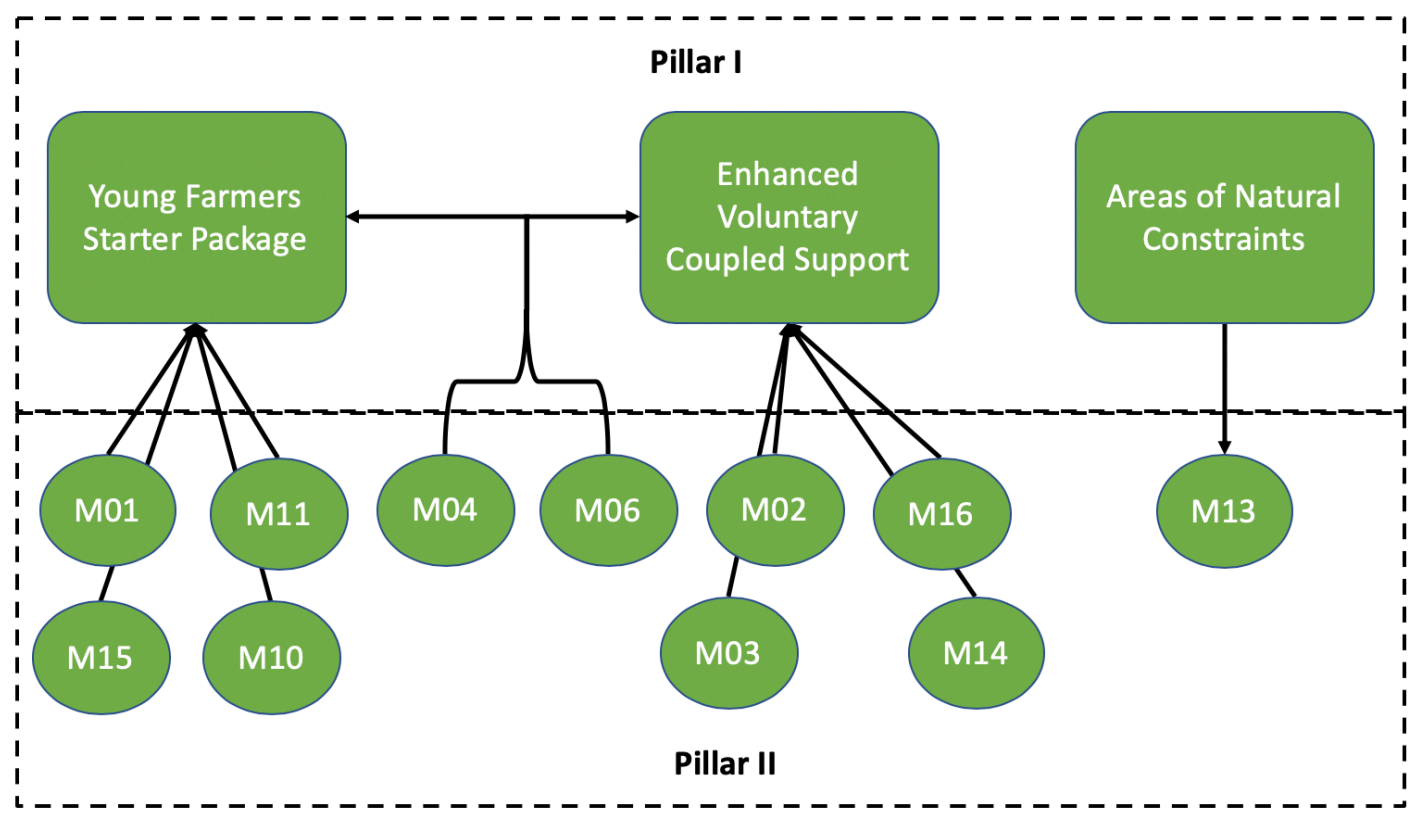

Figure 15: Connection of Pillar II measures with selected Pillar I schemes; Source: Own compilation 


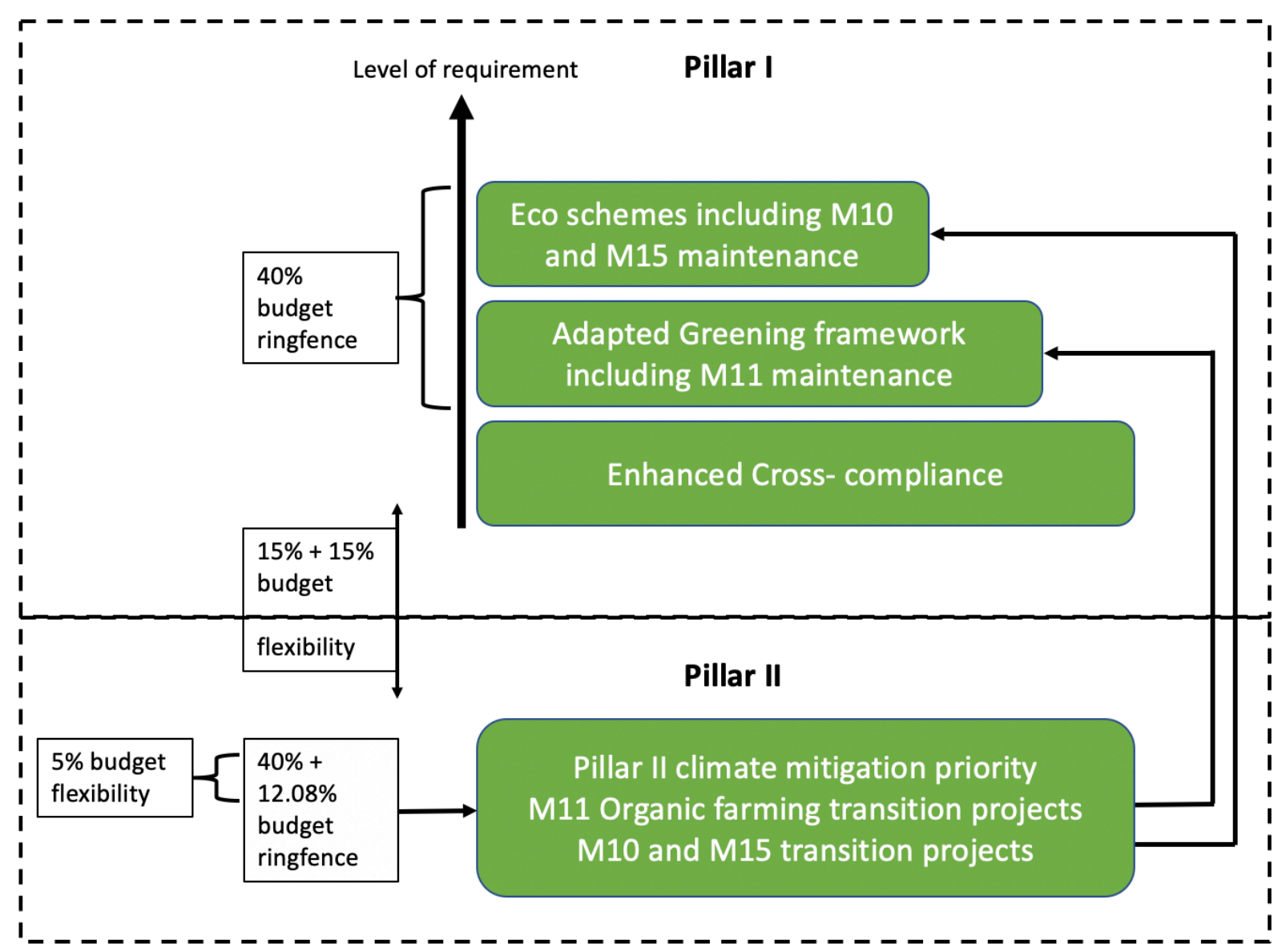

Figure 16: Summary of proposed Pillar I and II architecture and budgetary implications; Source: Own compilation

\section{Appendix L}

\section{Statement of Authenticity}

I hereby declare that I have written the present thesis independently, without assistance from external parties and without use of other resources than those indicated. The ideas taken directly or indirectly from external sources (including electronic sources) are duly acknowledged in the text. The material, either in full or in part, has not been previously submitted for grading at this or any other academic institution.

Berlin, $23^{\text {th }}$ of September, 2020

Place, Date

Signature 